\title{
PERCEPTIONS OF NON-TEACHING WORKLOAD FOR FACULTY IN HIGH TECHNOLOGY \\ BACCALAUREATE DEGREE PROGRAMS
}

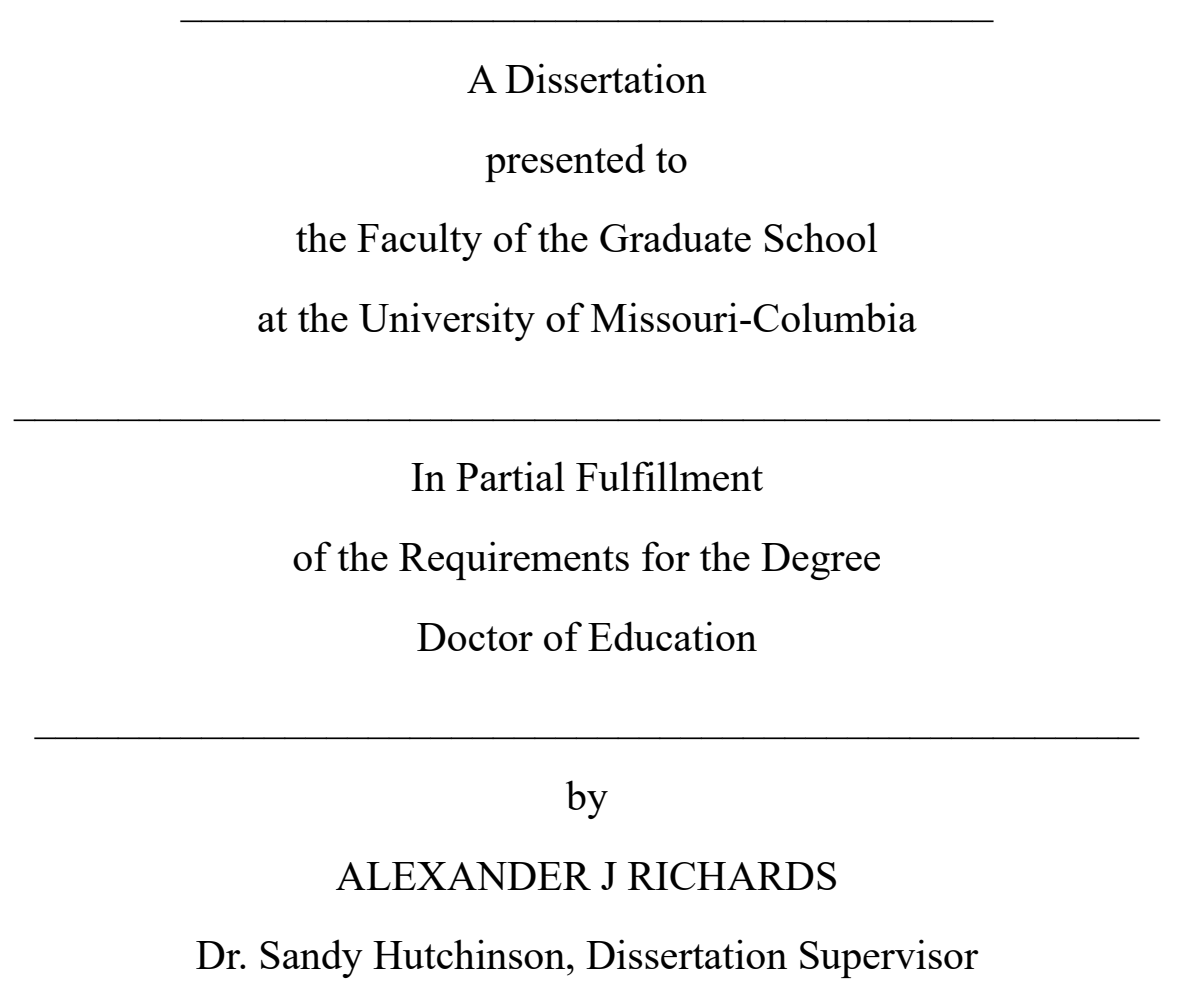

December 2018 
(C) Copyright by Alexander J Richards 2018

All Rights Reserved 
The undersigned, appointed by the dean of the Graduate School, have examined the thesis or dissertation entitled

\section{PERCEPTIONS OF NON-TEACHING WORKLOAD FOR FACULTY IN HIGH TECHNOLOGY BACCALAUREATE DEGREE PROGRAMS}

presented by Alexander J Richards, a candidate for the degree of Doctor of Education in Educational Leadership and Policy Analysis, and hereby certify that, in their opinion, it is worthy of acceptance.

Dr. Sandy Hutchinson

Dr. Douglas Koch

Dr. Steven Ritter

Dr. Barbara Martin 


\section{DEDICATION}

I would like to dedicate this work in memory of my late Maternal Grandfather, Alexander John Grzesik, who passed away on October 11, 2016 before he could see me achieve this goal. Rest in peace Grandpa. I love you! 


\section{ACKNOWLEDGMENTS}

I would like to personally and professionally acknowledge many people whom have aided me in my pursuit of this Doctoral Dissertation. This goal would have been impossible for me to achieve without you. First, I would like to acknowledge my adviser, Dr. Sandy Hutchinson. Without her leadership, guidance, and calm demeanor I likely would have quickly been buried under this momentous task. My committee members, Dr. Douglas Koch, Dr. Barbara Martin, and Dr. Steven Ritter, spent countless hours with their watchful eyes analyzing this research until it was the best it could be. My wife, Ashley, was a constant reminder that I am lovable (even in my unlovable moments) and capable of my goals proved yet again that she is the single best decision I have ever made; I love you

To the rest of my friends, family, students, colleagues, and pets, I appreciate your time, your dedication and your patience with me during this process. It has been a long road, and I am sorry I did not get to go to that party, or grade that paper as quickly as you would have liked, or forced you to call in a favor or two when it counted the most. To my cats, the research is still out on your methods of proofreading via osmosis.

Nevertheless, thank you for your services in holding everything I need firmly on the table or couch. To the dog, I am sorry I could not play fetch very often, but now that this thing is done, thanks for your patience! Without you all, this process of growth for me would have never happened. I would also like to acknowledge the owners of Black Coffee Lounge in Pleasant Hill Missouri, who at the time I needed it most, provided me a quiet and peaceful place to work. 


\section{TABLE OF CONTENTS}

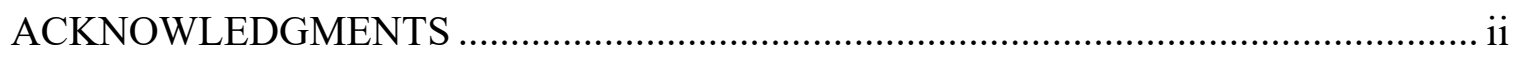

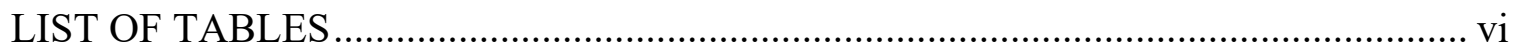

LIST OF ABBREVIATIONS ............................................................................ vii

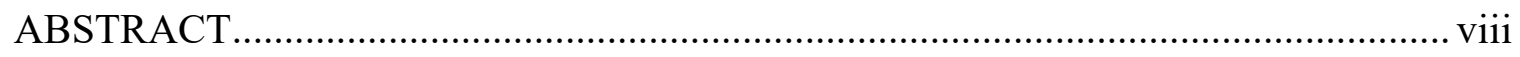

\section{CHAPTER}

1. Introduction to the Dissertation-in-Practice ....................................................... 1

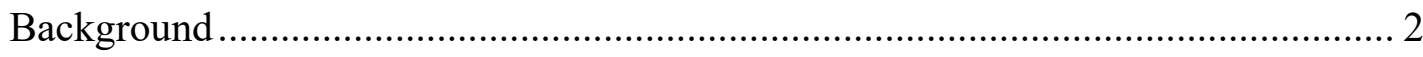

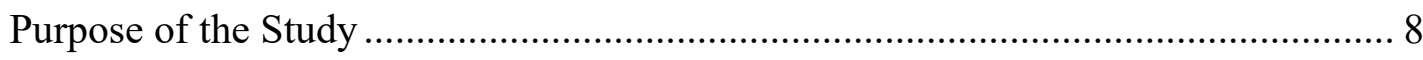

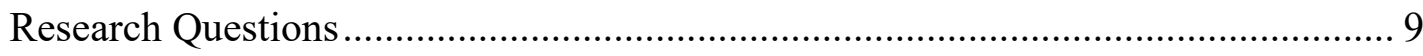

Conceptual/Theoretical Framework............................................................... 9

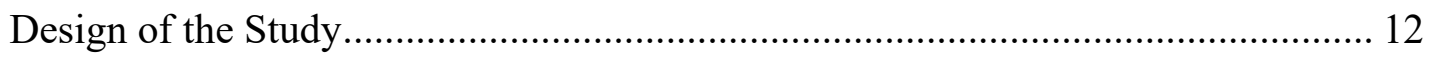

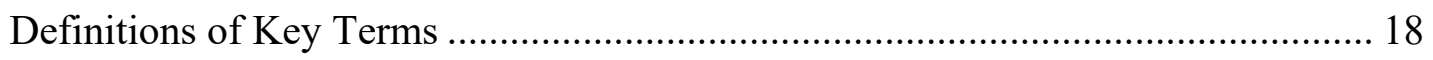

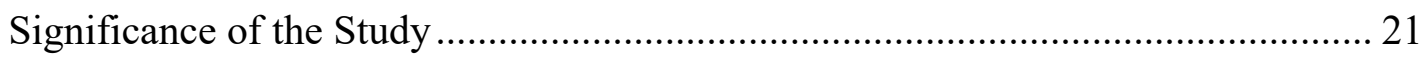

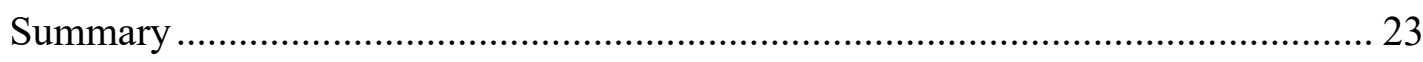

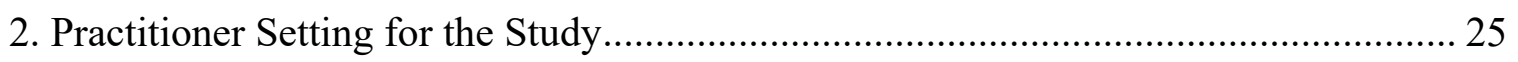

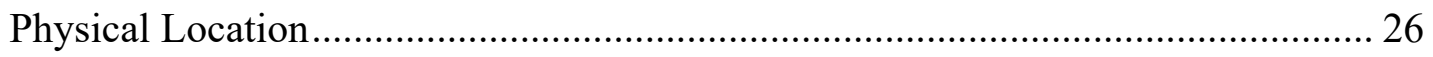

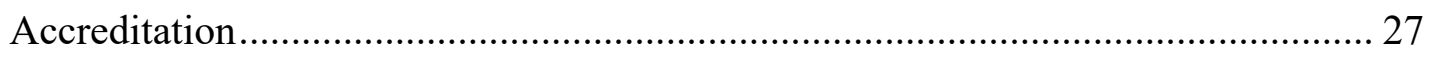

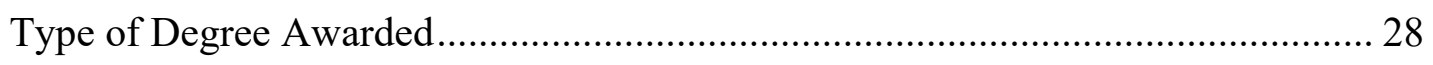

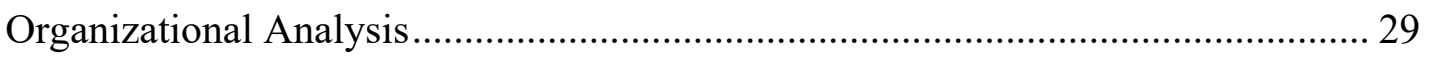

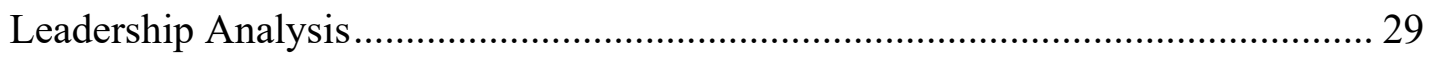

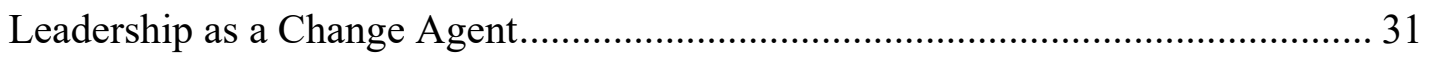

Implications for Research in Practitioner Setting ............................................... 32

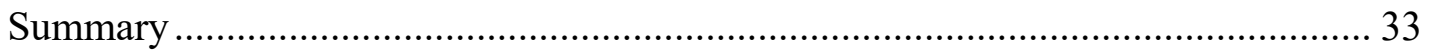

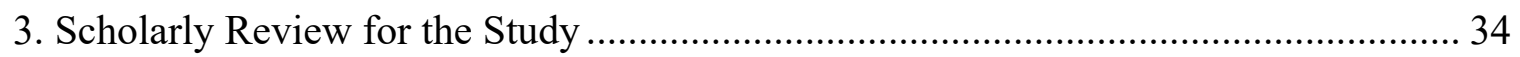

Demand for STEM Career Training ................................................................... 36

Characteristics of the Applied Baccalaureate Program ......................................... 39

Funding Sources and Research for Programs ................................................... 41 
Bolman and Deal's Frameworks........................................................................... 44

Faculty's Perceived Balance in Non-teaching vs. Teaching Responsibilities .......... 52

Faculty's Perceived Efficacy in the Classroom when Considering Non-teaching

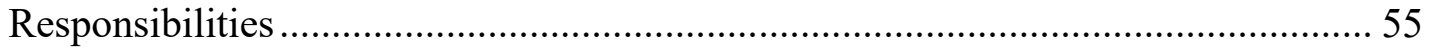

Faculty's Perception of Total Workload................................................................ 57

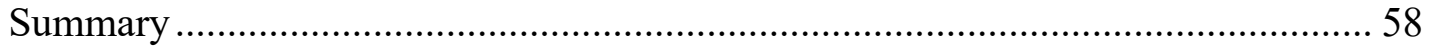

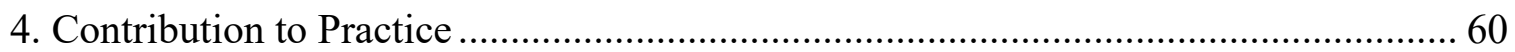

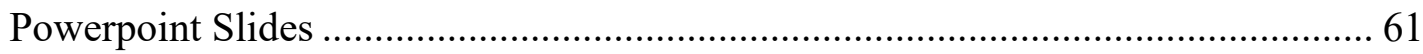

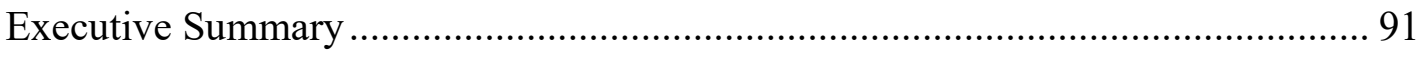

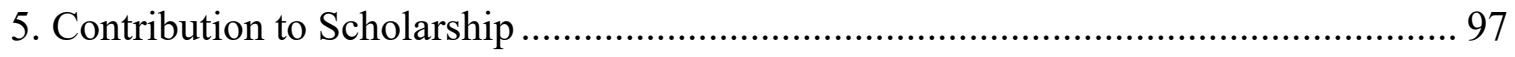

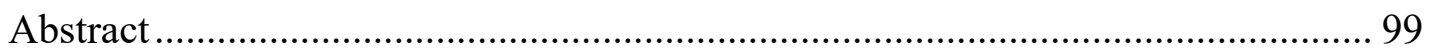

Faculty's Perceived Efficacy in the Classroom when Considering Non-teaching

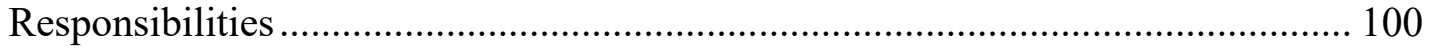

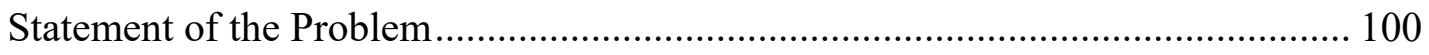

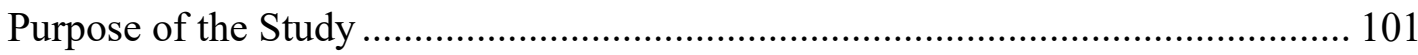

Research Question ……............................................................................ 102

Scholarly Review for the Study .................................................................... 102

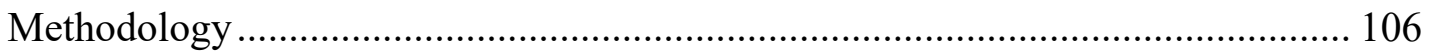

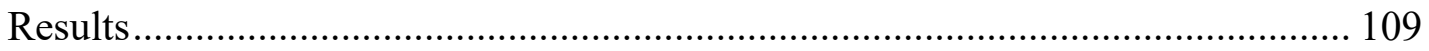

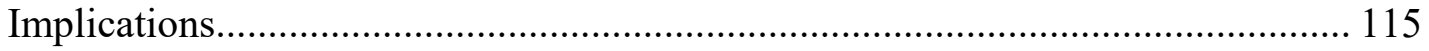

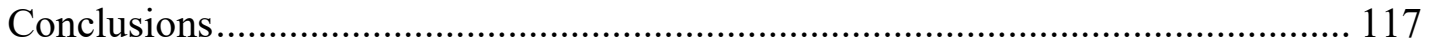

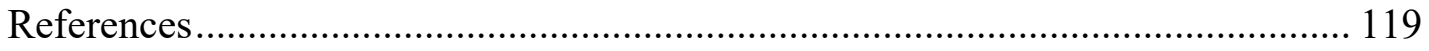

6. Scholarly Practitioner Reflection........................................................................... 123

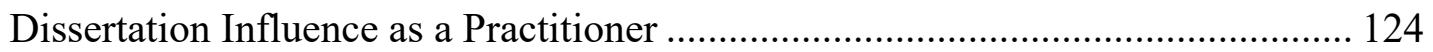

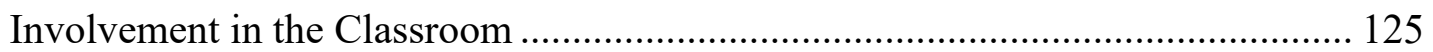

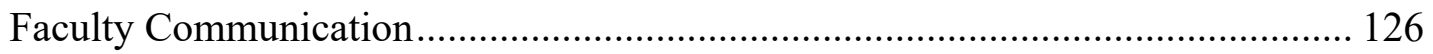

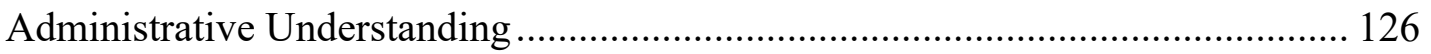

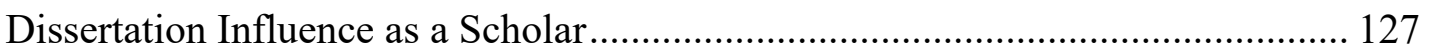

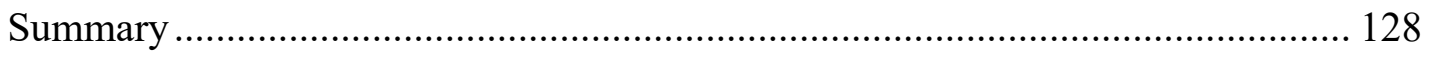

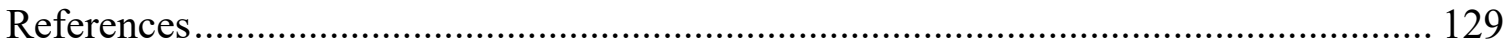

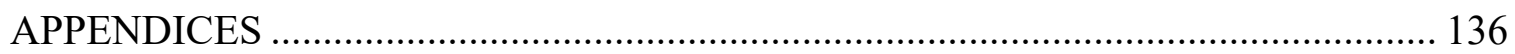


Appendix A - Results .

Appendix B - Interview Protocol (Individual Interview) ........................................ 183

Appendix C - Interview Protocol (focus group) ......................................................... 186

Appendix D - Focus Group Participant Information Slides...................................... 189

Appendix E - Google Form for Focus Group Participant Demographic Information.... 191

Appendix F - Consent Form to Participate in a Research Study ................................. 192

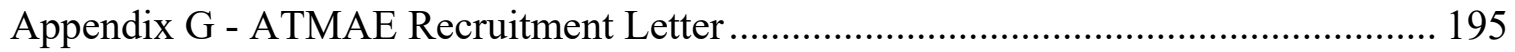

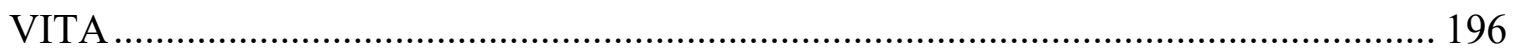




\section{PERCEPTIONS OF NON-TEACHING WORKLOAD}

\section{LIST OF TABLES}

1. Table 1 - Demographic Information of Participants........................93 
PERCEPTIONS OF NON-TEACHING WORKLOAD

\section{LIST OF ABBREVIATIONS}

ABET: Accreditation Board of Engineering Technology

ATMAE: Association of Technology Management and Applied Engineering

CADD: Computer-Aided Drafting and Design

CENG: Civil Engineering Technology

CMGT: Construction Management

HLC: Higher Learning Commission

M/ENGT: Mechanical/Engineering Technology

NATEF: National Automotive Technician Education Foundation

STEM: Science, Technology, Engineering, and Math

INDT/INDM: Industrial Tech/Management 


\title{
PERCEPTIONS OF NON-TEACHING WORKLOAD
}

\begin{abstract}
As educators, both intrinsic and extrinsic motivations persist as career outcomes. However, educators are often asked to contribute to their workplace through tasks not directly related to students and student outcomes. These non-teaching workloads can result in a lack of intrinsic motivation and job satisfaction for faculty in high technology areas where non-teaching workloads are especially high. Coupled with a demand for the support of STEM, applied and career-focused baccalaureate education from industry it becomes crucial to support these faculty in their endeavors to educate the future of their respective industry. This qualitative research sought to investigate the particular circumstances surrounding faculty in high-technology programs. The study found nearly all the participants shared a common desire and intrinsic motivation to support students and their program to the best of their ability. The study also concluded that faculty often see these non-teaching workloads as detracting from students' classroom experiences or the instructor's own classroom efficacy. These experiences often were discussed as having a demotivating effect on faculty and frequently resulted in negative feelings towards administration and administrative practices at each institution. The study recommends a thorough investigation into how workloads, especially non-teaching workloads, are distributed to faculty members in these high-demand areas. Keywords: Faculty, Job-Satisfaction, Classroom Efficacy, Applied Baccalaureate, STEM, Higher Education
\end{abstract}


Section One - Introduction to the Dissertation-in-Practice 


\section{Section One: Introduction to the Dissertation in Practice}

As educators, desire to further our students' success has persisted as a common interest. The intrinsic reward educators reap from working with, and subsequently experiencing the success of, their students represents one of the most motivating aspects of the career. Student success stories are especially prevalent in Applied Baccalaureate and Technical degree fields in which students quickly attain gainful employment, often placed in high-salary positions that pay dividends for the remainder of their career. Despite the intrinsic value added to the educator's career via student success, there remain questions about the extrinsic rewards of the career. Particularly, what value those intrinsic rewards offer if educators feel undervalued or overworked at their place of employment. A thorough understanding of the experiences of these educators can allow administrators to make informed decisions when faced with decisions that influence their faculty workloads, satisfaction and career motivation.

\section{Background}

An ever-increasing demand for an educated workforce places high importance on modern forms of education at the post-secondary level. Without an education that appropriately prepares them, the American workforce remains subject to a deficit in their journey into the modern workplace (Townsend, Bragg, \& Ruud, 2008). Organizations such as the National Commission on Mathematics and Science Teaching for the $21 \mathrm{st}$ Century (2000) stated the Science, Technology, Engineering and Math (STEM) shortage looms both drastic and catastrophic, carrying probability of widespread and severe global economic impact for the United States. Some research further contested that the immense pressure for results on the scientific industry accomplished nothing but reduce 
the United States' chances of prospering in those burgeoning fields of technology in the future without the proper support (Committee on Prospering in the Global Economy of the 21 st Century, 2007). Largely in response to these arguments, the America Competes Act sought to bolster STEM fields and STEM-related educational programs at the federal level by offering funding and driving further research in implementing STEM programs (America Competes Act, 2007). These programs sought to not only aid in the recruitment and promotion of current or new STEM graduates, but also sought to support students who may not otherwise persist into a career within their career field. Even after the efforts of the America Competes Act, Hagedorn and Purnamasari (2012) blamed the quality of K-12 STEM programs and the preparation for those programs in the elementary years for a continued lack of persistence of STEM graduates into a related career. They argued a lack of qualified STEM teachers at the K-12 level contributed to the problem.

Alternatively, others have proposed that drastic outcomes remained unlikely to result from STEM shortages. For instance, Salzman and Lowell (2007) has countered, with supporting evidence for the notion that supply of trained STEM graduates never failed to meet demand. Lowell and Salzman (2009) later argued that based on this data, the quantity of STEM fields and opportunities for students appears to remain bountiful and balanced. This dichotomy could be explained by both conclusions being true to an extent. A U.S. Bureau of Labor Statistics Report (2015) found that certain segments of the highly diversified STEM labor market experience significant surplus and significant deficits depending on conditions in those particular fields. Therefore, potentially both 
conclusions could be true or false depending on the specific field, career area, and market conditions.

While most of these arguments acknowledge that doomsday predictions seem overstated, STEM fields remain highly productive and influential here in the United States. Additionally, a gender and minority gap remains within STEM fields that some authors such as Hagedorn and Purnamasari (2012) posited justify further incentive for supporting post-secondary STEM programs further into the future. This gender and minority gap extends into lower socioeconomic districts and rural districts alike, further inciting the issues of maintaining or expanding the supply chain of qualified STEM graduates.

Recently, conflicting arguments arose within the fields of STEM education. Regardless of the lack of consensus, research suggests a continuation of burgeoning STEM fields continues to play a crucial role in our educational future in the United States. It then follows that qualified teachers play a continued role in supporting the continuation of STEM education in post-secondary as well as K-12 schools.

\section{Statement of the Problem}

Defined by Bragg, et al. (2009), the applied baccalaureate was a product of forces within education demanding a combination of applied associate coursework and the higher order thinking skills demanded by employers. The applied baccalaureate degree recently gained notoriety, representing a relatively new concept in educational circles. However, the benefits of even a traditional baccalaureate and by extension the applied baccalaureate, seldom go disputed. Cabrera, Burkum, and LaNasa (2005) presented the baccalaureate degree as the gatekeeper to a wide variety of benefits. In the case of the 
applied baccalaureate, the applied sciences and the four-year degree portions of the educational landscape collide. The relatively new idea of an applied baccalaureate places potentially unknown and unique circumstances on the faculty teaching in them. Little is known about the faculty members' experiences in applied baccalaureate programs and how they may assist or detract from faculty members' job satisfaction and self-efficacy. These circumstances arise from the uniquely high cost associated with applied baccalaureate degree programs and the diverse range of knowledge and skill sets required of these faculty to teach (Bragg, Townsend, \& Ruud, 2009).

In conclusion, the demand for STEM field graduates increased in recent years at the baccalaureate level (Xue \& Larson, 2015). Hagedorn and Purnamasari (2012) suggested expectations for high-quality graduates rose simultaneously in the high technology and highly competitive STEM career job market. This movement makes retention of the qualified teaching faculty who effectively train future graduates for their careers essential and understanding of those faculty members' experiences vital.

\section{Problem of Practice}

Limited understanding exists about the perceptions of non-teaching responsibilities for faculty in high technology, STEM, or career-prep programs such as the applied baccalaureate. These responsibilities are often as unique as the programs that host and faculty roles that accomplish them. While the literature addresses job satisfaction concerns, retention of qualified faculty, and recruitment of new faculty outside of the STEM fields, it remains imperative that existing faculty within these programs are not Over-utilized while simultaneously attracting qualified faculty to the profession (Jacobs \& Winslow, 2004; Ranđelović \& Stojiljković, 2015). To facilitate 
these actions, understanding the nature and scope of these non-teaching responsibilities helps researchers understand how faculty react and cope with these tasks.

Little is understood about applied baccalaureate faculty members' perceptions of the impact of non-teaching responsibilities and how those perceptions affect job satisfaction and classroom efficacy. In broader context, while some researchers could argue shortages of highly trained professional graduates exist, a consensus on the shortage of qualified teaching personnel who seem attracted to the idea of teaching also exists. Even fewer of these potential candidates meet the requirements to teach (Galosy \& Gillespie, 2013). This deficit makes job satisfaction and positive feelings of self-worth and classroom efficacy crucial in motivating existing faculty to continue to teach regardless of the extrinsic benefits offered outside of the university.

Faculty burnout occurs when a loss of enthusiasm affects one's job satisfaction. In the context of faculty in applied baccalaureate degrees, burnout often results in a career change (Matheny, Gfroerer, \& Harris, 2000). Undesirable consequences of burnout and dissatisfaction commonly affect students through job satisfaction and selfefficacy concerns of faculty (Frisby, Goodboy, \& Buckner, 2015; Matheny et al., 2000; Ranđelović \& Stojiljković, 2015; Zee \& Koomen, 2016). In this sense, motivated faculty who want to teach and enjoy teaching tend to maintain a positive motivational effect on their students. Alternatively, unmotivated or burned out faculty typically exhibit lower classroom efficacy, resulting in a deleterious effect on student outcomes (Zee \& Koomen, 2016). These effects, while secondary to the faculty perceptions of job satisfaction and classroom efficacy, affect the existing pool of faculty who could potentially consider leaving the educational field. 
It was the goal of this researcher to inform administrators at host universities for these applied baccalaureate programs of the perceptions of their faculty. Further, the researcher hoped to reveal the context, scope, degree, and nature of non-teaching workload as well as the faculty members' perceptions of their workloads. These workloads, because of their nature, do not necessarily offer the direct intrinsic benefit to the faculty members present when working directly with students in the classroom.

\section{Existing Gap in Literature}

Research by Bilimoria et al. (2006) sought to understand how faculty understand job satisfaction. This understanding brings context to how administrators might utilize faculty input and perceptions to better help faculty achieve this goal. If job satisfaction is not reached, faculty could become burned out. Jacobs and Winslow (2004) observed burnout manifesting in diminishing returns on productivity, workload, and faculty efficacy in the classroom. In addition, Matheny, Gfroerer and Harris (2000) argued burnout potentially results in faculty departure from their positions. While these observations are not specific to Science, Technology, Engineering and Math (STEM) areas, these feelings and actions of faculty were corroborated by research accomplished in STEM fields (Box-Steffensmeier et al., 2015). In these particular fields, given the demand for STEM and applied baccalaureate educators, it has become ever more important to ensure that retention of existing faculty and recruitment of new faculty is at the forefront of administrative leadership.

Although broad research exists on faculty workload and the correlation to burnout, it fails to address faculty workload in high technology and STEM areas. These programs represent the focus areas for the study. As Bragg, Townsend and Ruud (2009) 
posited, these programs categorized as applied baccalaureate, high-technology or STEM degrees exist within the boundaries of unique and specific sets of variables and context. This research hopes to bring about better understanding from the faculty perspective about how non-teaching duties and responsibilities have an impact on faculty, specifically in high-technology applied baccalaureate programs.

\section{Purpose of the Study}

The purpose of this study was to better understand the faculty perceptions of nonteaching workloads in applied baccalaureate or STEM areas. This research focused specifically on the non-teaching responsibilities, as opposed to the teaching responsibilities, and their perceived effect on faculty at a personal and professional level. Non-teaching duties represent many facets of instructor workload but, for the study, it constitutes any job responsibility of teaching faculty members not directly related to student outcomes or activities. Some examples of non-teaching responsibilities include grant writing, accreditation preparation or maintenance, industry relations and/or networking, and university service.

It was the researcher's hope to inform administrators responsible for the applied baccalaureate programs in the study about potential job satisfaction or self-efficacy outcomes for their faculty. By doing so, administrators bolster their program's resistance to potential problems that already have begun to surface in recruiting and retaining highly qualified personnel (Galosy \& Gillespie, 2013). It was the hope that practices and policies considered commonplace in academia, such as measuring faculty workload via credit hours versus actual contact hours, are subject to review through the lens of this work. This practice, depending on the findings of the study, could disproportionately 
apply heavy workloads to instructors and could result in future faculty turnover or lack of job satisfaction due to burnout or a lack of job satisfaction.

\section{Research Questions}

The following research questions guided this study:

RQ1: How do faculty perceive the balance of assigned workload in their program between non-teaching versus teaching responsibilities?

RQ2: How do faculty perceive their self-efficacy in the classroom when considering non-teaching responsibilities?

RQ3: How do faculty in high technology areas perceive their total workload?

\section{Conceptual/Theoretical Framework}

The study uses Bolman and Deal's (2013) political and structural frameworks as a conceptual framework from which to analyze the motivation and job satisfaction through the perceptions and experiences of faculty members. These frameworks, as Bolman and Deal wrote, represent consistent and repeated concepts that enable anyone to more clearly interpret day to day interactions within an organization. In the case of this study, the political and structural frameworks relate concepts of workload and job satisfaction through the experiences of faculty members and their situational positioning in applied baccalaureate or STEM programs at universities. This situational positioning is a product of the faculty member's position within the organization, as well as the faculty member's understanding of the organizational culture and politics of that particular workplace. Since the organizational culture contributes to the faculty members' overall experiences in the workplace the research is guided by the summation of these experiences and the environment in which they happen (Mercadal, 2014). 
The academic, structural, and political environment in which these experiences exist invites unique opportunities to understand faculty experiences and how faculty interact within the academic space at their university. Faculty motivation to complete tasks, especially non-teaching tasks, and then becomes a question of how they are motivated. Faculty, for instance, could be motivated extrinsically through authoritative input, political pressure, or reward which could be isolated to one of the two frames. Alternatively, faculty could be intrinsically motivated via student achievement or outcomes. Generally, intrinsic motivation comes from working directly with students, a value-added proposition not always present when non-teaching workloads are involved. It becomes crucial, then, that the study informs administrators of the potential impact on faculty that additional non-teaching workload, with or without extrinsic reward, might bring.

Bolman and Deal's (2013) frameworks help researchers understand the unique power structure and influences present in organizations. Universities, like many large organizations, contain a culture that can often be structurally and politically complicated. For these reasons, a benefit exists to understanding the organizational construction and political significance associated with organizational positions. Often for new faculty, this benefit materializes slowly with working experience in the university environment. Lewallen et al. (2003) showed how this structural understanding of the organization can help to minimize undue stress, especially in new faculty as their study found "unfamiliarity with the university culture were identified as major stressors" (p. 258). Bolman and Deal's (2013) structural framework makes the physical structure of the university more understandable. Most vitally, Bolman and Deal wrote about how the 
structure influences members of that organization as it operates. For instance, structural influence comes from administrative ranks and hierarchy over faculty members. From an understanding of the structural frame, one understands how authoritative influences from a higher level or administrative roles influence and lead faculty in lower ranking positions. This leadership and influence also modifies faculty members' capabilities of affecting change in the organization. In application, an understanding of this structural framework can help faculty in coping with a lack of autonomy within their respective positions (Lewallen et al. 2003). This understanding can potentially add value and importance to non-teaching workloads that hold little or no intrinsic or extrinsic value to faculty members.

The structural frame allows the research to analyze the physical or administrative order of command. To gain a complete picture of the university environment as an organization, one must analyze it from a political frame as well. This is evident when the role of tenure and promotion is introduced into the structural model. While nearly identical in structural roles and job description, differences in tenure pathways or status can hold dissimilar levels of political power in the university. This imbalance demonstrates an additional layer of complexity to a comparatively simplistic structural organization of the university. Bolman and Deal (2013) demonstrated that, in theory, one could easily understand the categories, levels, and formal structure and job description of each member of the university. In practice, additional layers of complexity to the structural frame remain misunderstood. As Lewallen et al. (2003) observed, these additional layers result in stressful circumstances and confusion for newer faculty. These 
circumstances can become considerably more stressful if political pressure from colleagues or peers begin to compound workloads for faculty members.

Bolman and Deal (2013) summarized the political landscape that complicates the university environment within a series of assumptions. These assumptions of the political frame stated that organizations possess a diverse population of individuals and groups representing opposing interests. The dynamics of these assumptions and the people within the organization become a living component of the organization, not unlike theories explaining corporate culture and organizational culture discussed by Mercadel (2014). These members of opposing interests tend to believe in values and data, and sometimes possess different perceptions of true reality. These opposing interests can make decisions or debate the distribution of scarce resources. The decision-making parties and scarcity of resources allow conflict to become a central dynamic with political influence carrying high importance. In the case of this research, recall the difference of influence and the unequal distribution of power regardless of similarity of rank. What, then, can new faculty do to acculturate and gain job satisfaction and appreciation if they hold a position of low political influence in the university? Furthermore, in answering the research questions, the researcher can better answer how faculty achieve job satisfaction if they are not being intrinsically motivated by tasks that are politically or structurally assigned to them.

\section{Design of the Study}

The study is a qualitative analysis of faculty perceptions of their non-teaching workload. Using the phenomenological approach as described by Creswell (2014) the researcher plans to gain understanding of the lived experiences of faculty within the 
selected programs. The research was set in the Midwestern United States at four-year degree granting institutions. Thirty participants were selected from faculty members within STEM, high technology and applied baccalaureate degree programs offered at these institutions. A series of twenty-one semi-structured interviews, and two focus groups, as well as any document analysis relevant to interview, program or participant data constituted the data collection. Seven out of the 21 interviews were conducted via electronic means, with both case studies being conducted in person. Qualitative interview data was transcribed, processed and coded for common themes using emergent theme coding and blended with observations from other data sources (Creswell, 2014).

In addition to data triangulation during the data collection period, several member checks were performed with study participants who were willing and able to devote additional time to the project. These member checks were conducted after the researcher deemed the project had reached data saturation and no further interviews, focus groups or document analysis were to be completed.

\section{Setting}

The researcher recruited participants from several universities with four-year technical or applied baccalaureate programs in the Midwestern region of the United States. This region included Utah, Indiana, Illinois, Iowa, Kansas, Michigan, Missouri, Nebraska, Kentucky, and Oklahoma. The researcher identified an initial sample of different programs from areas of study such as design and drafting, construction management or technology, applied engineering or engineering technology, automotive technology, computer networking, and technology or industrial management. 


\section{Program and Participant Selection}

Programs were selected based on several factors. First, all programs participating in the study must have held current accredited status with a professional accreditation organization and the accreditation must be program-specific. University-wide accreditation such as accreditation through the Higher Learning Commission (HLC) was not considered, as it is not program-specific accreditation. These records were crosschecked against the participant list to ensure accreditation status was maintained throughout the study. Second, the programs must have been offered at the baccalaureate level at publicly funded institutions. Private institutions were excluded from the study. This was done as a method of controlling for variability in the scope and mission of the University. Since the conceptual framework of the study focuses on political and structural forces on faculty members, and the goal of the study is to inform policy makers and administrators within universities with high technology programs, it was deemed unnecessary and beyond the scope of the project to study privately funded institutions.

A majority of this pool of potential programs was obtained from accreditation records. The Accrediting Board for Engineering and Technology (ABET) and the Association of Technology, Management and Applied Engineering (ATMAE) are respected and represented in their fields and maintain contact information of accredited programs through which the researcher was able to obtain contact information and program names and locations. Participants were sampled from programs meeting the selection criteria for the study. A matrix of programs, their host universities, and their relevant accrediting bodies was assembled from this data. Programs were entered into this matrix with the assumption that the scope and nature of the program meets the 
definition of an applied baccalaureate based on the accreditation achieved and the careerbased outcomes present within it. Member checking with participants and department chairs or program coordinators throughout the research aided the researcher in assuring these programs meet the criteria necessary.

Priority was granted in selections of universities to those that maintain more than two programs eligible for the study. This practice enabled the researcher to sample programs more efficiently by potentially gathering data from multiple programs on one campus during one interaction. Initial contact with programs was directed to program coordinators and/or departmental chairs either directly or through email requests for participants sent via contact lists owned by accrediting bodies. All participating programs were encouraged to pass on researcher contact information to other eligible programs, faculty, or universities who may meet the qualifications for the study.

\section{Data Collection Tools}

The researcher conducted twenty-one semi-structured faculty interviews and two focus groups. As many interviews and focus groups as needed were held until data saturation was reached. The interviews lasted approximately one-half hour with focus groups lasting up to one hour. Both interviews and focus groups were researcher-guided and followed an interview protocol. Participants signed an informed consent before participating in an interview or focus group. Data were collected via high fidelity audio recordings. During the initial stages of the interview, as seen in the protocol, (see Appendix B and C) the researcher gathered limited demographic information on the participants such as time in the teaching profession, official title(s), role in the program of study, and characteristics of the program and host university. Important terms to the 
research questions such as efficacy and perception were also defined for the participant at that time.

Additional observation and document analysis such as course and faculty load, scheduling, accreditation documents, and program information were conducted to give context to faculty workload relevant to the study and emerging themes. These items were not vital to the success of the research, but served to further triangulate the data and grant perspective to the volume of work professors are asked to complete as part of their position (Creswell, 2014).

\section{Data Analysis}

It was the intent of the researcher to conduct as many interviews and focus groups in person on site. When necessary, electronic communication was utilized. On-site interviews and focus groups were recorded on digital recording devices for review and transcription later. Interviews and focus groups conducted using electronic communications were recorded and reviewed later via secure desktop video/audio capture software. Once interviews had been conducted, transcription was completed via Google voice recognition in a secure Google account and the interview transcripts were coded into themes using keywords and speech pattern analysis. The coding and analysis of the transcripts began with block text separation, in which the researcher pulled out important observations and entire responses or moments of interviews and focus groups. The second process was to identify themes and profiles of individual responses for summative analysis later. The emerging themes present in the transcripts were divided up manually within an Excel Spreadsheet, with color coding denoting participants' comments for usage later when the analysis was compiled. 


\section{Limitations and Assumptions}

Limitations of the research project stem primarily from the data collection and participant selection methods. Because of the unique position of applied baccalaureate programs within traditional academic structures, this research may not be transferable to other degree programs and faculty within them. In addition, academic structure and the positional power of programs within their host university may present different programlevel conclusions over the effects of the observed perceptions. A further limitation is additional factors outside the scope of this study contributing to job satisfaction or dissatisfaction. For example, faculty members who, comprehending the interview prompts, express their dissatisfaction with their workload may answer accordingly. These same faculty members may understand their dissatisfaction is rooted in a combination of many things that have little to do with faculty non-teaching workload but may not directly indicate that as a possibility. In this case, non-teaching workload (within the scope of this research) and other factors linked to job satisfaction (not necessarily within the scope of this research) may contribute to their input. By triangulating data points with other interviews, focus groups and documentation, and utilizing proper interview methods the researcher reduces the risk for this loss of context.

A further limitation falls on the study when establishing standards of measurement. This research sought to establish the overall experiences of faculty, but fell short in establishing how much or how little actual clock-time faculty spend on certain aspects of non-teaching workloads. This concept has been debated among academics for decades. Charters (1942) questioned this workload among more traditional liberal arts degree faculty. Still, most academics disagree on what constitutes appropriate or 
excessive workload on faculty, or what perceived effect these non-teaching workloads have on faculty who are responsible for student engagement and interaction in their classrooms or laboratories (McKenna, 2018).

It is the assumption of the researcher that faculty within the researched programs have at least a portion of their working responsibilities dedicated to non-teaching tasks. This assumption, as a central tenant to the research, isolates the risk involved in over assignment of tasks that are secondary to responsibilities that specifically elicit intrinsic rewards for faculty such as working with students.

\section{Definitions of Key Terms}

The following terms guided in the understanding of this inquiry:

Accreditation: Van Zanten, Boulet, and Greaves (2012) defined it as a systematic and thorough set of standards and protocols achieved by the program to enable a highquality learning experience.

Applied Baccalaureate: Defined by Bragg, Townsend, and Ruud (2009), applied baccalaureate programs are bachelor degree programs with specific and targeted degreerelated career outcomes. For example, Automotive Technology degree students have a specific degree designed to prepare them for the unique skills associated with working in the automotive technology service industry.

Automotive Technology: Automotive Technology is a widely recognized but seldom defined term used for programs teaching automotive skills. Depending on the educational setting, the goals, outcomes and curricular content may differ from program to program. According to the National Association of Automotive Universities (NAAU) there are approximately 20 recognized automotive technology baccalaureate programs in 
the United States. Similar program titles include Automotive Engineering, and Automotive Technology Management.

Construction Management: Construction management is a subset of the construction industry with focus on management, business and technical skills applicable to the construction industry. Much like the other Applied Baccalaureate programs, construction management programs typically are identified by their high degree of technical skill coupled with business or management skills.

Engineering Technology: As defined by ABET, Engineering Technology is a portion of the more broad Engineering classification of fields. While traditional engineering focuses on theoretical problems and solutions, Engineering Technology typically follows an application-driven path in implementation and working designs of projects. Similar program titles include Applied Engineering, and Industrial or Manufacturing Technology

Computer-Aided Design and Drafting (CADD): These degree programs evolved from the previous Design and Drafting coursework that has since progressed into Computer-Aided design. Design and Drafting can be summarized through any practice involving the sketching, drawing, or planning of structures or models through the use of virtual modeling or manipulation and is a subset of the engineering field.

Classroom Efficacy: For the purpose of this study, classroom efficacy is considered to be a measure, whether qualitative or quantitative, of an instructor's success and aptitude at conveying and getting students to retain information. Separate from curriculum development, it is often more focused on the ideas and methods used in a classroom to enable and monitor student learning from an instructional standpoint. 
Grant: These are typically pools of money set aside by a private institution or individual, government, or corporation for the purpose of pursuing an end goal of funding certain activities. In the academic sense, grants are used to fund equipment purchases that could not be budgeted by programs or universities, research or research projects, and development of faculty training, or curriculum. While each grant is unique, it is generally considered an effective means of temporarily funding specific objectives. Grants can range from hundreds to millions of dollars depending on the size, scope and complexity and can either come from internally at the institution or externally from the institution.

High-Technology Programs: These programs are considered for the sake of the study to be programs with applied career skills in fast-paced, cutting edge career fields. Separate from many liberal arts degrees, these programs often possess higher costs-per student ratios and because of safety concerns, lower course offering sizes. In addition, these fields in comparison to typical liberal arts degrees can be categorized as having a higher relevant job-placement upon graduation.

Non-Teaching Workload: While definitions vary, for the purpose of this research, this is any workload not directly related to in-classroom activities. For example, developing course curriculum for a class would not be considered non-teaching workload; however, writing a grant to enable a program to purchase a necessary, but expensive, piece of equipment to be used in the classroom or laboratory would be considered non-teaching workload. This is because while the equipment is related to the curriculum and delivery of curriculum, the activity itself is a product of the program's financial situation, the necessity for the equipment, and represents further responsibilities 
to the instructor without the benefit of intrinsic rewards that are present when working with students.

Science, Technology, Engineering and Math (STEM): An educational subset focused on both the hard and soft sciences and their application to real-world critical thinking and problem solving for tomorrows careers.

Self-Efficacy: Defined by Bandura (1977) as believing in one's self to understand, comprehend and accomplish a task required to navigate a situation.

Tenure: Tenure or Academic Tenure as it is referred to in this research is a contractual obligation of the granting university to continue the employment a faculty member who earns that status. While the faculty member cannot be fired without just cause, it is generally considered in academic ranks as a status representing someone who cannot lose their job unless their program is no longer viable or financial needs of the university dictate their removal ("Tenure”, 2017). Originally designed to protect the educational freedom of instructors, teachers, and professors, tenure often brings political power within the organization once it is achieved.

Tenure-track: This describes any position or individual who is eligible at one point or another to receive tenure at their institution. Typically, being hired into a tenuretrack position requires a certain degree of work beyond basic job responsibilities with the promise, if granted, that the tenured individual cannot be fired without just cause.

\section{Significance of the Study}

Currently, career prep and high technology fields remain in demand (Xue \& Larson, 2015). The argument for increasing the number of STEM graduates and programs is ever present in education. From a marketplace competition perspective, 
these areas represent shares of the educational market that public schools and universities compete for against private schools and training facilities. Traditional academia must be flexible enough to adapt and change with the changing needs of high technology programs. Part of this flexibility involves maintaining good relationships with faculty members within these programs and retaining qualified faculty members.

\section{Contributions to Scholarship}

The research contributes to scholarship by reaching for a more broad understanding of the human element of teaching. While teachers, instructors, professors and all ranks in between share some common traits, understanding these facets of their lives and the impact their experiences have on their effectiveness as teachers can lead the industry toward a better understanding of how to best support teachers at these institutions.

While many studies have investigated the relationship of teachers and their students, little research has shed light on the experiences of the educators themselves. Studies such as the one conducted by Frisby et al. (2015), researched the perceived effect of dissenting students and their comments on their instructors. Other studies have analyzed teaching methods and individual emotions expressed by the instructor (Taxer \& Frenzel, 2015). As that study found, teachers are far more likely to fake a non-existence of non-positive emotions than to express them. Furthermore, Taxer and Frenzel also found teachers are likely to express their positive emotions leaving administrators in the dark on how their faculty member's truly feel about their job and their responsibilities. These emotions, when put in context of Self-Determination theory posited by Ranđelović 
and Stojiljković (2015), could contribute to a lack of job-satisfaction and, potentially, an exit from the practice of teaching.

\section{Contributions to Practice}

In practice, this research contributes to the overall understanding of faculty members' perceptions of workload at administrative levels of management in education. Due to the unique demands of the technical fields in academia, the researcher hopes to shed light on the unique situation those faculty work in and perhaps on goals, standards, and accommodations those faculty and administrators can make to prevent qualified faculty from leaving the educational career. These departures could potentially impact smaller institutions the hardest where the loss of even one faculty member represents a significant setback to the program. It is the hope that together with qualitative data collected in this research, administrators can make more informed decisions about faculty satisfaction, workload and perspectives. As a lens to the specific challenges presented to high technology Applied Baccalaureate programs this research can clarify the specific challenges and workloads present within these areas of academia.

\section{Summary}

As Xue and Larson (2015) wrote, highly qualified technical graduates remain in demand. As a byproduct to that phenomenon, university faculty members continue to play a significant role in the success and continuance of programs. Still, these faculty members must be motivated and qualified to continue in the endeavor. There remains a significant shortage of qualified teaching personnel in many technical fields (Galosy \& Gillespie, 2013). To mitigate these shortages, administrators need to understand the perspectives of the faculty and the unique experiences and workloads that faculty in these 
areas experience. Further, administrators who understand the political and structural challenges at the university continue to remain in positions to advocate and aid faculty in acculturating and fostering changes and individual autonomy within their programs. The researcher hopes that by shedding light on faculty perspectives of their duties required outside of the classroom and additional workload while in the classroom, administrators make more informed decisions that have positive effects on their faculty. 
Section Two - Practitioner Setting for the Study 


\section{Section Two: Practitioner Setting for the Study}

This section intends to inform the reader on the setting for the study, specifically to ensure the reader grasps the scope of the setting in respect to the study participants. While no singular setting exists, commonalities between experiences of different research participants in different programs at different universities are apparent based on the material and experiences drawn forth. These familiar and common experiences shape the phenomenology of this study and serve to isolate common experiences of faculty. These commonalities fall into three distinct areas. These areas are physical region or location, accreditation, and type of degree awarded.

\section{Physical Location}

The setting of the study is contained among several public universities in the Midwestern United States. This region includes Utah, Indiana, Illinois, Iowa, Kansas, Michigan, Missouri, Nebraska, Kentucky, and Oklahoma. Among these universities, there exist two specifically different types. These types are Carnegie classifications of either research-based or teaching-based institutions. Both research institutions and teaching institutions will be investigated and data on what type of institution the participants are part of will be collected for the purposes of future research. The differences in types lie with the core mission of the organization. Teaching institutions focus on teaching and the scholarly pursuit of pedagogy, while research institutions tend to champion faculty development through continued research contributions in their educational field. These missions are independent of the individual programs; however, they may or may not influence the types and goals of these programs and how they are achieved. While no singular university constitutes the subject of this study, similarities 
among the programs at different universities and settings become the focus in which these experiences exist.

\section{Accreditation}

Accreditation is a concept about which Harvey and Green (1993) stated becomes a measure of a program, curriculum, or university as a whole. These organizations, whether at the large multi-national university level or small regional course offering level, can be measured for quality using standards that are often tailored to the field, competency level, or specialty that is being taught. Harvey and Green discussed that quality often means many things for many people. Accreditation is a tool that enables programs to set standards and allows them a measure by which to evaluate their performance in meeting those standards. For example, accreditation bodies exist so that different programs can be evaluated for quality that may have drastically different outcomes and drastically different purposes. Even further, quality can have different measurement techniques, definitions and implementations depending on the field in which the program is evaluated. Accrediting agencies are utilized to give accountability within a certain area to the practices, curriculum, and methods used by educational institutions. Accreditation then becomes a way to measure similar courses, programs, and universities using consistent methodology in order to determine their overall quality.

Accreditation is a broad term, and the principle of accreditation becomes more narrow when discussed in context of a specific program. For instance, a measure of quality for automotive programs, both at the secondary and post-secondary level, begins with accreditation granted by the National Automotive Technicians Education Foundation (NATEF). This accreditation not only certifies specific qualities of the program, but also 
specifies the level of program training it is intended to produce through multiple levels of accreditation available to programs. These levels allow NATEF to accredit programs at the high-school through post-secondary and baccalaureate level program stages in a learner's education. It is through these levels that NATEF accreditation between programs can identify, both for perspective students, parents, and or administrators, the quality and the level of education present within that program.

The study will utilize accreditation documentation to determine a pool of likely programs that could be utilized for the research. Since accreditation is a measure of quality, it is assumed accredited programs hold a measure of quality based on their participation in their respective accrediting organizations. Accrediting bodies from which participating programs will be chosen include ABET, ATMAE, and NATEF. All of which are nationally recognized accreditation organizations recognized by industry.

\section{Type of Degree Awarded}

The Applied Baccalaureate degree, as defined by Townsend, Bragg, and Ruud (2008), is subject to various interpretations depending on the source. Townsend, Bragg, and Ruud characterized the Applied Baccalaureate degree as a degree that prepares students for imminent positions within high-technology areas such as automotive, construction, computer-aided drafting and design, and engineering areas. Differing from more traditional degree programs, transfer credits from associate's degree institutions, job placement and prospects, and efficient, targeted curricula are core traits of the degree progress. 


\section{Organizational Analysis}

In general, the organization of a university can be linked to its singular leadership position of either the president, chancellor or other high-authority figure. These leaders typically report to the state in public institutions as representatives of the university on the legislative level. Immediately below these leadership positions are the leaders of each subset of university operations. Typically these positions involve a chief academic officer, facilities management, and executive management. Within the context of this study, the academic officer, or provost as it is sometimes known, oversees the operations in regard to academic programs at the university. Typically these programs are broken into individual colleges, with their respective deans who oversee departmental chairs and program coordinators. These coordinators or department chairs directly oversee the faculty within each program of study.

As described in Section One, political influences and positions are distributed among faculty. Faculty members can be tenured or tenure-track, with various levels of seniority depending on their career status, publications, service to the university and other nearly endless factors. The difference between what some call teaching or instructional faculty and tenured or tenure track faculty, for instance, illustrates a difference in political influence on campus regardless of their promotional status.

\section{Leadership Analysis}

As an assistant professor, the researcher holds little positional power in the context of the university. Politically, some of that power is realized through the process of Promotion and Tenure. Still, even without the leadership title, there are many aspects of the teaching position that allow the expression and practice of leadership skills. These 
skills are informed by this research through the understanding of the circumstances of instructional faculty in high-technology degree areas.

As Merriam and Bierema (2013) wrote about learners, each holds a critical perspective on topics and viewpoints. This critical perspective is shaped by the practice of critical thinking. Arguably, critical thinking remains an important trait in leadership in any setting or organization. The ability to analyze and understand problems is paramount when the decision rests on the shoulders of leadership. Fortunately, Merriam and Bierema offered some applicable knowledge to leadership. By investing in the idea that critical perspectives can be molded and shaped by new information, a leader can continually seek out and pursue a new understanding of situations and work toward better answers.

In seeking out answers to difficult problems, leaders must work much like educators in grounding their staff with concepts that make sense to them. These practices also empower individuals to aid in the decision making process, naturally boost morale, and can help foster a sense of teamwork among the group. In the same way an educator may present an analogy to explain a complex system of motors and gears, leaders must base their decisions and reasoning in the confidence of their own prior decision-making and in ways their subordinates can understand. A solution that is too foreign or complex to employees may alienate them from the leader and complicate the process of obtaining buy-in. When done properly, the proper understanding of the employee's critical perspectives coupled with appreciation for their critical thinking skills results in a more diversified approach to problem solving. 


\section{Intrinsic and Extrinsic Motivations of Faculty}

While faculty faced with decreasing funding for programs often face few opportunities for a substantial increase in salary or other extrinsic motivation at their place of employment, occasionally, simple recognition of efforts could represent a significant shift in job satisfaction Appreciation and positive reinforcement in the working environment in academia is often lacking or fails to exist entirely and yet Bilimoria et al. (2006) found most faculty seek job satisfaction through their support from leadership. Bilimoria et al. found this support was most often realized through adequate workloads that reflect and support research. Much of this support was delivered to faculty in the form of relational and academic support within the university. Whether this support allowed faculty time and resources to conduct research or simply the flexibility to achieve objectives with their own guidance, it was noted as being critical for faculty to realize their own job satisfaction. The relatively decentralized nature of higher education institutions means that educational leaders often forget adults want to know when they are doing a good job, as well. Positive feedback, when possible, and negative feedback, when needed, is essential to success and meeting goals. This minor intrinsic reinforcement, in lieu of more substantial monetary or job benefit motivation, coupled with the additional intrinsic value of working with students on the faculty-level, could contribute to faculty persistence.

\section{Leadership as a Change Agent}

Example is a powerful motivator and it is one that allows leadership to be demonstrated by anyone without needing the position of leadership as a passkey. Sanborn (2006) reflected on this concept, quoting a famous politician who once said "the 
longer the title, the less important the job" he discussed a leader at a small school who lacked any true professional title at all. To the nearly 200 students at the school, she was simply known as mom. While Sanborn discussed her many roles at the school, it is the core example of the story that she is a leader, certainly without the pomp and circumstance that comes with the title.

\section{Implications for Research in Practitioner Setting}

Combined with increasing demand for career-focused education, noted by Xue and Larson (2015), and declining pools of faculty members who are qualified and willing to teach, discussed by Galosy and Gillespie (2013), the importance of understanding faculty members' experiences, motivations, and level of job satisfaction is vital to continuing to retain existing qualified faculty. With decreasing funding for schools and public institutions, administrators must make informed decisions about their current faculty, as well as determine where budgetary and resource support is most needed. Sweeping budget cuts that threaten budgets regardless of degree granting areas can disproportionately affect higher technology programs. As Middaugh, Graham, Shahid, and the National Center for Education Statistics Ed. (2003) found, most programs in higher technology areas typically carry a higher cost of educating students than other non-applied fields.

Faculty efficacy in classroom management and student engagement can be detrimentally affected by burnout. Due to over exertion and additional faculty load, burnout can cripple faculty members, especially those who normally represent highperforming members of the organization (Frisby et al., 2015; Matheny et al., 2000; Ranđelović \& Stojiljković, 2015; Zee \& Koomen, 2016). To continue serving the 
educational industry and the students and faculty within it, administrators must inform themselves on the benefits, the outcomes, and the proper ways to grant resources to programs in high-demand and highly technical career field areas.

In addition, programs can bolster themselves against additional workload demands by taking a team-focused and student centered approach to everything they accomplish. As evidenced by the data collected in the study, student focus is a primary contributor to intrinsic value in the career to faculty and could ensure the retention of those faculty into the future. This gives a value-added proposition to the practice and allows faculty to find more meaning and connection with their work even if it does not directly correlate to student outcomes.

\section{Summary}

In conclusion, the researcher sought to focus the research upon specific circumstances within applied technology baccalaureate degree programs. These programs, accredited within their own fields of study, represent high-quality applied research and student outcomes. These programs also exist within the structure of their host university. In understanding the structure and influences on faculty members at their respective institutions, the researcher hopes to summarize the experiences of these faculty members, how they realize job satisfaction, and their motivations for remaining in the profession. 
Section Three - Scholarly Review for the Study 


\section{Section Three: Scholarly Review for the Study}

This literature review will discuss several components of the literature relevant to the study. The first component is the need for STEM employable graduates and the characteristics of the programs that educate them. The overall characteristics of the degree and funding sources are discussed. Job satisfaction and faculty experiences follow closely to this section as it becomes necessary to understand and accommodate for faculty experience and job satisfaction in maintaining the high quality of these accredited programs. In further discussing faculty, the results of burnout, lack of job satisfaction and self-efficacy will also be investigated. The aim of this exercise is to characterize the environment in which the applied baccalaureate or STEM educator teaches. The conceptual framework of the study is discussed as it relates to the literature next, with the research questions discussed individually in the context of the literature last.

The existing literature fails to address the experiences of STEM faculty, more specifically, faculty in four-year applied baccalaureate programs. Little has been discussed about how faculty experiences affect faculty within baccalaureate programs that fall under STEM and/or applied baccalaureate fields. Further, the current review of the literature reveals little about the common characteristics of faculty in STEM fields and applied baccalaureate programs. The broad diversity of STEM programs means a thoughtful consensus on a typical faculty profile and experiences is difficult to surmise. Instead, the goal is to bring context to the study of the perceptions of these faculty members, aiming to characterize the environment in which the applied baccalaureate or STEM educator teaches. 


\section{Demand for STEM Career Training}

In educational research, demands for educating the future workforce frequently emphasize the importance of modern forms of technical education (Townsend, Bragg \& Ruud, 2008). A recent reemergence in technical education catered to efforts to close the Science, Technology, Engineering, and Math (STEM) gap. While most STEM-focused educational research has concentrated on K-12 areas, similar demands for STEM and career-path graduates at the baccalaureate level have shown a proportionate increase in recent years (Xue \& Larson, 2015). Dewitt (2015) supported this trend, observing the STEM gap and its continued existence at all levels of education. Dewitt suggested based on those observations that STEM education remains an issue worthy of discussion within all levels of educational research.

Townsend et al. (2008) admitted the American workforce stands unprepared for their journey into career productivity without a proper education. This education, while technical in nature often requires a huge amount of dedication from both the student and the faculty member to be successful. Dewitt (2015) summarized the continuing struggle to fill what he referred to as the STEM gap or the deficiency in STEM graduates to fill open STEM career positions. Wang (2013) described this gap as an issue of national importance. These arguments echo the requests of constituents and lobbyist groups alike and frame the STEM shortage argument. The National Commission on Mathematics and Science Teaching for the 21st Century (2000) warned the STEM shortage would represent a substantial deficit for the United States, as economic factors would shift skilled labor away from countries not adequately filling the demand for trained workers. In response to these pressures, the America Competes Act (2007) was drafted into law to 
bolster STEM fields and STEM-related educational programs at the federal level. This act sought to accomplish this goal by offering financial support to STEM programs and qualifying schools and driving further research in implementing STEM programs at schools (America Competes Act, 2007).

Alternatively, critics of the STEM shortage argument suggested limited impact from a STEM shortage, even going as far as to suggest a lack of any STEM shortage at all. Salzman and Lowell (2007) failed to locate supporting evidence for the notion that supply of trained STEM graduates failed to meet demand. Furthermore, Lowell and Salzman (2009) later argued that, based on this data, the quantity of STEM fields and opportunities for students appeared to remain bountiful.

These opposing outlooks both contain some element of truth. A U.S. Bureau of Labor Statistics Report (2015) found segments of the highly diversified STEM labor market demonstrate surplus and deficits depending on market stability in that particular job market. Therefore, both observations could be true or false depending on the specific field and career area at the time. While no direct meta-study has assimilated all the research in one publication, far more literature finds consensus with the idea of a STEM shortage than disagrees.

Literature suggests many additional variables affect the existing pool of STEM graduates. One of these variables, as Lewallen et al. (2003) wrote, is faculty. These faculty members remain critical for the continuation and proliferation of STEM programs (Newton, Utschig, \& Llewellyn, 2011). Referencing examples from the nursing field, Lewallen et al. demonstrated how a shortage of faculty inevitably leads to a shortage of qualified graduates. It remains obvious, then, to continue to close the STEM gap and 
ensure a continuous stream of employable and qualified STEM graduates, retention of existing faculty in STEM programs is vital. Further, potential new faculty must be drawn to the profession to continue to grow these programs (Jacobs \& Winslow, 2004;

Ranđelović \& Stojiljković, 2015). These goals combat the effects of teacher shortages well documented in elementary, secondary, and post-secondary STEM areas and work to attract more candidates to STEM education where few faculty candidates hold the necessary qualifications to teach (Galosy \& Gillespie, 2013). Within the context of Newton, Utschig, \& Llewellyn's (2011) study, it then remains a critical goal to continue to recruit and retain qualified faculty for these programs.

In order to continue to retain and recruit new faculty, the motivation and job satisfaction of faculty is exceedingly important throughout the process of faculty members' acculturation to their specific university. Intrinsic value in the career of teaching is found through the achievement and success of students. As an antithesis to this, non-teaching workload such as grant writing activities can present itself with little or no intrinsic value. This results from the lack of interaction or direct impact on students. These variables are, in part, what make faculty members' pursuit of competitive grants or excessive faculty load outside of the classroom in high technology areas unsustainable. Faculty who find no intrinsic value in a task are less likely to complete that task and, further, may struggle to realize job satisfaction because of it. At a time when faculty departures could represent a substantial impact to smaller or growing programs, this represents a significant deficit.

Faculty working climate represents another variable that plays a vital role in faculty members' abilities to find job satisfaction and encouragement. Previous research 
proposed Self-Determination Theory as a potential explanation for recurring burnout resulting from a lack of job satisfaction for faculty (Ranđelović \& Stojiljković, 2015). When viewed within the university environment through the lens of Bolman and Deal's (2013) structural framework, the challenges for faculty become apparent. Self-

Determination Theory posits a relationship between things such as autonomy and feeling part of a larger unit. Due in part to the massive structure of the university compounded by the more complicated political environment, this relationship presents difficulty for faculty to cipher beyond their program. Even still, many programs fail to foster this sort of camaraderie leaving some faculty wondering if they work alone or against shared goals of their colleagues. Faculty may believe they lack support and coalition with their colleagues to affect change within their program, college, or university (Bolman \& Deal, 2013).

\section{Characteristics of the Applied Baccalaureate Program}

Despite competing arguments over the STEM shortage, many industries have recognized the value in what Townsend et al., (2008) defined as the applied baccalaureate. Among the confines of a traditional baccalaureate degree, the applied baccalaureate offers students who are seeking a four-year education, an applied and career-focused approach to their education. Often career opportunities within applied baccalaureate programs reflect many industry programs widely considered to be under the STEM umbrella. Many of these industries, such as automotive, computer-aided design and drafting (CADD), applied engineering, and industrial management are within the scope of the applied baccalaureate. STEM fields appear to be very closely related to the concept of the applied baccalaureate and potentially share similar outlooks, 
challenges, and strategies (Townsend et al., 2008). For instance, STEM fields champion skills and subjects that feature both hard and soft sciences, Mathematics, Engineering, and Technology. All of these fields are represented and built upon in more applied programs such as the applied baccalaureate.

Limited research summarizes the commonalities between applied baccalaureate programs and the more traditional liberal arts degree counterparts. While programs are commonly discussed in STEM research and applied baccalaureate areas as Townsend et al. (2008) observed, few studies investigate the subtle differences or similarities among those programs. These differences, such as how students are motivated to begin a STEM or technical baccalaureate program, how the programs are funded, as well as what differentiates the program from a traditional baccalaureate, can make it difficult to identify similar phenomenon within the programs. For example, the literature suggests little is known about how technical or STEM program graduates migrate from associate level studies to their baccalaureate studies (Bahr, Jackson, McNaughtan, Oster, \& Gross, 2017). There is, however, consensus on demand for these career field baccalaureate degrees and a relationship between the more broadly named STEM baccalaureate degrees and the relatively new applied baccalaureate degrees (Dewitt, 2015; Townsend et al., 2008). It is thought, in the post-secondary education portion of education, that the applied baccalaureate could be a major part of the solution to the STEM shortage. There also exists evidence of consensus on budgetary models appropriate for these types of programs and best practices for fully supporting these programs at the departmental level (Middaugh et al., 2003). The research aims to further inform this process in the hope that appropriate funding and workload recommendations can be utilized for specialized 
applied baccalaureate and STEM career field programs.

While many elements of a traditional baccalaureate degree remain in the applied baccalaureate degree, typically the roots of the applied baccalaureate as discussed by Bragg, Townsend, and Ruud (2009) evolved from career based skill sets. Graduates in these programs often pursue career outcomes with the expectation of obtaining or retaining a position within their field of choice. Without abandoning the idea of a wellrounded degree program, these applied programs simply add focus to a traditional liberal arts degree for highly technical and future-focused vocational careers.

Despite remaining a relatively new concept in the area of baccalaureate degrees, the applied baccalaureate has gained traction since its relatively recent inception. Bragg et al. (2009) conducted a 50 state survey of baccalaureate and associate degree granting institutions and found that 39 states at the time offered at least one applied baccalaureate degree. The authors concluded the data were indicative of both a demand and an academic response to demand for graduates of these programs. This potentially means that not only is the applied baccalaureate a viable model from which to build programs, it is also having an impact and filling a need for career-ready graduates at the baccalaureate level.

\section{Funding Sources and Research for Programs}

The Delaware Study began in 1992 as a cumulative data collection effort by the University of Delaware (University of Delaware, 1996). The goal of the study included compiling data to establish cost factors in educational institutions over a longitudinal data set (University of Delaware, 1996). Over time, the Delaware Study grew to become a national data collection effort, with universities across the United States contributing 
data. As of 2003, the study had over 300 institutions participating and utilizing the data (Middaugh et al., 2003). A central tenet of the Delaware Study was to maintain consensus from participating institutions to refrain from utilizing the data for disciplinary or award purposes. Instead, data were to be utilized for longitudinal studies to establish trends and significant conclusions to aid administrative personnel in budgeting for continued viability and/or growth within programs across all disciplines. This effort was coordinated to develop a funding formula that could be utilized to identify undersupported or under-staffed programs and departments based on credit hour needs and costs per credit hour per student (Middaugh et al., 2003).

Research has acknowledged the probability and increasing level of administrative acceptance to differential tuition, at least in research based higher education institutions (Nelson, 2008). In some institutions, while differential tuition was not implemented on a program-level basis the Delaware study data had been utilized to establish levels of student and program fees. Both of these methods potentially stand to produce additional revenue for programs that could benefit from further offsetting the cost of educating students within those programs. In contradiction to this movement, many states have adopted a fixed tuition model for resident students. While, on the surface, proponents argue that fixed tuition rates stand to benefit students at the institution, Delaney and Kearney (2016) found fixed tuition for resident students was correlated with higher outof-state or non-resident tuition rates. This finding, Delaney and Kearney suggested, was indicative of a continued need for increasing revenue to institutions as a whole and that institutions frequently offset the lack of flexibility associated with fixed tuition models with either student fees and/or non-resident tuition. Performance-based funding models 
also stand to reason as another alternative to potential funding or accountability measures that could potentially become reality for public institutions and the programs within them. Many of these implementations could utilize data from the Delaware study as a method of calculating costs of programs and specific budgetary considerations for each program during the budgetary development process (Middaugh et al., 2003).

Middaugh et al. (2003) found the cost per student credit-hour was correlated with an institution's academic mix of disciplines. This observation using the Delaware Study data identified a potential error in the methods by which some academic programs in applied baccalaureate areas are funded. As the researchers concluded, an English major on college campuses within the Delaware Study pays the same tuition rate as engineering majors; however, the direct costs for programs to educate that English major were significantly lower as compared to the engineering major. While the literature on the Delaware Study is widely recognized in many areas, STEM and applied baccalaureate areas are only discussed through the broad categorization of types of programs. Carrigan (2008) categorized STEM and applied baccalaureate programs in category IV. This category in Carrigan's study represented the highest cost per credit-hour category of the four disciplines recorded in the Delaware study.

As discussed previously, funding sources for programs could potentially be made at the institution level through differential tuition, performance-based funding, or nonresident student tuition or additional program-specific or major-specific fees. Delaney and Kearney's 2016 study focused on alleviating financial burdens at the institution level. Whether that relief is passed onto STEM or applied baccalaureate programs that could make specific use of the additional revenue then becomes determined by the leaders of 
said institution. Certainly, alternative methods of implementing Applied Baccalaureate degrees have been proposed. Floyd, Garcia Falconetti, and Felsher (2012) researched the feasibility and potential benefits of implementing a Community College Baccalaureate. The community college baccalaureate is essentially a baccalaureate degree that is granted via a community college using articulation, transfer, or dual credit models. These are usually maintained in conjunction with a local baccalaureate degree-granting institution. These programs also represent a method to ensure a steady stream of enrollment into the applied baccalaureate program. These types of arrangements are already commonly utilized in various fields. These models and their subsequent funding methods still fail to represent a final solution to funding problems for programs that provide a complete baccalaureate degree since they often result in revenue loss for the baccalaureate institution as the total generated credit hours per degree awarded is lower.

Another potential source of funding for programs is through grant funding. Grants, as Koppelman and Holloway (2012) wrote have become increasingly competitive as the era of reduction of research funding, performance-based indicators and heightened levels of scrutiny for applications. This heightened competitive market for grant money results in situations and funding that is beneficial to programs, but unsustainable in the long term and could place unnecessary burdens on faculty. How, then, are these responsibilities, arguably outside the primary role of teaching, assigned to faculty in applied baccalaureate programs? The answer lies in the framework of this study.

\section{Bolman and Deal's Frameworks}

While Jacobs and Winslow (2004) suggested that there were many factors influencing faculty workload and job satisfaction. Those factors present themselves 
within an often highly politicized and hierarchical structure at a university. This structure represents a departure from the typical structures found in industry. Due to the nature of applied baccalaureate degrees and the technical training required, the majority of faculty members teaching in applied baccalaureate programs have industry experience or come from industry. Faculty could be former employees, managers or products of the industry their program serves. With this background, the transition from industry and its respective structure, politics, and hierarchy to academia presents further challenges to incoming faculty than initially expected. For example, while promotion and seniority may be prevalent in high technology workplaces, tenure is a concept that is unique to the university environment. This alone can represent a disconcerting reality for former industry employees entering academia. Potentially, this complicates coping with new tasks or added responsibilities. These adjustments work in either opposition to or in concert with intrinsic motivators present in faculty and student interaction. A faculty member's ability to cope with situational and political adjustments and become acculturated to the university environment can determine their success or failure to achieve job satisfaction. It then follows that it becomes vital to that faculty member's success in that organization to understand their structural position and political landscape that position functions within in the organization.

In illustrating concepts such as faculty workload and job satisfaction, the context in which these experiences occur cannot be understated. As the conceptual framework of this study, Bolman and Deal's (2013) political and structural frameworks act as a lens from which to analyze these topics in order to give meaningful context. These ideas, as Bolman and Deal wrote, are a "coherent set of ideas or beliefs forming a prism or lens 
that enables you to see and understand more clearly what goes on from day to day" (p. 41). The necessity of these frameworks from which to view the working environment of teaching faculty in applied baccalaureate or STEM programs is only understood when one considers the immense complexity of the typical university structure. The structural and political frameworks give insight into what motivates faculty to pursue certain goals in their employment. The structural framework gives context to the faculty's situational positioning, while the political framework gives further insight into the motivations of faculty outside of their supervisor's requirements. The political framework also enables the research to account for varying degrees of power and influence within a faculty member's position at the university which can either grant or retract a certain degree of autonomy and job satisfaction.

These frameworks help illustrate the power structure and influences present in any organization. With modern universities, both structural and political aspects of the working environment exist throughout. Universities have long been operated by a diverse structure that establishes order within their ranks. This structure may be wellobserved and apparent making an analysis of the structural frame of a university relatively straight-forward. However, the political landscape of the university may be quite different and often goes unspoken and undocumented. This is one of the many difficulties facing new faculty who may not be versed in the political landscape of that particular organization (Lewallen et al., 2003). There is benefit to understanding both the structure and the political environment in which STEM or applied baccalaureate faculty work. This understanding gives significance and depth to the experiences of those faculty members and their ability to seek job satisfaction and efficacy in their position. 
Bolman and Deal's (2013) structural framework helps the researcher understand the physical structure of the university. Bolman and Deal discussed the structure and its influences on members of the organization as it operates. An example of this influence in the university is illustrated between an administrative member of a program or college and a faculty member in that program or college. When presented within Bolman and Deal's framework, authoritative influence from the administrator over the faculty member is simple to understand. For example, while the administrator in the program has the authoritative influence on the faculty in that program, the Dean at the college level influences the program or department administrator. While this makes the physical structure of the university easy to understand, when leadership concepts are involved, Northouse (2007) regarded the authoritative hierarchy as a bad leadership practice. His idea of returning the power to the members of an organization under control of any leader can benefit those members and the organization as a whole. This practice, as Northouse discussed, can restore a sense of autonomy to the faculty member's in a university.

There are notable exceptions to the example of faculty and administrative structure. In the example, it is easy to see where the power and authority exist. However, due to the promotional structure and nature of the university, a higher ranking faculty member could hold multiple positions within the college. The Associate Dean of a college, who also teaches within a program but is not the program administrator, is a good example of this. In this case, an Associate Dean has authority over the program administrator but has little or no authority within the program as an instructor. This can produce a wide variance of possible scenarios whereby the administrator, program coordinator, or faculty members are in confusing or tense power struggles between 
leadership roles. Further, it can establish a discrepancy of workloads across faculty position descriptions in which seniority or positions of authority can play a significant role in reducing a faculty member's workload while simultaneously increasing that faculty member's salary. While many faculty in STEM fields have expressed that these political influences have a limited effect in what they choose to spend their working hours on these forces can still aid in producing a somewhat confusing working environment for faculty who may have not been well trained or prepared for their position (Robert \& Carlsen, 2017).

The dynamics that result from this layering of authority and structure are continually at play within the confines of a university. Bilimoria et al. (2006) found correlations between faculty job satisfaction and faculty perceptions of administrative support. This finding presents a necessity for understanding the dynamics of that relationship between the faculty and their administrator. It also potentially places faculty in a position in which they must choose between job satisfaction, continued working relationships, and/or the benefits of their students. Understanding the structure and power positions, and the faculty member's role within them, gives important perspective when navigating the structural terrain of the university. Lewallen et al. (2003) noted this as an example of the benefits of understanding the organization and how educational leaders can help reduce undue stress, especially in new faculty.

Tenure. The difference in tenured and non-tenured or tenure-track faculty on a university campus adds a layer of complexity to the understanding of the structure of a university. Tenure bridges two concepts presented by Bolman and Deal (2013), the structural framework and the political framework. Tenured faculty and non-tenured or 
tenure-track faculty remain similar in physical or structural roles and job description. However, these categories can hold dissimilar levels of political power in the university. This imbalance demonstrates an additional layer of complexity to a comparatively simplistic structural organization of the university. In applying Bolman and Deal's frames to the university the literature demonstrated that, in theory, one could easily understand the categories, levels, and formal structure and job description of each member of the university. In practice, there remain additional layers of complexity. As Lewallen et al. (2003) discussed, these additional layers result in occasionally stressful circumstances and possible confusion for newer faculty, especially when faculty fail to find belonging or a sense of team camaraderie among their coworkers (Bilimoria et al., 2006).

Like the structural frame Bolman and Deal (2013) described, the political element of the university can be viewed through a lens to simplify the understanding of a complex or vague concept. This frame operates within a set of assumptions. According to Bolman and Deal, these five assumptions construct the political frame: (a) organizations employ diverse populations of both individuals and groups; (b) these individuals and groups often represent opposing interests; (c) the members who subscribe to these opposing interests believe in certain data, moral values, and often possess differing perceptions of reality; (d) the opposing interests can make decisions or debate the distribution of scarce resources available to them; (e) the individuals or groups combined with the scarcity of resources allow conflict to become a dynamic within and between groups.

Out of all the factors present in the political frame, political influence under this 
model carries the most importance. Bolman and Deal (2013) described political power being introduced from multiple sources, such as structural dominance, coercive or informational dynamics, or by the control of accolades, data or skill-sets. When reviewing the example of faculty members who hold the same physical position in the university but differ in areas of tenure/tenure-track and non-tenured categories, the political power differences become defined. In this case, no structural difference between two faculty members exists; however, politically, the tenured faculty member may hold far more political power over the non-tenured faculty member. Effective leadership requires an ability to master these elements of the political terrain and an aptitude for mapping the political terrain before action (Bolman \& Deal, 2013). Using this knowledge of the political environment on a university campus also aids faculty in adjusting to the unknown territory (Bilimoria et al., 2006).

In the university structure, political power often remains distributed in ways that some outsiders perceive as illogical (Bilimoria et al., 2006). While some promotional structure exists, theoretically, a lower job position title potentially holds tenure and the political power that accompanies it over that of a non-tenure track colleague. This phenomenon represents an example of the complicated political landscape that could present difficulty to faculty members, especially those new to the environment. More importantly, this understanding may aid faculty in navigating their workplace more skillfully and reduce stress induced by a lack of job satisfaction brought on by misunderstanding of the political workplace (Lewallen et al., 2003).

In Bolman and Deal's (2013) political framework it becomes easy to see why physical structure and the hierarchy of an organization plays a role in the outcomes and 
working environment of the faculty. At the university level, faculty members often experience a political climate that does not always appear as readily obvious. While that climate seems innocuous in nature, it can play a drastic role in faculty members' feelings of power to affect change, job satisfaction and overall sense of self-worth and appreciation. In this framework, Bolman and Deal discuss the necessity of leadership having authoritative command and reasonable amounts of jurisdiction over subordinates, as well as the necessity of those leaders to foster buy-in and operate with transparency and faith in their team. These concepts were corroborated by the American Psychological Association (2015) which outlined seven areas in constructing a psychologically healthy workplace. These areas, employee involvement, work-life balance, employee growth and development, health and safety, employee recognition, communication, and the potential benefits of a psychologically healthy workplace, all work in concert to support, affirm, and draw attention to the needs of the faculty and how they can be met. As discussed by Lewallen et al. (2003), administrative practices like these can work to minimize stressors, especially in new faculty.

Even after understanding these structural and political frameworks, a unique aspect of the university environment still exists in the delegation of duties and workload. For example, accreditation in STEM fields is commonly used and accepted as a means to gauge quality of an academic program. Van Zanten, Boulet, and Greaves (2012) defined accreditation as a systematic and thorough set of standards and protocols achieved by the academic program to enable a high-quality learning experience. In high-technology areas, accreditation often becomes a minimum requirement for equipment and training donations, grant funding, and the overall validity of the program itself. Through 
accreditation, many high technology programs maintain consistent and current technology and equipment as dictated by their accreditation bodies. In industry, administrative or managerial staff often handle tasks such as budget, certification, and quality control processes similar to many accreditation requirements; however, in the university environment, faculty often must accomplish these tasks due to the increasingly intimate nature of many of these responsibilities. For example, one would not ask an administrator who knows little about the engineering field to write a grant or ensure an engineering program meets accreditation standards in curricula. This paradigm shift potentially becomes disconcerting to faculty who remain accustomed to a more structured hierarchy from industry that remains less solvent.

\section{Faculty's Perceived Balance in Non-teaching vs. Teaching Responsibilities}

Bolman and Deal (2013) presented the concept of the human resource frame within the context of organizational structure. The human resource frame as described by Bolman and Deal aids leaders of organizations in understanding the human capital that makes up organizations. Bolman and Deal determined these human resources operate best in a symbiotic relationship where neither the organization nor the human capital employed by the organization is being taken advantage of by the other party. In Bolman and Deal's explanation, there are certain unwritten rules or assumptions to this framework. The assumptions of the human resource frame are (a) organizations exist to serve the needs of their human resource; (b) the organization and its human resources operate symbiotically; (c) when the fit between organizations and their human resources is poor, one or both suffer; (d) a good fit benefits both parties. Bolman and Deal presented these assumptions together as a framework by which organizations can utilize 
their human capital effectively.

Discussed earlier in this review, the investigation of supporting STEM and applied baccalaureate degrees begins with the support of faculty within them. Bolman and Deal's (2013) recommendation was to observe and understand several models of how employees may be motivated to complete tasks at work. In practice, Lewallen et al. (2003) determined that to continue to supply graduates, the educational sector in the nursing field would need to continue to supply and support faculty within those nursing programs. Various methods of supporting faculty have been researched, but one model that is both familiar and useful to educators is Maslow's (1954) hierarchy of needs. Maslow's theory is widely recognized as central to educational and psychological studies worldwide (Noltemeyer, Bush, Patton, \& Bergen, 2012). In applying this model to the baccalaureate degree faculty, job satisfaction and personal needs can be understood through the lens of faculty motivation, situational position within their organization, and political power. This application is reflective of the symbiotic relationship Bolman and Deal described in many successful organizations.

In a physiological sense, Maslow's (1954) model explains much more about how an organization supports the human capital it employs. For instance, the physiological needs of food, shelter, and safety are typically employer-provided in the form of a paycheck or benefits the employee can utilize to obtain these things. It could be argued that most employers provide this within reasonable expectations. It is more difficult to see how higher level needs such as belonging, esteem, and self-actualization are gained from employment in an organization. These needs are often discussed by educators as most frequently being met via the intrinsic rewards present when working with students 
(Waltman et al., 2012). Bilimoria et al. (2006) observed faculty obtaining overall jobsatisfaction through their perceptions of the institution and its leadership. However, this satisfaction was only garnered through the support systems available to the faculty rather than direct influence from leadership. For example, faculty constructed their own satisfaction based on how well they felt supported in their efforts, not via direct input from administrators.

Waltman et al. (2012) observed more specific factors contributing to faculty satisfaction or dissatisfaction. In their study, non-tenure track faculty expressed working with students and flexibility in personal life as factors contributing to their job satisfaction. These factors closely resemble the esteem and self-actualization needs discussed by Maslow. However, Waltman et al. also found that the lower level needs such as belonging, or lack thereof described by Maslow, among non-tenure track faculty, contributed to a lack of job satisfaction. Waltman et al. indicated this could reflect a necessity for administrators to take a more direct role in encouraging faculty when necessary.

Barkhuizen, Rothmann, and van de Vijver (2013) observed both workload and a lack of supporting resources as a contributor to faculty burnout and a lack of job satisfaction. It then follows that by using Maslow's hierarchy of needs, administrators should identify a potential roadblock to faculty job satisfaction. In addition, provided these signs can be identified by administrators, faculty showing signs of burnout could serve as an indicator for resource distribution. These faculty members may possess the necessary attitudes and experiences to obtain self-actualization and esteem but may be unable to reach it due to a deficiency in lower-level support of resources. 
In answering the question of how faculty perceive the balance of assigned workload in their program between non-teaching versus teaching responsibilities, administrators are more easily able to gauge potential faculty job satisfaction and potential negative aspects of burnout early on in the process. Ideally, this happens before those negative aspects become detrimental. This also can aid the administrators in decision-making when determining full-time faculty workloads beyond the context of credit hours taught. Using the conceptual framework of the study, understanding a faculty member's situational and political positioning within the university can help guide administrators in achieving a balance of faculty output without over burdening them. At the same time, this can maximize faculty output, while simultaneously maximizing faculty motivation, intrinsic and extrinsic value, and self-actualization and esteem needs of the faculty members.

\section{Faculty's Perceived Efficacy in the Classroom when Considering Non-teaching}

\section{Responsibilities}

Burnout is evidenced when faculty exhibit a loss of enthusiasm or motivation. This can be an extension or result of, or be caused in part by, a lack of job satisfaction. In applied baccalaureate degrees, a departure of a faculty member during a shortage in supply of STEM or applied baccalaureate faculty could translate to serious difficulties for programs. For this reason the departure of faculty from the career field as Matheny, Gfroerer and Harris (2000) described can be of serious concern to program administrators. Further, the undesirable results of faculty burnout often have a direct impact on students the faculty member instructs since classroom efficacy has also been shown to drop substantially with burnout (Frisby et al., 2015; Matheny, et al., 2000; 
Ranđelović \& Stojiljković, 2015; Zee \& Koomen, 2016). These outcomes have been observed widely in education, including but not limited to STEM fields (BoxSteffensmeier et al. 2015). By extension, Box-Steffensmeier et al. also demonstrated that faculty who have low efficacy in the classroom exhibit lower motivational effects on their students.

Faculty working climate plays a role in faculty's abilities to find job satisfaction and encouragement. Researchers have proposed Self-Determination Theory as an explanation for phenomena such as burnout which often propagates from a negative perception of working climate. Burnout was theorized as the outcome of a lack of job satisfaction for faculty (Ranđelović \& Stojiljković, 2015). To better understand the working environment in the university setting, the lens of Bolman and Deal's (2013) structural and political frameworks help break down the environment that can trigger these experiences. Together with these frameworks, the literature posits a relationship and necessity of balance between faculty autonomy and feelings of being part of a larger unit. This relationship reinforces Northouse's (2007) suggestions of the benefits of effective leadership practices. These practices, such as returning power to the faculty under leadership, can help ensure they do not get lost in the immense structure that is a modern university.

As discussed previously, the structure of the university, compounded by its highly political environment, makes it difficult for faculty to obtain true autonomy beyond their program. Even at the program-level, some programs potentially fail to foster this sort of input which potentially leaves faculty wondering if they work alone or against shared goals of their colleagues. Faculty may begin to believe they lack support and coalition 
with their colleagues when asked to affect change within their program, college, or university, much like as was discussed by Bolman and Deal. These negative feelings can present a working roadblock for faculty achievement of the necessary outcomes of selfactualization and esteem.

Bolman and Deal (2013) discussed the necessity of leadership having command and reasonable power over subordinates, but also stressed the necessity of educational leaders to obtain buy-in and operate transparently and communicate faith among their subordinates. As noted by Lewallen et al. (2003), administrative practices such as these can work to minimize stressors, especially in new faculty. These practices also help faculty feel more ingrained in the success of the program and foster the sense of autonomy that is very important to faculty job satisfaction and prevention of burnout.

\section{Faculty's Perception of Total Workload}

Following Bolman and Deal's (2013) model of the human resource frame can provide administrators with the tools to ensure successful leadership. Bolman and Deal presented these assumptions together as a framework by which organizations can utilize their human capital effectively. Together with assumptions and accommodations based on the understanding of political and structural frameworks administrators can make more informed decisions about their faculty and help them achieve optimal workload and maximum job satisfaction.

Jacobs and Winslow (2004) wrote about many factors that influence faculty job satisfaction. One of the positive factors investigated is the flexibility that an academic career provides (Waltman et al., 2012). As an antithesis to this positive aspect, Jacobs and Winslow also discuss the demanding nature of the job, citing professors who stress 
the continuing and ever-increasing responsibilities of the job. Adding to these concerns, most professors see their tenure at stake when considering a job or institution change. This places political pressure on the faculty member and may introduce additional stress factors in the working environment. Finally, many administrative, institutional, or governmental agencies fall short in properly evaluating and appreciating the efforts of faculty and accurately measuring their total workload. These stress factors are played out in the often politicized and complicated structural hierarchy present on a university campus. These structures and unspoken rules, while initially benign, have facets that extend deep into the university culture, objectives, and workload. They also typically do not mimic the structure and political complexity, or lack thereof, found in industry. This presents faculty with potentially difficult and unknown challenges in obtaining or maintaining job satisfaction from the day they are hired, regardless of the avenues by which they arrive at those results (Bilimoria et al., 2006). Potentially, this lack of job satisfaction could lead to burnout and departure from the career field (Box-Steffensmeier et al., 2015; Matheny, Gfroerer, \& Harris 2000).

In answering the question of how faculty perceive their workload, the researcher hopes to inform on the experiences of the faculty members and how their workload and motivations, situated in the political structure of the university environment, is perceived. While on the surface, the literature discusses these perceptions in a broad spectrum, little research has specifically explored STEM and applied baccalaureate areas in higher education.

\section{Summary}

Despite some skepticism about the existence of a STEM gap (Lowell \& Salzman, 
2009), there is little doubt that the demand for STEM graduates remains strong (Wang, 2013). As an extension of this phenomenon, high-technology and applied baccalaureate educators who are qualified and have the desire to teach are becoming more difficult to recruit (Galosy \& Gillispie, 2013). For these reasons, persistence and vigilance in retaining current STEM faculty are vital to the continuation of programs (Lewallen et al., 2003). This persistence among both STEM and applied baccalaureate programs has been recommended to be based on a strong understanding of structural, political, and human resource aspects of faculty members in STEM programs (Bolman \& Deal, 2013; Townsend et al., 2008). Through an understanding of faculty needs and motivations in the workplace, administrators are more adequately equipped to foster a sense of belonging and faculty buy-in to the universal vision of the program, college, and universities.

STEM fields and more traditional academic fields at the four-year level converge within the Applied Baccalaureate. This convergence places programs and, by extension, the faculty teaching in them, within unknown and unique circumstances. Many of these circumstances arise from the uniquely high cost associated with applied baccalaureate degree programs (Carrigan, 2008; Middaugh et al., 2003). Other instructional and implementation differences have also been observed resulting from the unique nature of an applied baccalaureate within a traditional academic structure (Bragg et al., 2009). These differences must be understood and accounted for provided these programs are expected to remain successful and viable in the present and future. 
Section Four - Contribution to Practice 


\section{Powerpoint Slides}

\section{FACULTY'S PERCEIVED EFFICACY IN THE CLASSROOM WHEN CONSIDERING NON-TEACHING RESPONSIBILITIES}

A Research Presentation Presented By:

Alexander Richards

University of Central Missouri 


\section{Abstract}

- Educators often asked to contribute to their workplace through means not directly related to students.

- What is the faculty's perceived efficacy in the classroom when considering non-teaching workloads?

- Nearly all participants shared a common desire and intrinsic motivation to support students and their program.

- Faculty see these non-teaching workloads as detracting from classroom experiences for students.

- These experiences often had a de-motivating effect on faculty and frequently resulted in negative feelings towards administration and administrative practices. 


\section{Considering Non-Teaching Responsibilities}

- Common interest among educators - further our student's success

- Not all workloads are directly related to students

- Unsupported by extrinsic benefits

- Not accounted for in faculty workload

- What effect does this workload have on faculty?

- An increasing demand for an educated workforce places high importance on modern forms of education at the post-secondary level

- STEM fields remain highly productive and influential

- Review Extrinsic and Intrinsic reward definitions/theory

- Discuss how non-teaching workloads are accounted for in job descriptions

o Lenny "Where is it in my job description?"

o Penelope "There is no intrinsic rewards in the system, so once that exciting new period wears off, it becomes burdensome, there is no monetary rewards, there is no payback."

- STEM field demand

- Discuss and Connect STEM fields to Applied Baccalaureate and Degree fields present in the study 


\section{Statement of the Problem}

- The relatively new idea of a high technology or applied baccalaureate places potentially unknown and unique circumstances on the faculty

- May assist or detract from job satisfaction

- Uniquely high costs

- Diverse range of knowledge and skill sets required

- Recruitment and retention becomes crucial

- Few potential candidates meet the requirements

- Job satisfaction, self-worth, and classroom efficacy are crucial in motivating existing faculty to continue to teach

- Give personal experiences of types of non-teaching loads that are specific to hightechnology areas.

o Difficulty in finding qualified faculty

o Scan tool and diagnostic tool update and administrative tasks

- Struggles with IT departments

o Knowledge of new tooling, techniques and industry trends

- Industry networking and update training

o Limited funding and alumni/advisory board donations

- Donations often move fast, within hours in some cases and opportunities must be taken as they present themselves.

- Requires faculty relationships with members of alumni or advisory board to be consistently maintained.

- Keenan's struggle with laptop and diagnostic equipment in labs 


\section{Purpose of the Study}

○ Research Question

- How do faculty perceive their self-efficacy in the classroom when considering non-teaching responsibilities?

( Inform administrators responsible for applied baccalaureate programs similar to the ones in the study

- Potential job satisfaction

- Self-efficacy outcomes for their faculty

- Recruiting and retaining highly qualified personnel 


\section{Scholarly Review for the Study}

- Several components of the literature relevant to the study

1. The need of qualified faculty and the characteristics of the programs

2. Lack of job satisfaction and self-efficacy

- Characterize the environment

3. Little is known about the common characteristics of faculty in STEM and applied baccalaureate programs

- Job satisfaction and the environment faculty teach in

o Intrinsic vs. extrinsic rewards

o Bolman and Deal's frameworks and their affect on faculty 


\section{Demand for STEM, Applied Baccalaureate} and High-Technology Faculty

o The importance of modern forms of technical education

- An increase in demand for STEM and career-path graduates at the baccalaureate level

o Continue to retain and recruit new faculty

- Faculty working climate

- Self-Determination Theory (Ranđelović \& Stojiljković, 2015)

- The relationship between autonomy and feeling part of a larger unit

- The massive structure of the University compounded by the more complicated political environment

- Mention Northouse's leadership theories

o Specifically buy-in and organizational leadership

- Elaborate on Bolman and Deal's political and structural frames 


\section{Bolman and Deal's Frameworks}

○ Factors influencing faculty workload and job satisfaction present themselves within a politicized and hierarchical structure at a University

- Majority of faculty have industry experience or come from industry

- A faculty member's ability to cope with situational and political adjustments can determine their success or failure to achieve job satisfaction

- Penelope's quote 'In academia, it's tough because I didn't feel I had the backing to tell that tenured faculty member what they needed to do to help me so those responsibilities fell on me" 


\section{Bolman and Deal's Framework Continued}

- Bolman and Deal's (2013) political and structural frameworks act as a lens from which to analyze these topics

- Insight into what motivates faculty to pursue certain goals in the university environment

- Structural framework = situational positioning

- Political framework = motivations of faculty

- These forces can aid in producing confusing working environment for faculty (Robert \& Carlsen, 2017)

- Penelope "As a coordinator this was a confusing point, in industry a subordinate could be told, do this, and it must be done by a certain date"

- Yes, you know who you can ask for things, Workload, vs. willingness vs. skillset 


\section{Faculty's Perceived Efficacy in the Classroom}

- Burnout is evidenced when faculty exhibit a loss of enthusiasm or motivation

- Departure of a faculty member could translate to serious difficulties for programs

- Faculty burnout often have a direct impact on students

- Classroom efficacy has been shown to drop

- Faculty working climate plays a role in faculty's ability to find job satisfaction and encouragement

- Balance between faculty autonomy and feelings of being part of a larger unit

- Larry "I look at other people in other departments and see us leaving at 6pm every day and everyone else was gone at noon or coming in saturdays and we all get paid the same... It's not equitable, but at the same time I love what I do and wouldn't teach in any other area."

- Charlie "The younger guys, who need the work, who need tenure, they're the ones that get taxed the most. 


\section{Methodology}

( Q Qualitative analysis of faculty perceptions of their non-teaching workload

- Research is set in the Midwestern United States at four-year degree granting institutions

- All programs in study must hold current accredited status with a professional accreditation organization and must be program specific

- Programs must be offered at the baccalaureate level at publicly funded institutions

- Participants selected from faculty members within STEM, high technology and applied baccalaureate degree programs

- Qualitative interview data were transcribed, processed and coded for common themes (Creswell, 2014)

- 30 Participants

- 21 interviews

- 9 Focus group members split between two Focus Groups

- ATMAE, ABET and NATEF were primary contacts for list-serve email requests

O No response from ABET

- Some participants were ABET accredited

- Two were snowball sampled from other contacts

- One was cold call through program coordinator

o ATMAE had good response from many schools

o NATEF had limited response - scope vs. audience. 


\section{Data Collection Tools}

○ Researcher conducted 21 semistructured faculty interviews and 2 focus groups

- Researcher-guided and followed interview protocol

- Data collected via audio recordings

- Participants signed an informed consent before participating

- Limited demographic information on participants was collected 


\begin{tabular}{|c|c|c|c|c|c|c|c|}
\hline \multicolumn{8}{|c|}{ Demographic informarion of Participanrs } \\
\hline Participant & $\begin{array}{l}\text { Years of } \\
\text { Teaching }\end{array}$ & Field & $\begin{array}{c}\text { Univers } \\
\text { ity } \\
\text { Foevs }\end{array}$ & $\begin{array}{c}\text { Did } \\
\text { Participant } \\
\text { Havea } \\
\text { Position } \\
\text { Change? }\end{array}$ & $\begin{array}{c}\text { Taught } \\
\text { Multiple } \\
\text { Programs? }\end{array}$ & $\begin{array}{l}\text { Taught } \\
\text { Outside High } \\
\text { Tech Areas? }\end{array}$ & Why Did Participant Start Teaching? \\
\hline Jacbe & 11 & Design/Drafting & $\mathrm{Tt}$ & $\begin{array}{l}\text { Yes- } \\
\text { Coordinator }\end{array}$ & Yes & $\mathrm{No}$ & Intrinsic Value to Teachng \\
\hline James & 6 & Automobue & T1 & $\mathrm{Na}$ & Na & No & Family members were teechers \\
\hline Frark & 3 & ENGI & T1 & No & No & No & Teacher infusence \\
\hline Debra & 19 & Construction & $\mathrm{T1}$ & $\begin{array}{l}\text { Yes- } \\
\text { Coordinatur }\end{array}$ & No & No & $\begin{array}{l}\text { Perception of more equity for women in } \\
\text { profession }\end{array}$ \\
\hline Brad & NGA & Autamotive & $\mathrm{T} 1$ & NAS & No & Yes & Teacher intuence \\
\hline Kaleb & 11 & Creer $/$ Tech ED & $\mathrm{T} 1$ & $\begin{array}{c}\text { Yes- } \\
\text { Coordinator }\end{array}$ & Yes & No & NA \\
\hline Sam & 5 & ENGT, MENGT & $\mathrm{T1}$ & No & Yes & No & Teacher infuence \\
\hline Thornas & 13 & $\begin{array}{c}\text { Industnal Tech. } \\
\text { ENGT }\end{array}$ & $\mathrm{Tt}$ & $\begin{array}{c}\text { Yes- } \\
\text { Courdinatur }\end{array}$ & Yes & No & Teaching Benefits/Schedule \\
\hline Joschim & 12 & Automolive & $\mathrm{T1}$ & $\begin{array}{l}\text { Yes - } \\
\text { Courdinator }\end{array}$ & Yes & Yes & 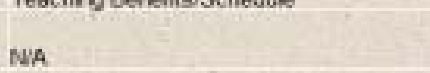 \\
\hline Penelape & 15 & CADO, ENGT & T1 & $\begin{array}{c}\text { Yes- } \\
\text { Courdinatar }\end{array}$ & Yes & No & Intrinsic Vabe to Teaching \\
\hline Larry & 12 & Automoove & $\mathrm{TH}$ & $\begin{array}{l}\text { Yes- } \\
\text { Conrdinatnr }\end{array}$ & Na & No & Teacher influence \\
\hline Ofver & 12 & $\begin{array}{l}\text { ENGT, indusorial } \\
\text { WGMT }\end{array}$ & $\mathrm{Tt}$ & $\begin{array}{l}\text { Yes - } \\
\text { Courdinatur }\end{array}$ & Yes & Yes & Fambly members were teachers \\
\hline Lenny & 5 & $\begin{array}{l}\text { CHGT, CENG. } \\
\text { ENGT }\end{array}$ & TI,Rt & $\begin{array}{l}\text { Yes- } \\
\text { Courdinator }\end{array}$ & Yes & No & Teacher influencelintnnsic Value \\
\hline Neil & 8 & Autemobive & $\mathrm{T1}$ & $\begin{array}{l}\text { Yes-Asst } \\
\text { Chair }\end{array}$ & No & No & Teaching Benents/Schedule \\
\hline Rabert & 12 & Autamotive & $\mathrm{T} 1$ & No & Nia & $\mathrm{Na}$ & Intrinsic Vabue to Teaching \\
\hline George & 12 & Automobive & $\mathrm{T} 1$ & No & No & No & NAA \\
\hline Chsie & 17 & INDTIConst. & $\mathrm{Tt}$ & $\begin{array}{l}\text { Yes- } \\
\text { Courdinatur }\end{array}$ & Yes & No & Teacher influence \\
\hline Maynard & 18 & Autumotive & $\mathrm{T} 1$ & No & No & Yes & Farrity members were teachers. \\
\hline Keenan & 14 & Automotive & R1 & Na & Yes & Yes & Teacher influence \\
\hline
\end{tabular}

- Worth noting how many participants were or held a role as coordinator

- Interesting responses to motivation to start teaching

o Family members

o Previous teachers

o Consistent with published research from course project on CTE recruitment 


\section{Data Analysis}

- Interviews and focus groups conducted using electronic communications were recorded and reviewed later via secure desktop video/audio capture software

- Once interviews were conducted verbatim transcription was completed

( ) Interview transcripts were coded into themes and categories

- School contact matrix

- Collection data matrix 


\section{Limitations and Assumptions}

- This research may not be transferable to other degree programs and faculty within them

- Different program-level conclusions over the effects of the observed perceptions

- Assumption that faculty within the researched programs have a portion of their working responsibilities dedicated to non-teaching tasks

- Additional factors outside the scope of this study

- Actual clock-time faculty spend on certain aspects of non-teaching workloads 


\section{Results}

1. Demographic information on participants

2. Perception of the effects their nonteaching workload had on their classroom efficacy

3. A series of four primary questions were asked with a semi-structured interview protocol that allowed researcher to expand upon participants responses 


\section{Perception of the Impact Non-Teaching Responsibilities has on Teaching}

- Category 1: non-teaching responsibilities had "none, to little" affect on classroom activities and efficacy

- Lenny stated that his performance in the classroom was personally regarded as his highest priority in his job function

- Alternatively, he suggested that he likely sacrificed non-teaching responsibilities for those related to his teaching

- Industry networking opportunities allowed him to incorporate more industry-driven topics into the classroom

- Opportunities to bring content back to the classroom was a very common theme among participants

- This was likely the most frequently discussed positive thing that participants talked about. 


\section{Perception of the Impact Non-Teaching Responsibilities has on Teaching}

- Category 2: non-teaching responsibilities had a negative affect on their classroom

- Larry expressed a disheartened attitude at feeling pressure to close and lock office door in able to focus on work in lieu of devoting time for students

- Penelope stated that outside responsibilities take time away from analyzing her lessons and revising them to make them better

- Many participants had a feeling that they could have contributed more or prepared more for their classroom lessons if they did not feel so overburdened with nonteaching loads. 


\section{Perception of the Impact Non-Teaching} Responsibilities has on Teaching

- Category 3: non-teaching responsibilities had a positive affect on their classroom

- Participants frequently commented on the ability to take industry or University service experiences back into the classroom

- Maynard suggested that it is hard to come up with negative experiences since long term, so many of those demands have a positive effect in the classroom or on the program. 


\section{Institutional Importance}

○ How are faculty members motivated?

- Intrinsic vs. extrinsic factors

- Teaching evaluations and how it can be abused

○ A misalignment of priorities at the administrative or university level may contribute to faculty dissatisfaction

- Leads to burnout in faculty members and potentially results in faculty departure

Frank "UCM does chair evaluations on teaching, that one day you have to be on point, the rest of the time there is a lot of lax in it." "Not so much, it has to be intrinsic, you're supposed to following through with goals and I've seen a lot that don't follow through" 


\section{Institutional Importance Continued}

- Category 1: Administrative words vs. actions

- Many faculty in the first focus group conducted expressed that at the program level, "it is not always students first" even though administrators want to believe this statement is true

- Joachim stated that administrators often say faculty are there to teach, but they also assign additional workloads to those faculty members

- Thomas remarked that administrators localize their support for teaching efforts, but do not necessarily support them in the same way behind the scenes. 


\section{Institutional Importance Continued}

○ Category 2: Administrative understanding or misunderstanding or workload

- Larry stated "I think it's human nature, the president of the University will never understand our degree, so its always going to be difficult for them to know how to properly do so" when discussing administrative understanding of faculty programs

- Kaleb estimated a $80 \%$ teaching load with and $20 \%$ being devoted to service and research

- Joachim felt that non-teaching workload is important but "there is that struggle and internal fight." 


\section{Institutional Importance Continued}

- Category 3: Evaluating or rewarding faculty

- Jackie suggested a reward system for faculty who develop or achieve better student learning outcomes

- Competency-based assessments show a university interest in teaching

- She stated "all of us could be paid better for the services we provide"

- Debra stated "In reality if you are not recruiting and promoting the program, the employers aren't happy so you are sort of forced to do that just to make it run."

- Recruiting loads and high technology areas

- Higher cost of programs vs. business model politics on University Campuses, possible future research? 


\section{Sacrifice or Contribution to Student Experience}

o Category 1: Contributing to classroom experience

- Often industry related or University related benefits

- Debra stated making relationships with employers help build connections which in turn help with curriculum and program currency

- Advantages of networking at professional conferences and the training they provide to instructors

- Network with faculty within their own institutions (i.e. committee work) 


\section{Sacrifice or Contribution to}

\section{Student Experience}

- Category 2: Detracting from classroom experience

- Most of the 21 participants reconciled a time where their classroom experiences were impacted negatively

- Jackie stated that lacking the time to design memorable learning experiences is a logical outcome when there are so many other tasks to do

- Frank noted being part of a search committee having to cut classes short and it detracted from his time to prepare for class

- Larry cited his personal conflict, stating that "if it's not your family, it's your students." 


\section{Implications}

- Faculty remain critical for the continuation and proliferation of STEM programs (Newton, Utschig, \& Llewellyn, 2011), thus retention of existing faculty is vital

- Potential new faculty must be drawn to the profession to grow these programs (Jacobs \& Winslow, 2004; Ranđelović \& Stojiljković, 2015)

( ) Faculty view their non-teaching workload in many ways depending on the timing, the task, and whether or not it contributes to their classroom 


\section{Implications Continued}

- Theme 1: Despite negative experiences of these faculty and their feelings of limited classroom efficacy, several participants stated positive remarks about their profession and their work with their students

- Faculty was highly motivated by and exceptionally focused on the success of their students above all else

- Many participants expressed more positive outlooks on university level work 


\section{Implications Continued}

- Theme 2: Administrators on many levels in the participant's institutions often lack the industry experience, or program level experience to understand faculty member's total workload

- Many participants remarked on their feelings that administrators did not understand their workload, the amount of time it takes to accomplish tasks, and how much time that takes away from faculty/student interaction

- Faculty had to decide what could be sacrificed for the purpose of accomplishing those tasks 


\section{Recommendations for Practice}

- University administrators need to take a more active role in understanding the more specialized load that faculty in high technology face

- Program resource reduction

- Additional workload for faculty

- Many participants do not feel their own workload is being justifiably understood or accounted for

- Extrinsic rewards (salary or benefits)

- Intrinsic rewards (appreciation from superiors) 


\section{Conclusions}

○ Non-teaching workloads for faculty is burdensome and often does not carry as much intrinsic benefit to the faculty member

- Faculty experiences with non-teaching workload should be accounted for

o Hopefully this work and experiences recorded within it will contribute to the discussion of workloads for faculty teaching in high-technology and in-demand areas 


\title{
Executive Summary
}

\section{FACULTY'S PERCEIVED EFFICACY IN THE CLASSROOM WHEN CONSIDERING NON-TEACHING RESPONSIBILITIES}

A Research Presentation Presented By Alexander Richards University of Central Missouri

\begin{abstract}
As educators, both intrinsic and extrinsic motivations persist as career outcomes. However, often educators can be asked to contribute to their workplace through means not directly related to students and student outcomes. This can result in a lack of job satisfaction for faculty in high technology areas where non-teaching workloads are especially high. Coupled with a demand for support of STEM, applied, and career-focused baccalaureate education from industry it becomes crucial to support these faculty in their endeavors to educate the future of their respective industry. This qualitative research sought to inform administrators for these programs on the particular circumstances surrounding these faculty and their programs. More specifically, to answer the question; What is the faculty's perceived efficacy in the classroom when considering non-teaching workloads?. The study found nearly all the participants shared a common desire and intrinsic motivation to support students and their program to the best of their ability. The study also concluded that often, faculty see these non-teaching workloads as detracting from classroom experiences for students or their own classroom efficacy. These experiences often were discussed as having a demotivating effect on faculty and frequently resulted in negative feelings towards administration and administrative practices at each institution.
\end{abstract}

\section{Statement of the Problem}

- The relatively new idea of a high technology or applied baccalaureate places potentially unknown and unique circumstances on the faculty

- May assist or detract from job satisfaction

- Uniquely high costs

- Diverse range of knowledge and skill sets required

- Recruitment and retention becomes crucial

- Few potential candidates meet the requirements

- Job satisfaction, self-worth, and classroom efficacy are crucial in motivating existing faculty to continue to teach

\section{Research Question}

- How do faculty perceive their self-efficacy in the classroom when considering non-teaching responsibilities?

\section{Scholarly Review for the Study}

- The need of qualified faculty and the characteristics of the programs (Galosy \& Gillespie, 2013).

- Lack of job satisfaction and self-efficacy (Ranđelović \& Stojiljković, 2015).

- Characterize the environment

- Little is known about the common characteristics of faculty in STEM and applied baccalaureate programs

- The importance of modern forms of technical education (Xue \& Larson, 2015). 
- An increase in demand for STEM and career-path graduates at the baccalaureate level

- Continue to retain and recruit new faculty

- Faculty working climate and Self-Determination Theory (Ranđelović \& Stojiljković, 2015)

- The relationship between autonomy and feeling part of a larger unit (Northouse, 2007).

- The massive structure of the University compounded by the more complicated political environment

- Bolman and Deal's (2013) political and structural frameworks act as a lens from which to analyze these topics

- Insight into what motivates faculty to pursue certain goals in the university environment

- Structural framework $=$ situational positioning

- Political framework = motivations of faculty

- These forces can aid in producing confusing working environment for faculty (Robert \& Carlsen, 2017)

- Faculty's Perceived Efficacy in the Classroom

- Burnout is evidenced when faculty exhibit a loss of enthusiasm or motivation (Frisby et al., 2015; Matheny, et al., 2000; Ranđelović \& Stojiljković, 2015; Zee \& Koomen, 2016).

- Departure of a faculty member could translate to serious difficulties for programs

- Faculty burnout often have a direct impact on students (Frisby et al., 2015).

- Classroom efficacy has been shown to drop

- Faculty working climate plays a role in faculty's ability to find job satisfaction and encouragement

- Balance between faculty autonomy and feelings of being part of a larger unit

\section{Methodology}

- Qualitative analysis of faculty perceptions of their non-teaching workload

- Research is set in the Midwestern United States at four-year degree granting institutions

- All programs in study must hold current accredited status with a professional accreditation organization and must be program specific

- Programs must be offered at the baccalaureate level at publicly funded institutions

- Participants selected from faculty members within STEM, high technology and applied baccalaureate degree programs

- Qualitative interview data were transcribed, processed and coded for common themes (Creswell, 2014)

\section{Data Collection Tools}

○ 21 semi-structured faculty interviews and 2 focus groups

- Researcher-guided via interview protocol

- Data collected via audio recordings 
- Limited demographic information on participants was collected

\section{Limitations and Assumptions}

- This research may not be transferable to other degree programs and faculty within them

- Different program-level conclusions over the effects of the observed perceptions

- Assumption that faculty within the researched programs have a portion of their working responsibilities dedicated to non-teaching tasks

\section{Results}

- Additional factors outside the scope of this study

- Demographic information on participants

\begin{tabular}{|c|c|c|c|c|c|}
\hline \multicolumn{6}{|c|}{ Table 1: Demographic Information of Participants } \\
\hline Name & $\begin{array}{c}\text { Years } \\
\text { Taught }\end{array}$ & Field & $\begin{array}{c}\text { Org. } \\
\text { Focus }\end{array}$ & $\begin{array}{l}\text { Position } \\
\text { Change? }\end{array}$ & Motivation to teach? \\
\hline Jackie & 11 & Design/Drafting & $\mathrm{T}$ & Yes & Intrinsic Value to Teaching \\
\hline James & 6 & Automotive & $\mathrm{T}$ & No & Family members were teachers \\
\hline Frank & 3 & ENGT & $\mathrm{T}$ & No & Teacher influence \\
\hline Debra & 19 & Construction & $\mathrm{T}$ & Yes & Perception of more equity for women \\
\hline Brad & N/A & Automotive & $\mathrm{T}$ & N/A & Teacher influence \\
\hline Kaleb & 11 & Career/T ech ED & $\mathrm{T}$ & Yes & N/A \\
\hline Sam & 5 & ENGT, MENGT & $\mathrm{T}$ & No & Teacher influence \\
\hline Thomas & 13 & Ind T ech, ENGT & $\mathrm{T}$ & Yes & Teaching Benefits/Schedule \\
\hline Joachim & 12 & Automotive & $\mathrm{T}$ & Yes & N/A \\
\hline Penelope & 15 & CADD, ENGT & $\mathrm{T}$ & Yes & Intrinsic Value to Teaching \\
\hline Larry & 12 & Automotive & $\mathrm{T}$ & Yes & Teacher influence \\
\hline Oliver & 12 & ENGT, Ind MGMT & $\mathrm{T}$ & Yes & Family members were teachers \\
\hline Lenny & 5 & CMGT, CENG, ENGT & $\mathrm{R}$ & Yes & Teacher influence/Intrinsic Value \\
\hline Neil & 8 & Automotive & $\mathrm{T}$ & Yes & Teaching Benefits/Schedule \\
\hline Robert & 12 & Automotive & $\mathrm{T}$ & No & Intrinsic Value to T eaching \\
\hline George & 12 & Automotive & $\mathrm{T}$ & No & N/A \\
\hline Charlie & 17 & INDT/Construction & $\mathrm{T}$ & Yes & Teacher influence \\
\hline Maynard & 18 & Automotive & $\mathrm{T}$ & No & Family members were teachers \\
\hline Keenan & 14 & Automotive & $\mathrm{R}$ & No & Teacher influence \\
\hline
\end{tabular}

- Question: Perception of the effects their non-teaching workload had on their classroom efficacy

- Perception of the Impact Non-Teaching Responsibilities has on Teaching

- Response Category 1: non-teaching responsibilities had "none, to little" affect on classroom activities and efficacy

- Participant Lenny stated that his performance in the classroom was personally regarded as his highest priority in his job function

$\circ$ Alternatively, he suggested that he likely sacrificed nonteaching responsibilities for those related to his teaching

- Industry networking opportunities allowed him to incorporate more industry-driven topics into the classroom 
- Response Category 2: non-teaching responsibilities had a negative affect on their classroom

- Participant Larry expressed a disheartened attitude at feeling pressure to close and lock office door in able to focus on work in lieu of devoting time for students

- Participant Penelope stated that outside responsibilities take time away from analyzing her lessons and revising them to make them better

- Response Category 3: non-teaching responsibilities had a positive affect on their classroom

- Participants frequently commented on the ability to take industry or University service experiences back into the classroom

- Participant Maynard suggested that it is hard to come up with negative experiences since long term, so many of those demands have a positive effect in the classroom or on the program.

- How much Importance does your Institution Place on Teaching?

- Response Category 1: Administrative words vs. actions

- Many faculty in the first focus group conducted expressed that at the program level, "it is not always students first" even though administrators want to believe this statement is true

- Participant Joachim stated that administrators often say faculty are there to teach, but they also assign additional workloads to those faculty members

- Participant Thomas remarked that administrators localize their support for teaching efforts, but do not necessarily support them in the same way behind the scenes.

- Response Category 2: Administrative understanding or misunderstanding or workload

○ Participant Larry stated "I think it's human nature, the president of the University will never understand our degree, so its always going to be difficult for them to know how to properly do so" when discussing administrative understanding of faculty programs

- Participant Kaleb estimated a $80 \%$ teaching load with and $20 \%$ being devoted to service and research

- Participant Joachim felt that non-teaching workload is important but "there is that struggle and internal fight."

- Response Category 3: Evaluating or rewarding faculty

$\circ$ Participant Jackie suggested a reward system for faculty who develop or achieve better student learning outcomes

- Competency-based assessments show a university interest in teaching 
○ She stated "all of us could be paid better for the services we provide"

- Participant Debra stated "In reality if you are not recruiting and promoting the program, the employers aren't happy so you are sort of forced to do that just to make it run."

- Non-Teaching Workloads Sacrifice or Contribute to Student Experience

- Response Category 1: Contributing to classroom experience

$\circ$ Often industry related or University related benefits

- Participant Debra stated making relationships with employers help build connections which in turn help with curriculum and program currency

$\circ$ Advantages of networking at professional conferences and the training they provide to instructors

- Network with faculty within their own institutions (i.e. committee work)

- Response Category 2: Detracting from classroom experience

$\circ$ Most of the 21 participants reconciled a time where their classroom experiences were impacted negatively

- Participant Jackie stated that lacking the time to design memorable learning experiences is a logical outcome when there are so many other tasks to do

- Participant Frank noted being part of a search committee having to cut classes short and it detracted from his time to prepare for class

Implications

- Participant Larry cited his personal conflict, stating that "if it's not your family, it's your students."

- Faculty remain critical for the continuation and proliferation of STEM programs (Newton, Utschig, \& Llewellyn, 2011), thus retention of existing faculty is vital

- Potential new faculty must be drawn to the profession to grow these programs (Jacobs \& Winslow, 2004; Ranđelović \& Stojiljković, 2015)

○ Faculty view their non-teaching workload in many ways depending on the timing, the task, and whether or not it contributes to their classroom

Themes

- Theme 1: Despite negative experiences of these faculty and their feelings of limited classroom efficacy, several participants stated positive remarks about their profession and their work with their students

○ Theme 2: Administrators on many levels in the participant's institutions often lack the industry experience, or program level experience to understand faculty member's total workload

\section{Recommendations for Practice}

- University administrators need to take a more active role in understanding the more specialized load that faculty in high technology face

- Program resource reduction

- Additional workload for faculty 
- Many participants do not feel their own workload is being justifiably understood or accounted for

- Extrinsic rewards (salary or benefits)

- Intrinsic rewards (appreciation from superiors)

\section{Conclusions}

- Non-teaching workloads for faculty is burdensome and often does not carry as much intrinsic benefit to the faculty member

- Faculty experiences with non-teaching workload should be accounted for 
Section Five - Contribution to Scholarship 


\title{
Section Five: Contribution to Scholarship
}

FACULTY'S PERCEIVED EFFICACY IN THE CLASSROOM WHEN CONSIDERING NON-TEACHING RESPONSIBILITIES

\author{
A Research Article \\ presented to
}

The Journal of Technology, Management, and Applied Engineering

by

Alexander Richards

University of Central Missouri

2018 


\begin{abstract}
As educators, both intrinsic and extrinsic motivations persist as career outcomes. However, often educators can be asked to contribute to their workplace through means not directly related to students and student outcomes. This can result in a lack of job satisfaction for faculty in high technology areas where non-teaching workloads are especially high. Coupled with a demand for support of STEM, applied and careerfocused baccalaureate education from industry it becomes crucial to support these faculty members in their endeavors to educate the future of their respective industry. This qualitative research sought to inform administrators for these programs on the particular circumstances surrounding these faculty and their programs. More specifically, to answer the question; what is the faculty's perceived efficacy in the classroom when considering non-teaching workloads? The study found nearly all the participants shared a common desire and intrinsic motivation to support students and their program to the best of their ability. The study also concluded that often, faculty see these non-teaching workloads as detracting from classroom experiences for students or their own classroom efficacy. These experiences often were discussed as having an unmotivating effect on faculty and frequently resulted in negative feelings towards administration and administrative practices at each institution.

Keywords: Faculty, Job-Satisfaction, Classroom Efficacy, Applied Baccalaureate, STEM, Higher Education
\end{abstract}




\section{Faculty's Perceived Efficacy in the Classroom when Considering Non-teaching}

\section{Responsibilities}

As educators, desire to further our student's success has persisted as a common interest. The intrinsic reward educators reap from working with, and subsequently experiencing the success of, their students represents one of the most motivating aspects of the career. However, not all workload at the post-secondary level is directly related to students. Much of this work is unsupported by extrinsic benefits of the career and not accounted for in faculty workload. What effect then, does this workload have on faculty? In a larger scale, an ever-increasing demand for an educated workforce places high importance on modern forms of education at the post-secondary level. STEM fields remain highly productive and influential here in the United States so it then follows that continued support of STEM programs requires continued support of the qualified faculty within them. This research seeks to understand the perspectives of those faculty and how they feel they can be better supported within their programs to positively affect their feelings of self-efficacy and job satisfaction.

\section{Statement of the Problem}

In the case of the applied baccalaureate, the applied sciences and the four-year degree portions of the educational landscape collide (Bragg, et al. 2009). The relatively new idea of a high technology or applied baccalaureate places potentially unknown and unique circumstances on the faculty teaching in them. Little is known about applied baccalaureate or high technology baccalaureate faculty member's perceptions and experiences in these programs and how they may assist or detract from faculty member's job satisfaction and self-efficacy. These circumstances can arise from the uniquely high 
cost associated with applied baccalaureate degree programs and the diverse range of knowledge and skill sets required of these faculty to teach (Bragg, Townsend, \& Ruud, 2009). Increasing expectations for high-quality graduates in the highly competitive STEM career market like the ones observed by Hagedorn and Purnamasari (2012) solidify that recruitment and retention of those qualified teaching faculty becomes essential. This recruitment and retention becomes crucial in an era when a consensus on the shortage of qualified teaching personnel who seem attracted to the idea of teaching exists. Even fewer of these potential candidates meet the requirements to teach (Galosy \& Gillespie, 2013). This deficit makes job satisfaction and positive feelings of self-worth and classroom efficacy crucial in motivating existing faculty to continue to teach regardless of the extrinsic benefits offered outside of the university.

\section{Purpose of the Study}

The purpose of this study was to better understand the faculty perceptions of nonteaching workloads in applied baccalaureate, high technology or STEM areas. This research focuses specifically on the non-teaching responsibilities and their perceived effect on faculty at a personal and professional level. Non-teaching duties represent many facets of instructor workload but, for the study, it constitutes any job responsibility of teaching faculty members not directly related to student outcomes or activities. It is the researchers hope to inform administrators responsible for applied baccalaureate programs similar to the ones in the study about potential job satisfaction or self-efficacy outcomes for their faculty. By doing so, administrators bolster their program's resistance to potential problems that already have begun to surface in recruiting and retaining highly qualified personnel (Galosy \& Gillespie, 2013). 


\section{Research Question}

The study's purpose was to answer the question: How do faculty members perceive their self-efficacy in the classroom when considering non-teaching responsibilities?

\section{Scholarly Review for the Study}

This scholarly review will discuss several components of the literature relevant to the study. The first component is the need for qualified faculty and the characteristics of the programs that educate them. Job satisfaction and faculty experiences follow closely to this section as it becomes necessary to understand and accommodate for faculty experience and job satisfaction in maintaining the high quality of these accredited programs. In further discussing faculty, the results of burnout, lack of job satisfaction and self-efficacy is also investigated. The aim of this exercise is to characterize the environment in which the applied baccalaureate, high technology or STEM educator teaches.

The literature does not address the experiences of STEM faculty, more specifically, faculty in four-year applied baccalaureate programs. Little has been discussed about how faculty experiences affect faculty within baccalaureate programs that fall under STEM and/or applied baccalaureate fields. Further, the current review of the literature reveals little about the common characteristics of faculty in STEM fields and applied baccalaureate programs. The broad diversity of STEM programs means a thoughtful consensus on a typical faculty profile and experiences is difficult to surmise. Instead, the goal is to bring context to the study of the perceptions of these faculty members, aiming to characterize the environment in which the applied baccalaureate or 
STEM educator teaches.

\section{Demand for STEM, Applied Baccalaureate and High-Technology Faculty}

In educational research, demands for educating the future workforce frequently emphasize the importance of modern forms of technical education (Townsend, Bragg \& Ruud, 2008). A recent reemergence in technical education catered to efforts to close the Science, Technology, Engineering, and Math (STEM) gap. While most STEM-focused educational research has concentrated on K-12 areas, similar demands for STEM and career-path graduates at the baccalaureate level have shown a proportionate increase in recent years (Xue \& Larson, 2015). Dewitt (2015) suggested that STEM education remains an issue worthy of discussion within all levels of educational research.

In order to continue to retain and recruit new faculty, their motivation and job satisfaction is exceedingly important throughout the process of acculturation to their specific university. Faculty working climate represents another variable that plays a vital role in faculty's abilities to find job satisfaction and encouragement. Previous research proposed Self-Determination Theory as a potential explanation for recurring burnout resulting from a lack of job satisfaction for faculty (Ranđelović \& Stojiljković, 2015). Self-Determination Theory posits a relationship between things such as autonomy and feeling part of a larger unit. Due in part to the massive structure of the university compounded by the more complicated political environment, this relationship presents difficulty for faculty to cipher beyond their program. When viewed within the university environment through the lens of Bolman and Deal's (2013) structural framework, the challenges for faculty become apparent. 


\section{Bolman and Deal's Frameworks}

While Jacobs and Winslow (2004) suggested that there were many factors influencing faculty workload and job satisfaction, those factors are present within an often highly politicized and hierarchical structure at a university. This structure represents a departure from the typical structures found in industry. Due to the nature of applied baccalaureate degrees and the technical training required, the majority of faculty members teaching in applied baccalaureate programs have industry experience or come from industry. With this background, the transition from industry and its respective structure, politics, and hierarchy to academia presents further challenges to incoming faculty than initially expected. A faculty member's ability to cope with situational and political adjustments and become acculturated to the university environment can determine their success or failure to achieve job satisfaction.

Bolman and Deal's (2013) political, and structural frameworks act as a lens from which to analyze these topics in order to give meaningful context. The structural and political frameworks give insight into what motivates and allows faculty to pursue certain goals in the complex university environment. The structural framework gives context to the faculty's situational positioning, while the political framework gives further insight into the motivations of faculty outside of their supervisor's requirements. The political framework also enables the research to account for varying degrees of power and influence within a faculty member's position at the university which can either grant or retract a certain degree of autonomy and job satisfaction. Further, it can establish a discrepancy of workloads across faculty position descriptions in which seniority or positions of authority can play a significant role in determining a faculty member's 
workload. While many faculty in STEM fields have expressed that these political influences have a limited effect in what they choose to spend their working hours on, these forces can still aid in producing a somewhat confusing working environment for faculty who may have not been well trained or prepared for their position (Robert \& Carlsen, 2017).

The dynamics that result from this layering of authority and structure are continually at play within the confines of a university. Bilimoria et al. (2006) found correlations between faculty job satisfaction and faculty perceptions of administrative support. This finding presents a necessity for understanding the dynamics of that relationship between the faculty and their administrator. It also potentially places faculty in a position in which they must choose between job satisfaction, continued working relationships, and/or the benefits of their students. Understanding the structure and power positions, and the faculty member's role within them, gives important perspective when navigating the structural terrain of the university.

\section{Faculty's Perceived Efficacy in the Classroom when Considering Non-teaching}

\section{Responsibilities}

Burnout is evidenced when faculty exhibit a loss of enthusiasm or motivation.

This can be an extension or result of, or be caused in part by, a lack of job satisfaction. In applied baccalaureate degrees, a departure of a faculty member during a shortage in supply of STEM or applied baccalaureate faculty could translate to serious difficulties for programs. For this reason the departure of faculty from the career field as Matheny, Gfroerer and Harris (2000) described can be of serious concern to program administrators. Further, the undesirable results of faculty burnout often have a direct 
impact on students the faculty member instructs since classroom efficacy has also been shown to drop substantially with burnout (Frisby et al., 2015; Matheny, et al., 2000; Ranđelović \& Stojiljković, 2015; Zee \& Koomen, 2016). These outcomes have been observed widely in education, including but not limited to STEM fields (BoxSteffensmeier et al. 2015). By extension, Box-Steffensmeier et al. also demonstrated that faculty who have low efficacy in the classroom exhibit lower motivational effects on their students.

Faculty working climate plays a role in faculty's abilities to find job satisfaction and encouragement. Researchers have proposed Self-Determination Theory as an explanation for phenomena such as burnout which often propagates from a negative perception of working climate. Burnout was theorized as the outcome of a lack of job satisfaction for faculty (Ranđelović \& Stojiljković, 2015). To better understand the working environment in the university setting, the lens of Bolman and Deal's (2013) structural and political frameworks help break down the environment that can trigger these experiences. Together with these frameworks, the literature posits a relationship and necessity of balance between faculty autonomy and feelings of being part of a larger unit.

\section{Methodology}

The study is a qualitative analysis of faculty perceptions of their non-teaching workload. Using the phenomenological approach as described by Creswell (2014), the research is set in the Midwestern United States at four-year degree granting institutions. All programs participating in the study must hold current accredited status with a professional accreditation organization and the accreditation must be program-specific. 
Additionally, the programs must be offered at the baccalaureate level at publicly funded institutions. Private institutions were excluded from the study. Pools of potential programs were obtained from accreditation records maintained by The Association of Technology, Management and Applied Engineering (ATMAE). The participants were selected from faculty members within STEM, high technology and applied baccalaureate degree programs offered at these institutions. A series of semi-structured interviews, and focus groups, lasting one-half to one hour as well as any document analysis relevant to interview, program or participant data constituted the data collection. Qualitative interview data were transcribed, processed and coded for common themes using emergent theme coding and blended with observations from other data sources (Creswell, 2014). In addition to data triangulation during the data collection period, several member checks were performed with study participants who were willing to devote additional time to the project.

\section{Data Collection Tools}

The researcher conducted 21 semi-structured faculty interviews and 2 focus groups. Both interviews and focus groups were researcher-guided and followed an interview protocol. Data were collected via audio recordings and participants signed an informed consent before participating in an interview or focus group. Each participant was assigned a pseudonym. The researcher gathered limited demographic information on the participants such as time in the teaching profession, official title(s), role in the program of study, and characteristics of the program and host university. These demographics are listed in chart form as Table 1. 


\begin{tabular}{|c|c|c|c|c|c|}
\hline \multicolumn{6}{|c|}{ Table 1: Demographic Information of Participants } \\
\hline Name & $\begin{array}{c}\text { Years } \\
\text { Taught } \\
\end{array}$ & Field & $\begin{array}{l}\text { Org. } \\
\text { Focus }\end{array}$ & $\begin{array}{l}\text { Position } \\
\text { Change? } \\
\end{array}$ & Motivation to teach? \\
\hline Jackie & 11 & Design/Drafting & $\mathrm{T}$ & Yes & Intrinsic Value to T eaching \\
\hline James & 6 & Automotive & $\mathrm{T}$ & No & Family members were teachers \\
\hline Frank & 3 & ENGT & $\mathrm{T}$ & No & Teacher influence \\
\hline Debra & 19 & Construction & $\mathrm{T}$ & Yes & Perception of more equity for women \\
\hline Brad & N/A & Automotive & $\mathrm{T}$ & N/A & Teacher influence \\
\hline Kaleb & 11 & Career/T ech ED & $\mathrm{T}$ & Yes & N/A \\
\hline Sam & 5 & ENGT, MENGT & $\mathrm{T}$ & No & Teacher influence \\
\hline Thomas & 13 & Ind T ech, ENGT & $\mathrm{T}$ & Yes & Teaching Benefits/Schedule \\
\hline Joachim & 12 & Automotive & $\mathrm{T}$ & Yes & N/A \\
\hline Penelope & 15 & CADD, ENGT & $\mathrm{T}$ & Yes & Intrinsic Value to T eaching \\
\hline Larry & 12 & Automotive & $\mathrm{T}$ & Yes & Teacher influence \\
\hline Oliver & 12 & ENGT, Ind MGMT & $\mathrm{T}$ & Yes & Family members were teachers \\
\hline Lenny & 5 & CMGT, CENG, ENGT & $\mathrm{R}$ & Yes & Teacher influence/Intrinsic Value \\
\hline Neil & 8 & Automotive & $\mathrm{T}$ & Yes & Teaching Benefits/Schedule \\
\hline Robert & 12 & Automotive & $\mathrm{T}$ & No & Intrinsic Value to Teaching \\
\hline George & 12 & Automotive & $\mathrm{T}$ & No & N/A \\
\hline Charlie & 17 & INDT/Construction & $\mathrm{T}$ & Yes & Teacher influence \\
\hline Maynard & 18 & Automotive & $\mathrm{T}$ & No & Family members were teachers \\
\hline Keenan & 14 & Automotive & $\mathrm{R}$ & No & Teacher influence \\
\hline
\end{tabular}

\section{Data Analysis}

It was the intent of the researcher to conduct as many interviews and focus groups in person on site. When necessary, electronic communication (web conferencing) was utilized. Interviews and focus groups conducted using electronic communications were recorded and reviewed later via secure desktop video/audio capture software. Once interviews were conducted, verbatim transcription was completed. The interview transcripts were coded into themes and categories using keywords and speech pattern analysis.

\section{Limitations and Assumptions}

Because of the unique position of applied baccalaureate programs within traditional academic structures, this research may not be transferable to other degree 
programs and faculty within them. In addition, academic structure and the positional power of programs within their host university may present different program-level conclusions over the effects of the observed perceptions. It is the assumption of the researcher that faculty within the researched programs have at least a portion of their working responsibilities dedicated to non-teaching tasks. A further limitation lies in additional factors outside the scope of this study contributing to job satisfaction or dissatisfaction. In this case, non-teaching workload (within the scope of this research) and other factors linked to job satisfaction (not necessarily within the scope of this research) may contribute to faculty input.

The researcher sought to establish the overall experiences of faculty, but was unable to establish how much or how little actual clock-time faculty spend on certain aspects of non-teaching workloads. This concept has been debated among academics for decades. Charters (1942) questioned this workload among more traditional liberal arts degree faculty. Still, most academics disagree on what constitutes appropriate or excessive workload on faculty, or what perceived effect these non-teaching workloads have on faculty who are responsible for student engagement and interaction in their classrooms or laboratories (McKenna, 2018).

\section{Results}

Interviews began with demographic questions that resulted in the data shown in Table 1. Following the demographic questions, participants were asked several questions relating to their perception of the effects their non-teaching workload had on their classroom efficacy. A series of four primary questions were asked, with a semistructured interview protocol that allowed the researcher to expand upon participant's 
responses when necessary for clarification or further description. The following responses and analysis is sorted based on the question and the key categories and topics discussed by the participants.

\section{Perception of the Impact (negative or positive) Non-teaching Responsibilities have on Teaching.}

Responses to this question were fit into three distinct categories. One category in particular had a single participant who mentioned that he felt those responsibilities had "none, to little" effect on his classroom activities, let alone his classroom efficacy. This participant, Lenny, continued to say that he did not feel non-teaching responsibilities had ever affected his classroom function because his performance in the classroom was personally regarded as his highest priority in his job function. Alternatively, he suggested that he had likely sacrificed non-teaching responsibilities for those that were related to his teaching. When questioned later about non-teaching workloads contributing positively to his classroom efficacy, he admitted that many of the industry networking opportunities offered by his program's internship course allowed him to incorporate more industry-driven topics into his current classroom.

Other participants held either a positive or negative view on non-teaching workload's contribution to their classroom. Larry mentioned topics such as trading off extra time with students by "shutting yourself off" which reflected literature surrounding the intrinsic motivations of faculty and their desire for student success. Larry expressed a disheartened attitude at feeling the pressure to have to close and lock his office door in the hopes of being able to focus on his work in lieu of devoting time for students. Penelope discussed both negative and positive effects of non-teaching workload and 
made extensive comments on non-teaching workload and its impact on continual improvement. "The downside is it takes away from the ability to think "how can I do this better' I want to be able to take every lesson and at the end, when it's fresh, revise it and make it better. Outside responsibilities whack that time off; continual improvement doesn't happen because as soon as you get out of class you're going off to a committee meeting."

\section{Institutional Importance of Instructional Ability, Student Outcomes, and Classroom}

\section{Efficacy}

Responses to this question were more varied than the first question, suggesting a highly variable perception of the expected importance on instructional ability and classroom efficacy. This is important to the study as through the conceptual framework it becomes clear how faculty may be motivated. Often intrinsic factors drive faculty to improve classroom experiences for the students, while extrinsic factors are often driving non-teaching responsibilities. Frank's response to this question highlighted this; "It has to be intrinsic, you are supposed to [be] following through with [teaching] goals and I've seen a lot that don't follow through". Later, he commented on teaching evaluations, discussing how, as opposed to industry, there is a lot of abuse in it. "One day, you have to be on point, the rest of the time... I hold myself to a pretty high standard [in the classroom], but not everyone does". A misalignment of priorities at the administrative or university level as demonstrated by systems and methods like these may contribute to faculty dissatisfaction with their job. The literature explains how this can lead to burnout in faculty members and potentially result in faculty departure from the position. Alternatively, an alignment of these priorities shows support for faculty workloads 
outside the classroom, without demanding faculty sacrifice personal time, or time with their students or classrooms.

Three categories again emerged from the participant responses. Those categories were administrative words versus actions (suggesting a difference or disconnect between the two), Administrative understanding or misunderstanding of workload, and Evaluating or Rewarding faculty.

From the first focus group conducted, members discussed the perception that comes from higher up (administration). Many of the faculty in the group expressed the idea that often administrators above the College Dean's often want to believe what they do is student based, but at the program level it is not always students first. This was a comment echoed by several other interview participants as well. Joachim remarked that in general, administrators often say that faculty are there to teach, but the administrators are the same people assigning this additional workload to those faculty. Joachim went further, saying "it is advertised and out in front, but there is this hidden background of 'you're going to do this work too' and I think there is a general feeling across campus that it takes away from the classroom". Thomas, who works at another institution, made similar comments, suggesting that administrators localize their support for teaching efforts, but do not necessarily support them in the same way behind the scenes. Lenny, a program coordinator, commented on the push for student outcomes at his institution. He felt that, while there was extra work involved in developing outcomes, the administration was happy with the outcomes, but they do not seem to push faculty to meet those outcomes. The first focus group also commented that their administration may recognize 
the importance of data such as outcomes, but often do not seem to have any idea what it means or how resources should be allocated at the program level.

Larry, taking a more positive note, discussed administrative understanding of faculty programs. "I think its human nature, the president of the university will never understand our degree, so it is always going to be difficult for them to know how to properly do so" he said. Sam referred to the faculty saying they see it as a matter of pride to have good teaching in their classrooms. Still, Joachim felt that non-teaching workload is still important but, "there is that struggle and that internal fight". Contrary to some of these perceptions, Kaleb disclosed a rather exact estimation of 80 percent teaching load with the remaining 20 percent being devoted to service and research. He suggested that for the most part he was satisfied with the balance and that administrators at his university understood his load.

In terms of evaluating and rewarding faculty, Jackie suggested a reward system for faculty who develop or achieve better student learning outcomes. At her university she cited competency-based assessments which in her opinion showed a university interest in teaching. Later in the interview, she remarked that "all of us could be paid better for the services we provide". Debra believed that not only are the rewards or penalties often distributed by administrators at her institution but, "In reality if you are not recruiting and promoting the program the employers aren't happy so you are sort of forced to do that just to make it run".

\section{Sacrifice or Contribution to Student Experience for Non-Teaching Workloads}

This question was posed as two separate questions in the interview process and focused on specific examples the participants had that they felt either detracted or 
contributed to their student's experience in the classroom. Closely tied to these positive or negative experiences are the instructors' classroom efficacy, or feelings of selfconfidence in teaching the lesson. The categories of the responses were contributing to classroom experience, detracting from classroom experience, and general emotions surrounding those experiences. Most of the 21 participants could recall a time where their classroom experiences were impacted negatively by non-teaching workloads. This suggests either a strong negative emotion which was reflected in some of their comments, or a frequent occurrence. When asked how often these negative experiences occur, most of the 21 participants remarked that it was not a frequent occurrence, suggesting that strong emotions were usually perceived by the participant when those experiences did happen rather than with a high frequency. Jackie, who appeared more emotional during this portion of the interview, remarked that lacking the time to design memorable learning experiences is a logical outcome when you have so many other tasks to do. Frank cited a search committee he was on where he had to cut entire class sessions short, saying "that really detracted from my time for preparation for class". Joachim had "no doubt" that he could have made things better but lacked the time to do so specifically because of those responsibilities. Larry even cited his personal conflict, explaining that “if it's not your family, it's your students".

Nearly all the participants who cited a contribution to their classrooms from nonteaching workload explained that often it was either industry related or University related benefits. For example, Debra commented, "When you are working with employers you are making relationships to bring in guest speakers and building those [connections] up to help with curriculum and program currency". Others discussed the advantages of 
networking with professional conferences or the training that they provide to instructors which can be brought back to the classroom. Further, some participants cited the ability to network with faculty even within their own institutions, mentioning that many times things like committee work can be beneficial to "see how others are meeting their goals".

\section{Implications}

Literature suggests one of the variables affecting the existing pool of STEM graduates are faculty (Lewallen et al. 2003). These faculty members remain critical for the continuation and proliferation of STEM programs (Newton, Utschig, \& Llewellyn, 2011). It remains obvious, then, to continue to close the STEM gap, retention of existing faculty in STEM programs is vital. Further, potential new faculty must be drawn to the profession to continue to grow these programs (Jacobs \& Winslow, 2004; Ranđelović \& Stojiljković, 2015). These goals combat the effects of teacher shortages well documented in elementary, secondary, and post-secondary STEM areas and work to attract more candidates to STEM education where few faculty candidates hold the necessary qualifications to teach (Galosy \& Gillespie, 2013).

In answering the research question, faculty view their non-teaching workload in many ways depending on the timing, the task, and whether or not it contributes to their classroom. Based on the responses of the participants, faculty classroom efficacy is impacted negatively when student experiences suffer because of non-teaching workload. This is especially true when the faculty member perceives little or no benefit to the student in either the short or long term. While this is not a frequent occurrence, often the participants commented with negative emotions about having to sacrifice classroom experience for non-teaching workload. This supports a study by Taxer and Frenzel 
(2013) which also found teachers are more likely to express their positive emotions rather than negative ones, leaving administrators in the dark on how their faculty members truly feel about their job and their responsibilities. Many participants also expressed more positive outlooks on university level work, such as committee's than originally anticipated by the researcher as many participants found value in interacting with colleagues across disciplines at each of their institutions. Very few participants remarked on the role of political power at their institutions, and instead focused on structural roles and administrative understanding of specific goals, outcomes, and environments that programs function within.

Several themes were demonstrated by the participant responses that relate to the research question answered in this work. First, despite the negative experiences of these faculty and their feelings of limited classroom efficacy almost all the participants had something positive to say about their profession and their work with their students. It was apparent to the researcher that these faculty were highly motivated by and exceptionally focused on the success of their students above all else. This suggests a highly intrinsically motivated faculty when students are involved.

A second major theme from the data collected was the conclusion that administrators on many levels in the participant's institutions often lack the industry experience or program level experience to understand faculty members' total workload. Many of the participants in the study remarked on their own feelings that administrators did not understand their workload, or how long it took to accomplish certain tasks and how much time it took away from faculty/student interaction. This theme was often referenced when participants knew that they had these tasks to do, but often did not feel 
they were able to devote adequate time to preparing for class lessons, setting up laboratories, maintaining equipment, or other tasks related to high-technology training. This meant that faculty had to decide what else could be sacrificed for the purpose of accomplishing those tasks.

\section{Recommendations for Practice}

Based on responses from participants it is the recommendation of the researcher that university administrators take a more active role in understanding the more specialized load that faculty in high technology areas face. Often, unilateral decisions cited by participants in the study resulted in program resource reduction, or additional workload for faculty that disproportionately applied additional perceived pressure to faculty within those programs. Many participants understand the conflict administrators have and the political and structural challenges administrators face, but do not feel their own workload is being justifiably understood, or accounted for, either via extrinsic rewards such as salary or benefits, or intrinsic rewards such as appreciation from their superiors. In order to maintain the current and upcoming pool of faculty, who are willing and qualified to teach, these small changes and the faculty who may benefit from them, should be considered.

In addition, programs can bolster themselves against additional workload demands by taking a team-focused and student centered approach to everything they accomplish. As evidenced by the data collected in the study, student focus is a primary contributor to intrinsic value in the career to faculty and could ensure the retention of those faculty into the future. This gives a value-added proposition to the practice and 
allows faculty to find more meaning and connection with their work even if it does not directly correlate to student outcomes.

\section{Conclusions}

In conclusion, in order to further support faculty in high technology and indemand applied baccalaureate programs their experiences with non-teaching workload should be accounted for. Non-teaching workload for faculty is especially burdensome and often does not carry as much intrinsic benefit to the faculty member as evidenced by the responses from participants. It is the hope that this work and experiences recorded within it will contribute to the discussion of workloads for faculty teaching in hightechnology and in-demand areas. 


\section{References}

Bilimoria, D., Perry, S. R., Liang, X., Stoller, E. P., Higgins, P., \& Taylor, C. (2006). How do female and male faculty members construct job satisfaction? The roles of perceived institutional leadership and mentoring and their mediating processes. The Journal of Technology Transfer, 31(3), 355-365. doi:10.1007/s10961-0067207-z.

Bolman,L. G., \& Deal, T. E. (2013). Reframing organizations (5 $5^{\text {th }}$ ed.). San Francisco, CA: Jossey-Bass Publishing.

Box-Steffensmeier, J. M., Cunha, R. C., Varbanov, R. A., Hoh, Y. S., Knisley, M. L., \& Holmes, M. A. (2015). Survival analysis of faculty retention and promotion in the social sciences by gender. PLoS ONE, 10(11), 1-22. doi:10.1371/journal.pone.0143093.

Bragg, D. D., Townsend, B. K., \& Ruud, C. M. (2009). The adult learner and the applied baccalaureate: Emerging lessons for state and local implementation. In Brief. Office of Community College Research and Leadership.

Charters, W. W. (1942). How much do professors work?. The Journal of Higher Education, (6), 298. doi:10.2307/1975366.

Creswell, J.W. (2014). Research design: Qualitative, quantitative, and mixed methods approaches (4th ed.). London, England: Sage.

DeWitt, S. (2015). Ensuring CTE is part of the stem solution. Techniques: Connecting Education \& Careers, 90(3), p.12.

Frisby, B. N., Goodboy, A. K., \& Buckner, M. M. (2015). Students' instructional dissent and relationships with faculty members' burnout, commitment, satisfaction, and 
efficacy. Communication Education, 64(1), 65-82. doi:

10.1080/03634523.2014.978794.

Galosy, J. A., \& Gillespie, N. M. (2013). Community, inquiry, leadership: Exploring early career opportunities that support STEM teacher growth and sustainability. Clearing House, 86(6), 207. doi:10.1080/00098655.2013.826485.

Hagedorn, L. S., \& Purnamasari, A. V. (2012). A realistic look at STEM and the role of community colleges. Community College Review, 40(2), 145-164. doi: $10.1177 / 0091552112443701$.

Jacobs, J. A., \& Winslow, S. E. (2004). Overworked faculty: Job stresses and family demands. Annals of the American Academy of Political and Social Science, 596, 104-129. doi: 10.1177/0002716204268185.

Lewallen, L. P., Crane, P. B., Susan, L., Jones, E., \& Jie, H. (2003). An innovative strategy to enhance new faculty success. Nursing Education Perspectives (National League For Nursing), 24(5), 257. Retrieved from:

http://www.nln.org/newsroom/newsletters-and-journal/nursing-educationperspectives-journal.

Matheny, K. B., Gfroerer, C. A., \& Harris, K. (2000). Work stress, burnout, and coping at the turn of the century: An Adlerian perspective. Journal of Individual Psychology, 56(1), 74-87. Retrieved from:

https://utpress.utexas.edu/journals/journal-of-individual-psychology.

McKenna, L. (2018). How hard do professors actually work? The Atlantic. Retrieved from: https://www.theatlantic.com/education/archive/2018/02/how-hard-doprofessors-actually-work/552698/?utm_source=atlfb. 
Newton, S. H., Utschig, T. T., \& Llewellyn, D. C. (2011). A demographic analysis of engineering majors with an interest in teaching. In ASEE Annual Conference and Exposition, Conference Proceedings. Retrieved from https://www.scopus.com/inward/record.uri?eid=2-s2.080051875359\&partnerID=40\&md5=d20504186632f117d27bdd9da8cab5a6.

Ranđelović, K., \& Stojiljković, S. (2015). Work climate, basic psychological needs and burnout syndrome of primary school teachers and university professors. TEME: Casopis za Društvene Nauke, 39(3), 823. Retrieved from: http://www.ni.ac.rs/Teme/.

Robert, J., \& Carlsen, W. S. (2017). Teaching and research at a large university: Case studies of science professors. Journal of Research in Science Teaching, 54(7), 937-960. doi:10.1002/tea.21392.

Taxer, J. J., \& Frenzel, A. F. (2015). Facets of teachers' emotional lives: A quantitative investigation of teachers' genuine, faked, and hidden emotions. Teaching \& Teacher Education, 49, 78-88. doi: 10.1016/j.tate.2015.03.003.

Townsend, B. K., Bragg, D. D., \& Ruud, C. M. (2008). The adult learner and the applied baccalaureate: National and state-by-state inventory. Office of Community College Research and Leadership. Retrieved from: http://occrl.illinois.edu/

Xue, Y., \& Larson, R. (2015). STEM crisis or STEM surplus? Yes and yes. Monthly Labor Review. doi: 10.21916/mlr.2015.14.

Zee, M., \& Koomen, H. M. Y. (2016). Teacher self-efficacy and its effects on classroom processes, student academic adjustment, and teacher well-being: A synthesis of 40 
years of research. Review of Educational Research, 86(4), 981. doi:

$10.3102 / 0034654315626801$. 
Section Six - Scholarly Practitioner Reflection 


\section{Scholarly Practitioner Reflection}

This scholarly reflection aims to characterize my experiences as a practitioner and as a scholar throughout the Dissertation in Practice. Throughout my experience as an educator during this time I have worked tirelessly to understand the traits and expectations of the position my colleagues and I are in. Being in a high-technology area, I looked forward to contributing to the field that I have had the privilege of teaching in. In addition, the desire to give back to the knowledge and summarize the experiences of my fellow colleagues drove me to contribute to this particular area of research.

This reflection will focus on two distinct areas. First, my experiences as a practitioner and how this research has affected my day-to-day duties, responsibilities and motivations. Second, my experiences as a scholar and how this contributes to my understanding of our little section of an educational institution, in the current educational landscape of this nation and this world. All of this was done with the goal in mind to better serve the students that come to us as educators for help, encouragement, positive reinforcement, and knowledge.

\section{Dissertation Influence as a Practitioner}

As a teaching practitioner, there are many feelings that are processed through the lens of this work. I felt validated to learn in a more official capacity that I was not entirely alone in the challenges I continue to face as a young Assistant Professor. Many of the participants that I spoke with remarked on the difficulty that they faced in transitioning from industry positions or other non-educational positions. These experiences were not all unlike my own experiences. It felt good that, at this stage in my career, I can feel like I am keeping my head above water, I could give back to others 
either coming into the field or considering leaving the field for many of the reasons discussed in this work. This project influenced my outlook on my career and granted perspective on what this career choice was about. In a more concrete way, as opposed to a conversation in a hotel bar during a technical training conference (where I often heard and participated in conversations that discussed these issues), I felt I could more adequately and eloquently summarize the experiences of my fellow educators and, in doing so, hope to affect the academic lives of thousands of students and educators over their lifetime.

I am not entirely sure what to expect from this career, or even what to expect from this research. What I do know, is there is several actionable objectives I would like to focus on based on the outcomes of this research. Should I ever find myself in the capacity to lead in the educational setting; these actionable items will serve as my guiding vows to my faculty and, by extension, my students.

\section{Involvement in the Classroom}

As a faculty member, one of the remarkably dissatisfying elements of the position is when administrators seem to have little knowledge or connection with the lives of their faculty or students in their programs. In the educational field, I believe my own experiences have taught me just how top-heavy higher education institutions can be. Further, this research has contributed to this understanding and helped me realize just how widespread this problem is. I have made a commitment to myself and to any students or faculty I serve, to continue to serve as much as possible within the classroom. As a policy, I believe this should be looked at throughout many areas for the benefit of all 
institutions. Through the lens of this study, I believe it would be especially beneficial for high technology and applied baccalaureate programs.

\section{Faculty Communication}

Often, throughout the course of this study, communication was brought up by participants who felt unheard or disconnected from their administrators. Taxer and Frenzel (2013) observed this in their study as well and I believe it contributes to the necessity of constant communication and show of support from administration directly to the faculty. Politically, the landscape of the university can be complicated. There should be little reason that I cannot help my own faculty directly rather than relying on the politics of the programs, departments, and colleges to relay the message for me.

Fostering a sense of transparency, and allowing all faculty members, regardless of rank or position, a stake in the argument at hand is a simple way of garnering faith and resilience in programs while simultaneously subduing negative emotions, resentment and apathy. Implementing this communication is something that will come with time. Based on the results of this research I would be careful to not further burden already over-burdened faculty for the sake of having a conversation with them. Most teaching professionals would agree that more meetings are never a positive force for good. However, a more positive and proactive approach on my part as a leader certainly could help transform the expectation of leadership to understand the challenges faculty and students face on a day to day basis.

\section{Administrative Understanding}

As mentioned in the previous section, administrative understanding of workloads is crucially important if we expect any sort of accountability or reasoning when 
overseeing any organization. Education is no exception to this. Often, participants in this study commented on the wide variance of understanding that administrators seemed to have when it came to their workload and their programs. No educator should have to enter the office of their department chair, dean, or provost and be asked to explain what their program is about. Yet, this study has shown me that this experience is more common than originally thought at the start of the research.

Transparency and effective leadership practices, as suggested in the literature review by Northouse (2014), encourage and place high importance on involvement of leadership from the onset of and throughout the life of an organization. It is together with the shared experiences researched in this study that as a leader I would work toward these goals.

\section{Dissertation Influence as a Scholar}

As a scholar, this dissertation has influenced me in many ways. I find so much of my life perspective has changed in the name of researching topics I am interested in or would like an answer to in more scholarly ways. Real research to me has become so much more of my worldview.

I can see where my perspectives on qualitative research have changed as well. Near the beginning of this educational process leading up to the dissertation I had discounted much of qualitative research as less intensive or less objective than quantitative research. What I have learned is how to tell a story through research. I still believe that both are stronger than only one. I also still see myself contributing more quantitatively to my field than qualitatively given the fields that I teach in. That does not 
discount the value of the story that can be told from qualitative research. It humanizes research in a way that quantitative numbers and calculations cannot.

\section{Summary}

In summary, I am grateful for having this scholarly experience as a part of my life. It was a long, hard battle, but I do feel changed because of it. This change will have a long term effect on my worldview and my perspective on educational leadership. I hope in many ways I can continue my career as an educational leader, not just for the benefit of me and my family, but so I can continue to benefit more of my students through my work. 


\section{References}

America Competes Act of 2007, Pub. L. No. 110-69 (2007).

ATMAE. (2018). JTMAE. Retrieved from: Http://www.atmae.org/?page=JTMAE.

Bahr, P. R., Jackson, G., McNaughtan, J., Oster, M., \& Gross, J. (2017). Unrealized potential: Community college pathways to STEM baccalaureate degrees. Journal of Higher Education, 88(3), 430-478. doi:10.1080/00221546.2016.1257313

Bandura, A. (1977). Self-efficacy: Toward a unifying theory of behavioral change. Psychological Review, 84, 191-215.

Barkhuizen, N., Rothmann, S., \& van de Vijver, F. J. R. (2013). Burnout and work engagement of academics in higher education institutions: Effects of dispositional optimism. Stress and Health, 30(4), 322-332. doi:10.1002/smi.2520.

Bilimoria, D., Perry, S. R., Liang, X., Stoller, E. P., Higgins, P., \& Taylor, C. (2006). How do female and male faculty members construct job satisfaction? The roles of perceived institutional leadership and mentoring and their mediating processes. The Journal of Technology Transfer, 31(3), 355-365. doi:10.1007/s10961-0067207-z.

Bolman,L. G., \& Deal, T. E. (2013). Reframing organizations (5 $5^{\text {th }}$ ed.). San Francisco, CA: Jossey-Bass Publishing.

Box-Steffensmeier, J. M., Cunha, R. C., Varbanov, R. A., Hoh, Y. S., Knisley, M. L., \& Holmes, M. A. (2015). Survival analysis of faculty retention and promotion in the social sciences by gender. PLOS ONE, 10(11), 1-22.

doi:10.1371/journal.pone.0143093.

Bragg, D. D., Townsend, B. K., \& Ruud, C. M. (2009). The adult learner and the applied 
baccalaureate: Emerging lessons for state and local implementation. In Brief. Office of Community College Research and Leadership.

Cabrera, A. F., Burkum, K. R., LaNasa, S.M., \& Bibo, E.W. (2005). Pathways to a fouryear degree. In Seidman, A. (2012), College student retention: Formula for Student Success. (pp. 167-210). Lanham, MD: Rowman \& Littlefield.

Carrigan, S. D. (2008). Formula funding, the Delaware Study, and the University of North Carolina. New Directions for Institutional Research, 2008(140), 65-78. doi:10.1002/ir.270.

Charters, W. W. (1942). How much do professors work?. The Journal of Higher Education, (6), 298. doi:10.2307/1975366.

Committee on Prospering in the Global Economy of the 21st Century, 2007

Creswell, J.W. (2014). Research design: Qualitative, quantitative, and mixed methods approaches (4th ed.). London, England: Sage.

Delaney, J. A., \& Kearney, T. D. (2016). Alternative student-based revenue streams for higher education institutions: A difference-in-difference analysis using guaranteed tuition policies. Journal of Higher Education, 87(5), 731-769. doi: jhe.2016.0028

DeWitt, S. (2015). Ensuring CTE is part of the stem solution. Techniques: Connecting Education \& Careers, 90(3), p.12.

Floyd, D. L., Garcia Falconetti, A. M., \& Felsher, R. A. (2012). Applied and workforce baccalaureate models. New Directions For Community Colleges, 2012(158), 5-11. doi: $10.1002 /$ cc.20012

Frisby, B. N., Goodboy, A. K., \& Buckner, M. M. (2015). Students' instructional dissent and relationships with faculty members' burnout, commitment, satisfaction, and 
efficacy. Communication Education, 64(1), 65-82. doi:

10.1080/03634523.2014.978794.

Galosy, J. A., \& Gillespie, N. M. (2013). Community, inquiry, leadership: Exploring early career opportunities that support STEM teacher growth and sustainability. Clearing House, 86(6), 207. doi:10.1080/00098655.2013.826485.

Hagedorn, L. S., \& Purnamasari, A. V. (2012). A realistic look at STEM and the role of community colleges. Community College Review, 40(2), 145-164. doi: $10.1177 / 0091552112443701$.

Harvey, L., \& Green, D. (1993). Defining Quality. Assessment \& Evaluation in Higher Education, 18(1), 9-34. doi:10.1080/0260293930180102

Jacobs, J. A., \& Winslow, S. E. (2004). Overworked faculty: Job stresses and family demands. Annals of the American Academy of Political and Social Science, 596, 104-129. doi: 10.1177/0002716204268185.

Koppelman, G. H., \& Holloway, J. W. (2012). Successful grant writing. Paediatric Respiratory Reviews, 13(1), 63. doi: 10.1016/j.prrv.2011.02.001.

Lewallen, L. P., Crane, P. B., Susan, L., Jones, E., \& Jie, H. (2003). An innovative strategy to enhance new faculty success. Nursing Education Perspectives (National League For Nursing), 24(5), 257. Retrieved from: http://www.nln.org/newsroom/newsletters-and-journal/nursing-educationperspectives-journal.

Lowell, L., \& Salzman, H. (2009). Will science and engineering now be a good career? Education Week, 29(11), 32, 26. Retrieved from: http://www.edweek.org/ew/index.html. 
Maslow, A. H. (1954). Motivation and personality. New York : Harper, [1954]. Retrieved from: http://search.ebscohost.com/login.aspx?direct=true \&db=cat04885a\&AN $=$ merlin.b1473809\&site $=$ eds-live $\&$ scope $=$ site

Matheny, K. B., Gfroerer, C. A., \& Harris, K. (2000). Work stress, burnout, and coping at the turn of the century: An Adlerian perspective. Journal of Individual Psychology, 56(1), 74-87. Retrieved from: https://utpress.utexas.edu/journals/journal-of-individual-psychology. McKenna, L. (2018). How hard do professors actually work? The Atlantic. Retrieved from: https://www.theatlantic.com/education/archive/2018/02/how-hard-doprofessors-actually-work/552698/?utm_source=atlfb.

Mercadal, T. (2014). Organizational culture. Salem Press Encyclopedia.

Merriam, S. B., \& Bierema, L. L. (2013). Adult learning: Linking theory and practice. Hoboken, NJ: John Wiley \& Sons.

Middaugh, M. F., Graham, R., Shahid, A., \& National Center for Education Statistics (ED), W., DC. (2003). A Study of Higher Education Instructional Expenditures: The Delaware Study of Instructional Costs and Productivity. Research and Development Report.

National Commission on Mathematics and Science Teaching for the 21st Century (2000)

Nelson, G. R. (2008). Differential tuition by undergraduate major: Its use, amount, and impact at public research universities (Doctoral dissertation). Retrieved from: ETD collection for University of Nebraska — Lincoln. Paper AAI3297754.

Newton, S. H., Utschig, T. T., \& Llewellyn, D. C. (2011). A demographic analysis of engineering majors with an interest in teaching. In ASEE Annual Conference and 
Exposition, Conference Proceedings. Retrieved from

https://www.scopus.com/inward/record.uri?eid=2-s2.0-

80051875359\&partnerID $=40 \& m d 5=d 20504186632 \mathrm{f} 117 \mathrm{~d} 27 \mathrm{bdd} 9 \mathrm{da} 8 \mathrm{cab} 5 \mathrm{a} 6$.

Noltemeyer, A., Bush, K., Patton, J., \& Bergen, D. (2012). The relationship among deficiency needs and growth needs: An empirical investigation of Maslow's theory. Children and Youth Services Review, 34, 1862-1867. doi:

10.1016/j.childyouth.2012.05.021.

Northouse, P. G. (2007). Leadership: Theory and practice. Thousand Oaks: SAGE Publications.

Ranđelović, K., \& Stojiljković, S. (2015). Work climate, basic psychological needs and burnout syndrome of primary school teachers and university professors. TEME: Casopis za Društvene Nauke, 39(3), 823. Retrieved from: http://www.ni.ac.rs/Teme/.

Robert, J., \& Carlsen, W. S. (2017). Teaching and research at a large university: Case studies of science professors. Journal of Research in Science Teaching, 54(7), 937-960. doi:10.1002/tea.21392.

Salzman, H., \& Lowell, B. L. L. (2007). Into the eye of the storm: Assessing the evidence on science and engineering education, quality, and workforce demand. SSRN Electronic Journal. doi:10.2139/ssrn.1034801.

Sanborn, M. (2006). You don't need a title to be a leader. New York, NY: DoubleDay. Taxer, J. J., \& Frenzel, A. F. (2015). Facets of teachers' emotional lives: A quantitative investigation of teachers' genuine, faked, and hidden emotions. Teaching \& Teacher Education, 49, 78-88. doi: 10.1016/j.tate.2015.03.003. 
Tenure. (2017). Funk \& Wagnalls New World Encyclopedia, 1p. 1.

Townsend, B. K., Bragg, D. D., \& Ruud, C. M. (2008). The adult learner and the applied baccalaureate: National and state-by-state inventory. Office of Community College Research and Leadership. Retrieved from: http://occrl.illinois.edu/

University of Delaware. "1996 National Study of Instructional Cost and Productivity.” Newark: University of Delaware, 1996.

U.S. Department of Labor, Bureau of Labor Statistics. (2015, May). STEM crisis or STEM surplus? Yes and yes. Retrieved from: https://www.bls.gov/opub/mlr/2015/ article/stem-crisis-or-stem-surplus-yes-and-yes.htm.

Van Zanten, M., Boulet, J. R., \& Greaves, I. (2012). The importance of medical education accreditation standards. Medical Teacher, 34(2), 136-145. doi: 10.3109/0142159X.2012.643261.

Waltman, J., Bergom, I., Hollenshead, C., Miller, J., \& August, L. (2012). Factors contributing to job satisfaction and dissatisfaction among non-tenure-track faculty. The Journal of Higher Education, 83(3), 411-434. doi:

10.1080/00221546.2012.11777250.

Wang, X. (2013). Why students choose STEM majors: Motivation, high school learning, and postsecondary context of support. American Educational Research Journal, 50(5), 1081. doi: 10.3102/0002831213488622.

Xue, Y., \& Larson, R. (2015). STEM crisis or STEM surplus? Yes and yes. Monthly Labor Review. doi: 10.21916/mlr.2015.14.

Zee, M., \& Koomen, H. M. Y. (2016). Teacher self-efficacy and its effects on classroom processes, student academic adjustment, and teacher well-being: A synthesis of 40 
years of research. Review of Educational Research, 86(4), 981. doi:

$10.3102 / 0034654315626801$. 
Appendices 


\section{Appendix A - Results}

\section{Results}

For the purposes of the Dissertation in Practice, one research question of the three pursued by the researcher (research question two) was answered in Section Five:

Scholarly Contribution. To more adequately assess the remaining data, all of the data as well as answers to all three of the research questions are contained herein.

The data are organized in sections for the remaining two research questions. After the answers to questions asked pertaining to those research questions are presented and analyzed within the context of the interviews and focus groups, the themes from the project as a whole will be discussed. A final summary and answer for each of the research questions is then given.

\section{Research Question One}

Research Question One asked: - How do faculty members perceive the balance of non-teaching vs. teaching workload in their program? The goal of this research question was to more thoroughly understand the outlook of faculty and, more importantly, understand the working environment faculty experiences occur in. As Ranđelović and Stojiljković (2015) suggested, faculty burnout and lack of job satisfaction are issues that can arise simply from the environment an employee exists in rather than exclusively from how an employee is treated.

The questions posed for research question one were as follows:

- What is your working environment like within your program?

- What is your perception of the balance of teaching and non-teaching workloads within your program? 
- A last minute or important deadline project is introduced and your program needs to put together a comprehensive report on Student learning outcomes. Who might be delegated in your program to achieve this short term but important goal?

Several sub-questions were asked of the participants depending on their responses to these main questions. The following sections are categorized based on these questions.

\section{What is your Working Environment like Within your Program?}

As discussed by Ranđelović and Stojiljković (2015), faculty working climate can play a drastic role in faculty's feelings of job satisfaction and overall self-efficacy. It is for these reasons the researcher asked this question near the beginning of the interview process. The goal was to investigate the participants' outlook on the environment in which they work to characterize the participants' experience within the program.

Participant responses were grouped into six different categories for this question. The categories were: Positive environment, teamwork, and administrative support; Teaching load; Education or students being first priority; Balance of workload; NonTeaching workload; and External university forces, attitudes or politics.

Positive environment, teamwork, and administrative support. Most of the participants had positive things to say about their programs and departments. Brad, an automotive faculty member, had many positive things to say about his colleagues and his programs' financial support.

I have a wonderful bunch of gentleman I teach with, I have the unique position because three of the five of us I taught so that is unique. I work with some great guys, I feel like we are a complete team and whatever we discuss we can come up with a solution very quickly. 
Brad continued to discuss his program's administrative support, citing funding levels for his program. "We feel our budget is adequate, and we feel very fortunate." Joachim, an automotive department chair had a similar team experience, expressing that in his comments about his faculty colleagues.

Everyone I work with is heading the same direction, we aren't scattered. We are very clear and defined in what we do. The chair before me and the one before him cared about our classroom and were very hard workers.

Many of the comments made by participants were similar to Oliver, an Engineering Tech coordinator, and many others. As many as six of the participants in the study said their working environment was "good" or "great" and specifically cited people within their department or program as being the primary reason for this assessment. Frank, one particular faculty member from an Engineering Technology (ENGT) program, cited the camaraderie within his program as one of the key factors in the working environment. Yes, very much so, compared to coming from the High School environment where I was, there was no support there... you're thrown to the wolves and you get to fend for yourself. There is a pretty good camaraderie, in ENGT. Moving outside the program, responses on the university or college environment were more varied. Penelope, a faculty member who helped develop and now teaches in an Engineering Tech program was one of the most vocal participants about the lack of support she felt she received as a program coordinator and new faculty. Penelope remarked, "I have been given the freedom to develop the program" but lamented the fact that "Freedom to do what we want [is positive], but the other side is there is no guidance 
and starting from scratch is challenging." When asked for a specific example of this, she discussed some online course curriculum that had been developed.

We needed to get into the online world and they said "hey there's this webinar you can watch" Okay so there's the freedom which I like, we can create this thing the way we want and we can make it the most effective we can, we can really listen to employers, we haven't been constrained, but on the other side of that, the flip side of not being constrained is there's nothing [supportive], so does that make sense?

Penelope remarked that at this stage of her career some sort of mentorship would have aided her in her journey in transitioning from industry. She specifically wanted a mentor who was familiar with the field her program taught in (ENGT) and could help her make decisions about that program. In her case, at that stage of her career she was in the process of building up a new program which could indicate that the lack of team efforts on the part of the program and departments that offer these programs could be detrimental to the faculty within them.

Teaching, workload, and balance of workload. Some of the participants who cited a good environment in their program also had things to say about the workload that they were being put under. One of these participants, Jackie, an instructor and coordinator of a Design and Drafting program, discussed her responsibilities at length. So we actually have a good working environment but the load is very heavy. So many former faculty members [were] retiring, assigning more work to the existing faculty. I personally have the responsibility of teaching, program coordinator, student advising, I have to take care of our industry partners and our accreditation, take care of our website and mostly I do [it] myself. With the content sometimes I 
get help from my colleagues but I'm the main person that takes care of it. I have to take care of the transfer guides, do some research, grant writing, help with student organizations and maintain cutting edge labs for our students and many more responsibilities, so this is my job.

Jackie seemed to summarize many of the responsibilities cited by other participants. Most of the participants seemed to have similar teaching loads. The first focus group was held with a construction technology group at a state university. The chair of that program, Chuck, remarked that they are "pretty classical, our expectation is that everyone teaches 11-12 credit hours." "Other areas [on campus] are 6-8" he continued. When asked about the balance of the work, he discussed the mentality of the program and his faculty within it. "We have a teaching mentality, whatever needs to be taught we will teach." Debra, a professor in a construction program at another college, mentioned similar loads citing "3-4 classes" as her full-time load. Neil, another automotive faculty, had one of the more unique loads that illustrates the different scheduling needs many of these programs require.

I work four ten hour days, one year of mornings or one year of nights. Our classes are 5 hours a day including lecture and lab, and students have open lab they can work on their own vehicle.

Almost universally, participants seemed to carry the idea of students being first in their motivations for work with them when discussing loads. Brad commented "Our hearts are in it for the students and I've seen it differently elsewhere [on campus].” Keenan, an automotive faculty at a large state institution, mentioned that if he "could come in and teach my class and go home, I'd love it." Not surprisingly, regardless of the focus of the 
host institution being teaching or research, all but one of the 30 participants in the study interviews and focus groups cited a teaching load that occupied at least $50 \%$ or more of their time. Some participants, like Charlie, an Industrial Technology and Construction faculty, and Maynard, an Automotive faculty member at a small regional college, said their teaching load was as high as $70 \%$ with the remaining $30 \%$ occupied by other responsibilities. Joachim, the only participant that estimated less than half of his load was teaching, had his teaching load cut significantly when he began to fill a Chairperson's role for his department.

Before I took the chair position it was probably $80 \%$ classroom and $20 \%$ committee and service work. Now it's $80 \%$ administration and process and keeping the machine moving and only $20 \%$ teaching. I only teach one class now. Lenny, a construction management professor and coordinator, discussed his perceived role as a teacher and how his job responsibilities were split by the university, versus. how much actual time he felt he was spending on them. "They say $60 \%$ teaching, $20 \%$ research, $20 \%$ service. Teaching comes closer to $75 \%$, the last $25 \%$ has to make up for the rest of that university expected 40\%." "A lot of additional workloads that participants noted sometimes fall outside the normal business hours or contract dates for faculty members" he remarked. Sam, another Engineering Tech faculty member, shared his experience. "I do a lot of my prep work for classes during the summer. I'm [a] nine month employee but if I don't do that prep work ahead of time I won't get that $60 / 40$ mix." Chuck, while laughing, said in the focus group that his load added up to more than $100 \%$. He went on to mention that in his program, it is likely $60 \%$ teaching, $20 \%$ 
research, and 20\% service. Almost contrary to this official number that he cited, he continued to describe his non-teaching workload.

Our service load is huge, but it is self-serving. Kids, to adults, to seniors, teachers, professional society, churches etc. The reality is our service is well over $50 \%$ but we understand that is our job. Service is professional, community, and university service. And we are all willing to volunteer and want to tackle it like a project. [There is] no logical reason to do a lot of our service opportunities academically, and yet our success speaks volumes. As a department chair, I have argued that the service should be valued regardless of outlooks of other academic members on campus opinions.

This was perhaps one of the most positive and surprising moments of the entire data collection period. The comments Chuck made in the focus group were so positive despite the fact he was talking about working well above the 40 hour work week. Many of his faculty echoed this positivism and the team environment in the room was palpable. One of his faculty, Glen, spoke up during this period of the focus group and added, "Education is first, but a lot of things tie into student success."

When non-teaching workload was discussed in other interviews, the outlook from other participants was less positive. Larry, an automotive program coordinator remarked that "The non teaching responsibilities are too heavy to allow us to do a good job with teaching." Thomas echoed this opinion saying,

Committees and other stuff gets in the way and anytime you are working on something it is like you get to a point and you have to stop and think "this is all I can do for now because I have to go to a meeting." 
Larry continued with his comments, elaborating further, "We get asked to do a lot of extra things, we don't have budget to hire someone, so those responsibilities go back on the rest of us and it makes it so you scramble for class prep." Neil felt that he spent as much as two hours a day on things not related to teaching and "that feels like way too much." Neil added that "we are hired as an instructor; we should be focused on that." Keenan also commented on these workloads, adding that he felt "we always have to justify our jobs." Keenan felt that in his tenure within an automotive department "those loads have grown exponentially" and that now "you could spend two days a week on keeping up with everything they want done."

External university forces, attitudes, and politics. Many participants remarked on how these responsibilities and workloads came to be, or how they were being placed or demanded upon programs. In almost all of these cases the political environment of the university seemed to become apparent in its role to affect these varied workloads. Some, like Keenan, had a negative perspective on the political influence, saying "It seems like the university never understands what we do." Still, at Keenan's institution, a high administrative turnover seems to contribute to that feeling. "Every time you change higher level admin then something new comes down the line." James, an automotive faculty member, echoed this impact citing his own experience of being pushed into a leadership role. “Two faculty members took buyouts, third one went to the dean's office and a call came to me to take over the program." He mentioned that there was "A lot of politics at the time" and "Many of the political engagement wanted to see program dissolved rather than enhance it." Maynard, in his program, felt that there were meetings and political controls of power going on at his institution. "I get the feeling that there is 
secret meetings or there are certain people that get picked before I even know about it." This perception reflects some of the political environment that many of the participants observed during their careers. The literature addresses these political influences, describing how political influences and power can be attributed to exclusion of power, information or resources. "I don't like the alienation." Maynard said. "There are certain people that are after just the money."

Additionally, much like James' example, faculty turnover resulted in influences beyond the program's control as well. Jackie mentioned this when she cited "former faculty retiring" as a reason for her institution assigning more workload to the remaining faculty members. "It seems like the university never understands what we do." Keenan said in his interview. Neil elaborated stating that in his experiences it "feels worse than it actually is. It is the inability of the rest of the departments to do their jobs." Kaleb, a CTE instructor who teaches high technology courses, had a different perspective, stating that he felt "we are going too many different directions for the size of department we are." In the focus group, there was a singular understanding from the program faculty members that the political attitude across campus would not affect the program or its decisions. Chuck summarized this saying,

We all come out of industry, we see opportunity, we figure out how to get it done, the rest of campus likes to find a way to blame someone else. Across the university there is an attitude of "oh lets do a leadership course because we need more leadership qualities." We are different; we think it should be integrated into all [our] courses. 


\section{What is your Perception of the Balance of Teaching and Non-teaching Workloads within your Program?}

This question dealt specifically with the balance of these workloads and asked participants to characterize how they felt their programs and institutions balanced teaching and other non-teaching workloads. Many of these responses were echoed in the first questions as discussed in the previous section. Four categories of answers were defined in the data. These were: Changing workload demands; Variances in workload based on faculty position; Percentage split between workloads; and Benefits to students or the program.

The largest category of response during this period of questioning was devoted to discussing the percentage of time spent on teaching vs. non-teaching workloads. Since this category and the responses within it are similar to the responses of the previous question, those responses have been incorporated into the previous section.

Changing workload demands. One of the common themes identified early on in this study was the theme of changing requirements or demands depending on events surrounding programs and the faculty within them. Two of the second focus group participants, Greg and Steven, both automotive instructors, identified "lots of variability" in their workloads depending on what types of events were going on relating to their program or their university. Sam, an interview participant from an ENGT program, exemplified this in his comments.

Typical week I'll spend $60 \%$ teaching or prepping classes, [but] it depends week to week. $20 \%$ is with students and either homework or career advising, the remaining $20 \%$ is meeting industry or potential students. 
Other participants like Lenny, discussed the influence of new class preps. "New preps make things more difficult and would make managing that workload more difficult" he remarked. Lenny went on to say that in terms of managing more "typical" workloads, "I don't have a hard time doing it, we continually teach the same classes." Penelope's experience was similar in that her career progressed through a time of enormous change for her program as she became acculturated to the university life. She stated, It has changed tremendously. When I was in CADD there was a lot of vision but no details. So the first 10 or 15 years was developing curriculum. Now in the last few years I can work on individual courses [as I need to]. Now [with] 15 hours of load means my workload shifts more.

Thomas, who teaches at the same institution as Penelope, also reflected on that institution's decision to change the full-time instructional faculty load to a minimum of 15 semester hours.

You see things especially with administration that don't directly affect those tenure track faculty too... You see the decision to go from 12 hours of load for contract instructors going to 15 and they're saying they won't do any committee work. That workload then falls on tenure track individuals.

Variances in workload based on faculty position. While workloads themselves often changed for faculty depending on department or university needs at the time (such as accreditation renewals) several participants of the first focus group cited that workloads are "not the same on every faculty". Thomas, an Industrial Management professor, said, 
When you come in the door and you are an assistant professor you're still expected to serve, do grants, write papers, work on your doctorate... I don't see how assistant or even associate professors find the time, especially with young families.

Maynard felt that no matter what the load outside the classroom "you want to give it time" emphasizing his desire to do quality work no matter what. "We have an overload system" citing examples of instructors who will teach more than their minimum required hours as full-time faculty for the extra money. "It depends; [on what is needed] there is always something to do around the college." All three of the participants in the second focus group remarked and agreed that often, their loads change from week to week, semester to semester. Debra, a participant from an Industrial Technology program, felt that the focus of her institution was tied more closely to her varied workloads than any other factor. "I think if I were at an R1 I think it would be more swung toward research. Here they want you to focus on teaching."

Benefits to students or the program. In similar fashion to the responses given for the previous questions, many participants cited the benefits to the students or their programs as a primary motivational factor in their workloads. It was no different for this category of responses. Again, returning to the focus group participants, Chuck remarked that "We realize if we didn't do it, we wouldn't excel the way we do." Commenting on other programs at the higher education level he continued,

For twenty years we have held our hand out and asked the state [redacted] to fund our program, and where has that gotten us? So we might as well take our destiny 
into our own hands. Other programs still hold their hands out every year and bitch and moan about it [when they don't get what they want]

"We do what we do, [and] we do it for the students" Shane, another focus group participant from Chuck's Construction program exclaimed. "We all came from industry but doing all that service means we stay grounded in the real world." Citing the ability to network with industry during their service work being a huge difference-maker in their program. Moving toward university service the focus group again felt positive about the impact it made on their students and their program. "It takes a long time to get the liberal arts folks to understand you aren't just the dumb vocational people" said Billy. Still, students and university or institutional obligations also were at the forefront of these comments. Joachim, an automotive professor, said "As a teacher I saw the value of being involved in those on-campus activities even though they are a pain. It does add value to make sure the program has connections that pay dividends later." A similar comment was made in the first focus group that echoed that attitude. "If you are ignorant to the university functions, they will be ignorant to you." Joachim continued,

Don't sit over here and say they don't get us. That is a horrible statement, get off your butt and go get on a committee so they know who you are. It keeps my finger on the pulse of what we are doing as an institution.

"Students play a role. They expect responses at 9pm at night." Lenny commented during his interview. While this is one of the only responses that specifically cited students demanding additional workload from their instructor or changing the balance of workload, many faculty had mentioned student issues outside the classroom as 
contributing to their busy days. Many participants reflected upon the feeling of contributing to their students' efforts and feeling an obligation to their students' success.

\section{A Last Minute or Important Deadline Project is Introduced; Who might be Delegated in your Program to Achieve this Short-term but Important Goal?}

This question sought to gain an understanding of the workflow for programs, and how work might be divided up among the faculty within them. Again the goal was to bring context to how faculty accomplish tasks and how balanced those faculty perceive those workloads as being. The categories of responses received from participants were: Participant takes all the responsibility; Coordinator delegates based on skill or workload; Political influence or demands; Team effort; or Mixed messages or expectations.

Participant takes all the responsibility. Chuckling to himself, Neil joked after being asked the question. "So it's a normal day?" Neil cited the last minute time-frame in the question as something more common than one would expect. Neil continued saying, "It all depends what the project is, it's often me." Growing agitated he continued, "It might be something I turned in two weeks ago and they claim they never received it." "It is often last minute because of their poor planning so I do what I can." Within this response category, it was common for recipients to take the time-frame of the question in mind. Many of the responses suggested that given the short amount of notice, "The only one who would do it is me" said Debra, a faculty member in a Construction program. Jackie's response was similar, stating that she would be the person volunteered to take care of that sort of thing. Thomas elaborated on his thoughts of this situation explaining "I don't want to dump that on faculty that cannot absorb the load." He continued stating 
I fight hard to make sure last minute doesn't happen, but administration will change things on you last minute and you have to figure it out. I do not see how assistant or associate professors could absorb last minute stuff.

Penelope, who comes from a unique position of power within her program, had a unique perspective on this question. "In academia, it is tough because I did not feel I had the backing to tell that tenured faculty member what they needed to do to help me so those responsibilities fell on me." This situation as a new faculty member and chair of a program was exemplified in Penelope's experiences in working with existing faculty. Something that was confusing to me as a coordinator when I started out, because I came from 20 years of industry where we had a chain of command. I could tell my subordinate get this done by this date. I could not do that as coordinator and that was a very confusing thing for me because I did not have the backing or the guts to say to the tenured professor "hey, you need to get this portion of the report done by Tuesday!" So that atmosphere wasn't here. So as the coordinator that all fell on me, and then we have gotten better as a group, ENGT, especially with our last round of accreditation we really did spread that out a lot better. But in a university environment you could never tell someone else you must do this by this date or else something bad is going to happen.

Coordinators of several programs echoed these types of comments, with Joachim admitting "If I'm meeting with a student, is about my only exception to not taking on something like that [myself]."

Coordinator delegates based on skill or workload. Workload also had variances in distribution based on who in the program was qualified and what their 
current workload or capacity was. Lenny commented that the responsibility would come to him first, but then move above him or laterally to his other faculty or to more experienced people. Lenny continued and discussed the current dynamic of his program; "With $40 \%$ of our faculty being new, maybe a year from now I might be able to [delegate more] but right now it would be tough to do with new faculty." Larry said, as a coordinator "you know who you can ask for things. It's all workload, versus willingness, versus skill-set." Joachim, reflecting on his process, explained it would probably be him that takes care of the responsibility. "I've got our auto coordinator and our diesel coordinator, so big picture stuff I can draft and send it out to them to look it over." "If it is a quick turnaround and we just don't have time I would take it on myself, [but] if I'm not qualified and I need to have their input then it's different." Penelope, who was obviously reflecting on a cultural shift in her program, mentioned how many of the faculty within the program now know and understand where everyone's strengths are, as opposed to the more tumultuous past she had come into when she started. Penelope stated,

I'm going in our later years for example, anything, and I'm going to use [redacted] as an example, anything that has to do with data digging, that is [redacted] and we all know that is [redacted] and he will do that. But if you tell [redacted] you have to have a presentation ready to go to this committee... "I'm not doing it!" Okay, so yes to your question, we have learned, who can do what and I think that is, this is a hard thing because as soon as you change that balance with another person added to the group then we don't know the rules anymore and we need to figure out what can you do. 
Additionally, Sam commented that from a faculty perspective without a coordinator's role that "it depends on the issue". He added that "something may have to fall off someone's plate in those instances." "I have an Ed.D. so if it was to look at organization or assessments it would be given to me." Sam went on to talk about another faculty member in his program.

We have one very junior faculty member and we are kind of careful how much we load him with some of these more difficult tasks, so I generally find myself mentoring him. So I might pull him along a project but not necessarily take too much of his time so get him so at some point in time we don't have to treat him as a junior.

Frank cited the level or precision of work required for certain tasks. He suggested that accreditation needs more detail orientation. "It depends on the level and who is going to be looking at it. If it's for accreditation I would imagine someone would be having someone who looks a little more closely at detail."

Political influence or demands. Throughout some of the responses to this question, some participants reflected upon the political nature of the delegation of tasks. As Larry exclaimed, "Someone either volunteers or is told to do it." Penelope, reflecting on her culture shock, said "In industry we had tougher deadlines and more pressure but we also had a clear chain of command, this [academia] is not like this." She continued to acknowledge the politics of the university saying "Political environment definitely plays a role in how tasks are accomplished."

Team effort. Throughout many of these responses, much of the participants seemed to feel that a very team-involved nature was present within the culture of their 
programs. Larry discussed how each of the faculty in the program takes on the role of coordinator, taking turns in the leadership of the program. Brad, another member of the same program Larry currently coordinates, remarked that "It's nice to pass that coordinator position around because we all get experience in that role." Penelope remarked on how she feels "We do better now in ENGT, we are more team focused." Sam disclosed his program's process saying "We would likely decide as a group who would or could best handle that request." Kaleb, a CTE teacher who also teaches machining and welding commented that "It is a pretty team environment, we all step up when needed and we all seem to be able to push things that we find important." James elaborated on how he reacts to these responsibilities with a small program of only two faculty members. He shared,

That would actually fall on both me and my colleague. We would split up and do it from the point of view of the classes we teach. She consistently teaches 5 of the classes, I teach 4 of them, and then there is the internship that we take turns dealing with, and so I would get the necessary outcomes for my classes and we would sit down and talk about it. She would get the ones for her classes and then we would work or combine the report.

Mixed messages or expectations. Several participants cited frustration with this experience of vague, confusing, or changing tasks being asked of them. Many of those frustrations stemmed from mixed messages or expectations from administrators changing over the course of a project or request. Thomas' comment, "I fight hard to make sure last minute does not happen, but admin will change things on you last minute and you have to figure it out" exemplifies how these expectations can alter the course of a project or 
outcome. Kaleb added that "It always seems to be last minute information, but in some cases it's not very clear" and that "I don't care much for the way they collect the data." Neil voiced his frustrations, saying, "No one answers an email or phone. It is just a giant wonder where anyone is when we need something."

\section{Themes}

There were two major themes that came from the participant data for this research question. The first was "Student focused culture and faculty motivation within program." This was especially evident in more passionate faculty interviews where the participants were clearly invested in their student's success. Maynard was one of those participants. Not only were his words supportive and convincing of his motivations for teaching, but his demeanor and the way he thought about his contribution to his students gave the research a sense of purpose. Maynard had a hard time coming up with negative aspects of the non-teaching workload specifically because he felt that he found connections to students or activities that directly benefitted the students or the program. Even still, it was obvious that he was passionate about his students' success, and he recognized that even though the loads were demanding, he was contributing to his students' experience. "I have a really hard time thinking on that because I see so much positive come out of it. It hurts them in the short run, but then in the long run it helps."

The second theme was a collective feeling of being team focused/oriented among faculty within programs. This was perhaps most evident in the first focus group that was conducted with faculty members from a construction program. This focus group gave a sense that there was an energizing culture around the program, and that everyone in the program either contributed to it or contributed selflessly in another way. Many 
participants, like Brad, mentioned team work, especially when asked about how a last minute project or deadline would be dealt with on a program level. Brad said, "It's a pretty team environment. We all step up when needed and we all seem to be able to push things that we find important."

\section{Research Question One Answered}

In answering the question, How do faculty perceive the balance of non-teaching vs. teaching workload in their program, the research concludes that the balance overall for faculty is primarily at least $50 / 50$. Whether or not this is appropriate is beyond the scope of the study; however, very few faculty members in the study reported spending more than $60 \%$ of their perceived working hours on teaching responsibilities. It is also worthy of noting, that when asked to rank their responsibilities as faculty members, all 30 participants chose to rank Teaching as the highest priority. Further, those faculty felt that responsibilities within their department, especially non-teaching responsibilities often became a team effort rather than an individual effort. In addition, those non-teaching responsibilities had been observed as increasing over the past several years, with many participants feeling as though their workload had increased without a similar increase in rank or pay. Still, many participants felt as though it was a team effort in their program to accomplish those tasks and carried a relatively positive attitude about the culture and climate of their program, even if they did not share that outlook for the remainder of their institution.

\section{Research Question Two}

Research Question Two asked how faculty members perceive their self-efficacy in the classroom when considering non-teaching responsibilities. The purpose of this 
question was to evaluate how non-teaching workloads impacted faculty members in the classroom. The questions posed for Research Question Two were as follows:

- Tell me about how about the impact (negative of positive) you feel non-teaching responsibilities have on your teaching in the classroom

- With what importance do you believe your institution places instructional ability/student outcomes/classroom efficacy, etc.?

- Can you tell me about a time you felt you sacrificed student experience for workrelated responsibilities not directly linked to student outcomes?

- Can you tell me about a time when you felt student outcomes or experiences were improved by a non-teaching responsibility?

Several sub-questions were asked of the participants depending on their responses to these main questions. The following sections are categorized based on these questions.

\section{Perception of the Impact (negative or positive) Non-teaching Responsibilities have}

\section{on Teaching.}

Responses to this question were fit into three distinct categories. These categories were: No impact, Negative impact, and Positive impact.

No impact. One category in particular had a single participant who mentioned that he felt non-teaching responsibilities had "none, to little" effect on his classroom activities, let alone his classroom efficacy. This participant, Lenny, continued to say that he did not feel non-teaching responsibilities had ever impacted his classroom function because his performance in the classroom was personally regarded as his highest priority in his job function. Alternatively, he suggested that he had likely sacrificed non-teaching responsibilities for those that were related to his teaching. When questioned later about 
non-teaching workloads contributing positively to his classroom efficacy, he admitted that many of the industry networking opportunities offered by his program's internship course allowed him to incorporate more industry-driven topics into his current classroom.

Negative impact. Other participants held either a positive or negative view on non-teaching workload's contribution to their classroom. The negative impact was significantly more frequent in participants' responses. Larry, for example, mentioned topics such as trading off extra time with students by "shutting yourself off" which reflected literature surrounding the intrinsic motivations of faculty and their desire for student success. Larry expressed a disheartened attitude at feeling the pressure to have to close and lock his office door in the hopes of being able to focus on his work in lieu of devoting time for students. "When you see a student succeed it is a good feeling. You feel like you helped in that and it feels great but every time you have to shut yourself out from that, that is the tradeoff." Penelope discussed both negative and positive effects of non-teaching workload and made extensive comments on non-teaching workload and its negative impact on continual improvement. She shared,

The downside is it takes away from the ability to think "how can I do this better?" I want to be able to take every lesson and at the end, when it's fresh, revise it and make it better. Outside responsibilities whack that time off. Continual improvement doesn't happen because as soon as you get out of class you're going off to a committee meeting.

Neil also commented on the negative aspects of the increased non-teaching load citing interruptions, even during his lectures, that he often feels obligated to oblige by. 
On the weeks when there is too much, the class definitely suffers. I don't have the power point looked over, or the lab set up Et cetera. If the retention specialist comes down and asks for a tour, of course I'm going to say yes... even though I'm lecturing.

Maynard, while not having specific examples in which he could say non-teaching responsibilities hurt his classroom efficacy in the short and long term, discussed his vacation and personal time and how it relates to his students.

I've got 1200 hours of vacation accumulated and all my personal days. Very rarely if I can work around it [the obligation, I will] because it is more work to get a sub than to teach the class. It changes the students' perception of you when you push perfect attendance and then have to miss class for instructional counsel, they don't give a crap what instructional counsel is.

Charlie also had comments on the role of non-teaching responsibilities in the classroom, commenting that they definitely had a negative impact. Charlie mentioned that he "like[s] to have everything laid out and I like to share with the students the whole plan for lessons." Keenan was primarily concerned with the frequency at which these events that detracted from his student's experiences happened. "Seems like it happens randomly almost weekly, instead of working on your class or lab, there were times when students needing things, I just had to take those extra things home [because they wouldn't get done otherwise]." 


\section{Institutional Importance of Instructional Ability, Student Outcomes, and Classroom Efficacy}

Responses to this question were more varied than the first question, suggesting a highly variable perception of the expected importance on instructional ability and classroom efficacy. This is important to the study as through the conceptual framework it becomes clear how faculty may be motivated. Often intrinsic factors drive faculty to improve classroom experiences for the students, while extrinsic factors are often driving non-teaching responsibilities. Frank's response to this question highlighted this, "It has to be intrinsic, you are supposed to [be] following through with [teaching] goals and I've seen a lot that don't follow through." Later, he commented on teaching evaluations, discussing how, as opposed to industry, there is a lot of abuse in it. "One day, you have to be on point, the rest of the time... I hold myself to a pretty high standard [in the classroom], but not everyone does." A misalignment of priorities at the administrative or university level as demonstrated by systems and methods like these may contribute to faculty dissatisfaction with their job. The literature explains how this can lead to burnout in faculty members and potentially result in faculty departure from the position.

Alternatively, an alignment of these priorities shows support for faculty workloads outside the classroom, without demanding faculty sacrifice personal time or time with their students or classrooms.

Three categories again emerged from the participant responses. Those categories were administrative words versus actions (suggesting a difference or disconnect between the two), Administrative understanding or misunderstanding of workload, and Evaluating or Rewarding faculty. 
Administrative words vs. actions. From the first focus group conducted, members discussed the perception that comes from administration. Many of the faculty in the group expressed the idea that administrators above the College Dean's often want to believe what they do is student based, but at the program level it is not always students first. This was a comment echoed by several other interview participants as well. Joachim remarked that in general, "administrators often say that faculty are there to teach, but the administrators are the same people assigning this additional workload to those faculty." Joachim went further, saying "It is advertised and out in front, but there is this hidden background of 'you're going to do this work too' and I think there is a general feeling across campus that it takes away from the classroom." Thomas made similar comments, suggesting that administrators localize their support for teaching efforts but do not necessarily support them in the same way behind the scenes. Lenny, a program coordinator, commented on the push for student outcomes at his institution. He felt that while there was extra work involved in developing outcomes the administration was happy with, they do not seem to push faculty to meet those outcomes. The first focus group had also commented that their administration may recognize the importance of data like those outcomes, but often don't seem to have any idea what it means or how resources should be allocated at the program level.

Administrative understanding/misunderstanding of workload. Larry, taking a more positive note, discussed administrative understanding of faculty programs. "I think it is human nature. The president of the university will never understand our degree, so it is always going to be difficult for them to know how to properly do so" he said. Sam referred to the faculty saying they see it as a matter of pride to have good teaching in their 
classrooms. Still, Joachim felt that non-teaching workload is still important but, "there is that struggle and that internal fight." Contrary to some of these perceptions, Kaleb disclosed a rather exact estimation of 80 percent teaching load with the remaining 20 percent being devoted to service and research. He suggested that for the most part he was satisfied with the balance and that administrators at his university understood his load.

Evaluating or rewarding faculty. In terms of evaluating and rewarding faculty, Jackie suggested a reward system for faculty who develop or achieve better student learning outcomes. At her university she cited competency-based assessments that, in her opinion, showed a university interest in teaching. Later in the interview, she remarked that "All of us could be paid better for the services we provide." Debra felt that not only are the rewards or penalties often distributed by administrators at her institution, but "In reality if you are not recruiting and promoting the program the employers aren't happy so you are sort of forced to do that just to make it run."

\section{Sacrifice or Contribution to Student Experience for Non-Teaching Workloads}

This question was posed as two separate questions in the interview process and focused on specific examples the participants had that they felt either detracted or contributed to their students' experience in the classroom. Closely tied to these positive or negative experiences is the instructor's classroom efficacy, or feelings of selfconfidence in teaching the lesson. The categories of the responses were contributing to classroom experience, detracting from classroom experience, and general emotions surrounding those experiences.

Detracting from classroom experience. Most of the 30 participants could reconcile a time where their classroom experiences were impacted negatively by non- 
teaching workloads. This suggests either a strong negative emotion which was reflected in some of their comments, or a frequent occurrence. When asked how often these negative experiences occur, most of the 30 participants remarked that it was not a frequent occurrence, suggesting that strong emotions were usually perceived by the participant when those experiences did happen rather than with a high frequency. Jackie, who appeared more emotional during this portion of the interview, remarked that lacking the time to design memorable learning experiences is a logical outcome when you have so many other tasks to do. Frank cited a search committee he was on where he had to cut entire class sessions short, saying "That really detracted from my time for preparation for class." Joachim had "no doubt" that he could have made things better but lacked the time to do so specifically because of those responsibilities. Larry even cited his personal conflict, explaining that "If it's not your family, it's your students." He continued saying, "Student experience suffers rather than benefits. There are definitely times I feel that I'm less confident in the classroom.”

Contributing to the classroom experience. Nearly all the participants who cited a contribution to their classrooms from non-teaching workload explained that often it was either industry related or University related benefits. For example, Debra commented, "When you are working with employers you are making relationships to bring in guest speakers and building those [connections] up to help with curriculum and program currency." Others discussed the advantages of networking with professional conferences or the training that they provide to instructors which can be brought back to the classroom. Further, some participants cited the ability to network with faculty even 
within their own institutions, mentioning that many times things like committee work can be beneficial to "see how others are meeting their goals."

\section{Themes}

The research revealed two main themes as a result of investigating Research Question Two. The first theme is that most participants reconciled some sort of negative experience that they felt impacted their students directly in their classroom. This often had a negative effect on the faculty member and many participants felt badly about having to make that sacrifice at the time. Larry said "When you see a student succeed it is a good feeling, you feel like you helped in that and it feels great but every time you have to shut yourself out from that, that is the tradeoff... if it's not your family, it's your students.”

The second theme that became evident during the investigation of Research Question Two was that faculty members remain intensely focused on not sacrificing their students' experience in the classroom if they can help it. Maynard in particular commented on this topic directly.

I've got 1200 hours of vacation accumulated and all my personal days. Very rarely if I can work around it [the obligation, I will] because it is more work to get a sub than to teach the class. It changes the students' perception of you when you push perfect attendance and then have to miss class for instructional counsel, they don't give a crap what instructional counsel is...

In addition to this, often faculty had a positive outlook on their sacrifices, citing multiple ways they were able to contribute back to their classroom even if in the short term their efficacy was negatively impacted. Maynard was one of these participants who had an 
unusually positive outlook on those tasks despite recognizing that in the short term, his students did suffer occasionally.

\section{Research Question Two Answered}

In answering the research question about how faculty members perceive their self-efficacy in the classroom when considering non-teaching responsibilities, the research indicates that most all faculty members in this study perceive a negative effect on their classroom ability, preparedness, and efficacy when considering their nonteaching workloads.

\section{Research Question Three}

Research Question Three asked: - How do faculty members in high technology areas perceive their workload? The goal of this research question was to gain a general insight into faculty members' perception of their workload as a whole.

The questions posed for Research Question Three were as follows:

- In general, do you feel your personal workload is appropriate, overestimated (Underworked) or underestimated (Overworked)?

- Do you feel like non-teaching workloads are disproportionately assigned to faculty members?

- Tell me about a time you genuinely felt overwhelmed or underwhelmed by responsibilities at work.

Several sub-questions were asked of the participants depending on their responses to these main questions. The following sections are categorized based on these questions. 


\section{In General, do you Feel your Personal Workload is Appropriate, Overestimated (Underworked) or Underestimated (Overworked)?}

This question had three distinct categories that were apparent from participant responses. Those categories were: Appropriate workload, Overestimated workload (meaning the participant felt under-worked), and underestimated workload (meaning the participant felt over-worked).

Appropriate workload. Several participants in the study commented that they felt their own workload in general was appropriate. Lenny, who mentioned his ability to balance tasks as much as possible and take care to manage his time correctly, saw his workload as "less overwhelming." Kaleb felt his workload was appropriate and had no further comment on his outlook. Others commented on the changing and variable nature of the work. Much like questions asked pertaining to Research Question One, several participants acknowledged that their workload often changes over the course of a semester or a year. Brad is one of those participants, "It varies, and we don't have to advise students so during the latter part of semesters it was a lot of heavy workload that we no longer have to do. Some weeks are heavy, others are not." Penelope also acknowledged the advent of change stemming from the transition to a 15 semester hour full time teaching load. She disclosed, "Going into the future where I have to teach more, I don't know the answer just yet." Jackie, carrying a more existential perspective shared "Everyone might think they do a lot but there might be other faculty that do more and we aren't well informed about them."

Underestimated workload (overworked). Many of the participants commented on how overworked they sometimes felt they were in their job responsibilities. Some, 
like Neil were sure they were overworked; "Underestimated 100\%. I feel overworked." Others, like Larry, proposed that he felt his work load was only underestimated a little. He commented,

I would say it is underestimated a little. We are compensated very well, so I don't feel like "man they don't pay me" I do feel like "man they sure expect a lot." I look at other people in other departments and see us leaving at 6pm every day and everyone else was gone at noon or we are coming in Saturdays and we all get paid the same. It is not equitable, but at the same time I love what I do and wouldn't teach in any other area.

Sam had much to say on this particular topic and discussed at length his responsibilities and perspectives on the matter.

I think everybody in the department here thinks that our workload is underestimated by those that we work for and that we are requested to do way more than [expected]. It is not a 40 hour work week. It is not a 60 hour work week. It is whatever it takes to get it done. So, it just seems like that there are groups out there that are just thinking up more ways for faculty to be involved, and we all want to do that, but at some point there is just not enough time. If you are trying to do any self improvement at all, that's what has to give. There is no time to go research new teaching methods or go listen to a lecture that someone is giving because there is just too much. Especially advising. When we are asked to advise students, the students have a lot of expectations [for] what is going to come from a faculty member for advising. The students think we should make up their entire schedule. No one ever made a schedule for me, I made it for myself, so 
things have just changed over the years. But if you end up with a student who is a transfer student, that can just eat up 2 or 3 hours in a meeting. I think there is a general underestimation of how much time faculty [members] spend on faculty related requirements. You know, I think sometimes I think our chairs understand what is being expected of us, but I think from the Dean's above that there is just not a clear understanding of the amount of time we spend teaching and with students. It is like, oh we ask you to teach 12 credit hours... [and that is it]. Jackie reflected on how the added workload without additional extrinsic benefits made her feel.

Honestly, I think that especially this past year, the faculty load has been increased tremendously, and changing from 12 credit hours to 15 credit hours that adds more prep and more responsibility and not getting anything in return, and with all the state's budget issues, this will of course, this will have an effect on how a university can compensate faculty members, so I think all of us could be paid a little better, could be paid more for the service we provide.

Keenan, as well, expressed the dissatisfaction, not so much with the workload, but with the lack of additional benefits with increased workload demands. "Since 2008 it has been that long since we've had a raise or even merit pay so it is do more with less money" he said. In addition, Keenan did note, however, that his workload was not always $100 \%$ all the time. "I would say I'm about $85 \%$ load, but there is days that I'm way over $100 \%$ " adding that "To a certain extent you feel like there is not enough hours in the day, but it is not all the time." Others, like Charlie expressed similar attitudes, not unlike responses from other interview questions "My teaching workload, I'm overworked because of the 
[temporary] overload." "Being in applied technology I spend way more than the minimum workload in the classroom setting up and preparing as well." This temporary nature of the workload was recanted by other participants, like Frank, who was in the middle of a doctorate degree and expressed "While doing a Ph.D. it is definitely underestimated... there is no time for the research aspect of that."

Overestimated workload (underworked). Surprisingly, there were no comments from the participants that indicated any of them felt under-worked. However some of them commented on their abilities to manage time or accomplish work outside of the office, such as Lenny, who remarked "If I do 40, 50, 60 hours a week it is not like I'm always in the office. I can do some of those things at home." Jackie, who thought that most faculty will probably assume that "their load is the most" likely observed a very true sentiment among faculty that would suggest a valid reason why faculty may not feel under-worked.

\section{Do you Feel like Non-teaching Workloads are Disproportionately Assigned to Faculty Members?}

This question was designed to encourage faculty to elaborate on their perspectives of workload outside their own responsibilities. For instance, do faculty workloads change with rank or tenure? Or does the type of work or reward/benefit guide the amount of workload pursued? These categories of responses are explored below.

Rank. "If everything worked like a well-oiled machine [it would be better], but because nobody knows their job and they demand so much of you for continuing contract or promotion..." Neil trailed off, seemingly reminiscent of a time when he did not have so much additional work to do as a result of others' incompetence. "If I would say F-it... I 
don't want to go for promotion it wouldn't be so bad, [but] this is my career, I have to do that stuff and want to do that stuff." Charlie elaborated on how rank affects his outlook on how non-teaching workloads are assigned. "The younger guys, who need the work, who need tenure, they're the ones that get taxed the most." Lenny also thought that "Full professors... [I] expect that they would have to work a little bit harder since we pay them more." Other participants recognized this increased load for new faculty or faculty that are being promoted through ranks. Keenan however, mentioned that among certain ranks workload is probably pretty even, suggesting that when promotion or tenure is not on the line, workload is significantly reduced.

Tenure. Maynard cited tenure as a factor in workloads saying that "If you aren't tenured, you are going to have a lot thrown on you." This echoes many of the types of responses received from other participants who cited rank, promotion and tenure as a passage point in which faculty workloads transform.

Not disproportionately assigned. Joachim shared his perspective, which was not echoed by any other participants. He felt that the perception of disproportionate assignment of workload is present, but that in reality, it may not be as prevalent as some faculty would suggest. “Perception, yes, in reality, I don't think so; I don't think faculty are being pushed to do more than they should be. Again the three legged stool of academia." When pressed for more detail on his concept of the three legged stool, he added, "Faculty like to leave at 2 or 3:30, if they would spend that extra hour every day they could get it done" and "You [as faculty] signed up for that service and scholarly activity." 
Varied workload. Maynard also expressed his understanding of the circumstance of varied workload. "Some committees they take a lot more work than others" he said. Charlie, who has a similar opinion, shared that "In some cases yes, being on some of the committees I found that in some departments that is definitely the case. Especially in departments where they have a large advising load."

Rewarding benefit. Maynard had a rather apathetic view to this portion of the interview saying;

If you don't do a good job, you get less work for it, so you're not rewarded for doing a good job. What is my reward for good performance? It's more work! Some people really seem to be invested, others don't.

Penelope echoed this feeling with her response. "Some faculty members, I think you can be grumpy enough and not get those responsibilities, and that's the politics. Others get overburdened [because of them]."

\section{Tell me About a Time you Genuinely Felt Overwhelmed or Underwhelmed by Responsibilities at Work.}

This question was asked of participants to humanize the experiences of the participants. Many of them could recall specific times in their career that they felt overwhelmed and on the verge of burning out. Their answers were categorized into one of three responses. Those responses were: Frequently felt overwhelmed; Sometimes felt overwhelmed; and have never or cannot remember feeling overwhelmed. None of the participants in the study reported feeling underwhelmed by their experiences.

Frequently felt overwhelmed. Much like answers to previous questions, many participants felt overwhelmed at specific stages of their careers. Penelope, for example 
cited the beginning of her career, as a new instructor and Coordinator of a brand new program. She remarked, "I knew I had to get it done, so it was a challenge and I wasn't going to fail." but reflected on her experience with feeling isolated in her struggles.

“Administrators and chairs didn't know what I was going through because no one else was from industry. But they were very kind, and they tried [to help].” Similar to Penelope, Jackie currently fills a coordinator role for her program and she remarked on her current workload situation.

Of course when the semester starts we get really busy, and then when you prepare for accreditation, it's crazy. We have to prepare the things [for accreditation], and not everyone cooperates the same way, so there are always one or two people who carry the heaviest load so then it's the time that I feel overwhelmed. Also recruiting. Now we have to recruit. Since our former faculty member, who was in charge of recruiting, retired now the recruiting responsibility has been distributed in programs and we are in charge. If we don't recruit we won't have enough enrollment. This is something that I feel overwhelmed, because I think about it all the time. How I can be productive. So this is so, I would say I can't say it is one week or every other week, depending on the situation the emergency situation we feel overwhelmed.

Larry also had a similar input as Jackie, but seemed to remember a higher frequency of times that he felt overwhelmed.

I would say, four or five times a semester I probably get to a point, and it is usually when there is some kind of deadline and it is often when that deadline coincides with other things going on such as the beginning or ending of a class, or 
uh, some event, or travel. You have to travel. That always sets you behind. But it is uh, I would say, I plan student trips and things like that and I advise our student organizations, so it is just when two or three of those large things coincide. Like I'm planning a student trip to Detroit for example, and trying to arrange all the details of the travel and making sure we have visits scheduled with all the people we are visiting, and then we have at that same time finals, final grades are due and I've got student emailing me and saying how come I have a zero, or why do I have an $\mathrm{F}$ and at the same time, then someone will call or email and say can we have by Friday, can you get back to me on this and give me this information you know. It is kind of a tipping point where you're like, na... I cannot take one more thing, and then I open up my email. I open up my inbox and I've got 95 new emails and my voicemail is flashing and all those kinds of things, and that, I definitely have it happen fairly frequently.

Brad and Frank seemed to reflect most deeply on how often they felt overwhelmed. Brad remarked that "Every day I feel overwhelmed during the semester." Frank, who is currently pursuing a doctorate degree, had similar feedback.

Knowing that it is a short time, that keeps my sanity. If I knew that this was going to be lifetime, like I know there are universities where they are expected to put 60 or 70 hours in a week doing research on top of their teaching load... I wouldn't be able to do that, so, knowing that it's a short term, it is still ok but there are still, I mean I get 4 or 5 hours of sleep during the week per night, so it does have an effect. I get pretty tired. 
Sometimes overwhelming. By far the most populated category of answer for this question was the sometimes overwhelming category. Many participants reflected on the nature of these negative experiences of feeling overwhelmed and how they coped with them. Participants such as Kaleb and Brad both remarked on how just simply knowing these experiences or workloads were temporary helped them when they reach a critical stage in which they recognized being overwhelmed but were able to persist in their career or tasks. Kaleb remarked;

It really depends on the time of the semester. It is a little bit of stress but I think I survived it. I've been through enough that I know this too will pass. I thought about the temporary nature of the responsibilities. I thought, that's what I like about my job. I know when the semester comes there's going to be a change, good or bad. It is not the same every year, year to year.

Sam reflected on how particular leaders of his organization had an effect on his workload. We had a chair that was demanding, I was working as an Associate professor and he just kept pushing, pushing, pushing, for me to take on this added responsibility with an idea I was not in agreement with. It was too much, and yet he kept hounding me about it.

James had similar comments, citing a transition period in his program as the source of many of his emotions on the job.

I was teaching all the classes. The faculty that left, left with all of their material, so I mean. I'm teaching all of these classes that I've got a paragraph on an old syllabus to explain what the class is about, and so I genuinely felt bad for the students because there was two years, when I took the program over, where I was 
the only instructor, and I couldn't. I just plain didn't do well on certain classes, you know? But I did what I could, and, you know we did move two classes, we took we substituted a couple courses from the college of business that were close to a couple of those, until we got the second, until we got [redacted] on board. She started out part time teaching and part time recruiting, and then moved into a full time, teaching tenure track role. So, for those first two years of taking over the program, I was, overwhelmed. I was completely overwhelmed. Now, No, I don't feel that way at all. Other than, you know, whatever personal, um you know, pressure I put on myself to you know, gosh I made that YouTube video last year but I should be able to use it this year but I was a little too specific so now I have to recreate [it] and that sort of thing.

Lenny, much like Penelope, felt that his feeling overwhelmed was a product of his new position at a university when he had not taught prior.

My teaching career has been somewhat short. I'll fall back to the first semester, 4 new class loads. I wanted to have everything mapped out for the whole semester. Instead I taught week to week. I didn't have time to prepare for my first semester. It would be nice from a faculty standpoint to pay faculty a small summer salary to prepare during that first semester.

No or cannot remember. Frank had a distinctly comparative attitude when it came to his workload. Admitting he felt pretty overwhelmed during his Ph.D. pursuits, he felt that compared to the ongoing load he felt at a previous position, his current position was "pretty good." Sam remarked on his experience in a similar way. 
I'm going to say that I haven't felt overwhelmed except maybe my first [semester]. But I wouldn't say then that I was overwhelmed but I would say that it was prior to teaching. So because I'd been asked to do so much in the past, you know. Probably when I felt most overwhelmed [was] when I was on a two week traveling trip through Europe where I was expected to be in a different country every day supporting a sales effort. By like day 12 I walked up to a counter at an airport, back when you had paper tickets, and I couldn't even tell the guy where I was going next. He asked me, and I was like, "I don't know." and he said here let me have your tickets and I'll figure it out, I'll get you there. But that was probably the one time that I felt like, just, lag and having to be on with the customer and trying to grab sleep on an airplane. It is just tough. That was probably it. But I haven't had anything like that happen here yet [in education].

\section{Themes}

The central theme that became apparent through this portion of the study was that while faculty can often become overwhelmed by their workloads, often this state is temporary and frequently comes and goes depending on the type and quantity of events that occur within a program. Kaleb gave a very introspective approach to answering this question saying;

It really depends on the time of the semester. It is a little bit of stress but I think I survived it; I've been through enough that I know this too will pass. I thought about the temporary nature of the responsibilities. I thought, that's what I like about my job. I know when the semester comes there's going to be a change, good or bad. It is not the same every year, year to year 
Accreditation visits, student advising loads, and transition periods within programs often were catalysts that alone, did not necessarily cause issues, but when combined with other workloads or new positions frequently caused stress in faculty members' lives. Larry's response was particularly attentive to this occurrence.

I would say, four or five times a semester I probably get to a point, and it is usually when there is some kind of deadline and it is often when that deadline coincides with other things going on such as the beginning or ending of a class, or uh, some event, or travel, you have to travel, that always sets you behind. But it is uh, I would say, I plan student trips and things like that and I advise our student organizations, so it is just when two or three of those large things coincide. Like I'm planning a student trip to Detroit for example, and trying to arrange all the details of the travel and making sure we have visits scheduled with all the people we are visiting, and then we have at that same time finals, final grades are due and I've got student emailing me and saying how come I have a zero, or why do I have an $\mathrm{F}$ and at the same time, then someone will call or email and say can we have by Friday, can you get back to me on this and give me this information you know. It is kind of a tipping point where you're like, na... I cannot take one more thing, and then I open up my email. I open up my inbox and I've got 95 new emails and my voicemail is flashing and all those kinds of things, and that, I definitely have it happen fairly frequently.

\section{Research Question Three Answered}

The research found that faculty members perceive their workload as both widely variable and also consistently changing. Variances such as changes in position, colleague 
turnover or positional changes, job description and requirements, or simply combinations of required tasks for faculty were the most observed traits of their total workload. Many faculty expressed a satisfaction with even high-stress portions of their career stating that the short-term nature of those stressful periods led them to persist through rather than burn out or leave the field.

\section{Implications for Practice}

Literature suggests one of the variables affecting the existing pool of STEM graduates are faculty (Lewallen et al. 2003). These faculty members remain critical for the continuation and proliferation of STEM programs (Newton, Utschig, \& Llewellyn, 2011). It remains obvious, then, to continue to close the STEM gap, retention of existing faculty in STEM programs is vital. Further, potential new faculty must be drawn to the profession to continue to grow these programs (Jacobs \& Winslow, 2004; Ranđelović \& Stojiljković, 2015). These goals combat the effects of teacher shortages well documented in elementary, secondary, and post-secondary STEM areas and work to attract more candidates to STEM education where few faculty candidates hold the necessary qualifications to teach (Galosy \& Gillespie, 2013).

In answering the research questions, faculty view their non-teaching workload in many ways depending on the timing, the task, and whether or not it contributes to their classroom. Based on the responses of the participants, faculty classroom efficacy is impacted negatively when student experiences suffer because of non-teaching workload. This is especially true when the faculty member perceives little or no benefit to the student in either the short or long term. While this is not a frequent occurrence, often the participants commented with negative emotions about having to sacrifice classroom 
experience for non-teaching workload. This supports a study by Taxer and Frenzel (2013) which also found teachers are more likely to express their positive emotions rather than negative ones, leaving administrators in the dark on how their faculty members truly feel about their job and their responsibilities. Many participants also expressed more positive outlooks on university level work, such as committee's than originally anticipated by the researcher as many participants found value in interacting with colleagues across disciplines at each of their institutions. Very few participants remarked on the role of political power at their institutions, and instead focused on structural roles and administrative understanding of specific goals, outcomes, and environments that programs function within.

Several themes were demonstrated by the participant responses that relate to the research questions answered in this work. In Research Question One, there were two major themes presented. The first was "Student focused culture and faculty motivation within program." This was especially evident in more passionate faculty interviews where the participants were clearly invested in their student's success. Maynard was one of those participants. Not only were his words supportive and convincing of his motivations for teaching, but his demeanor and the way he thought about his contribution to his students gave the research a sense of purpose. Maynard had a hard time coming up with negative aspects of the non-teaching workload specifically because he felt that he found connections to students or activities that directly benefitted the students or the program. Even still, it was obvious that he was passionate about his students' success, and he recognized that even though the loads were demanding, he was contributing to his students' experience. 
The second theme was a collective feeling of being team focused/oriented among faculty within programs. This was perhaps most evident in the first focus group that was conducted with faculty members from a construction program. This focus group gave a sense that there was an energizing culture around the program, and that everyone in the program either contributed to it or contributed selflessly in another way. Many participants, like Brad, mentioned team work, especially when asked about how a last minute project or deadline would be dealt with on a program level. Brad said, "It's a pretty team environment. We all step up when needed and we all seem to be able to push things that we find important."

Research Question Two led the researcher down a less positive road. Despite the negative experiences of these faculty and their feelings of limited classroom efficacy almost all the participants had something positive to say about their profession and their work with their students. It was apparent to the researcher that these faculty were highly motivated by and exceptionally focused on the success of their students above all else. This suggests a highly intrinsically motivated faculty when students are involved.

A second major theme from the data collected for Research Question Two was the conclusion that administrators on many levels in the participant's institutions often lack the industry experience or program level experience to understand faculty members' total workload. Many of the participants in the study remarked on their own feelings that administrators did not understand their workload, or how long it took to accomplish certain tasks and how much time it took away from faculty/student interaction. This theme was often referenced when participants knew that they had these tasks to do, but often did not feel they were able to devote adequate time to preparing for class lessons, 
setting up laboratories, maintaining equipment, or other tasks related to high-technology training. This meant that faculty had to decide what else could be sacrificed for the purpose of accomplishing those tasks.

The central theme that became apparent through answering Research Question Three was that while faculty can often become overwhelmed by their workloads, often this state is temporary and frequently comes and goes depending on the type and quantity of events that occur within a program. Accreditation visits, student advising loads, and transition periods within programs often were catalysts that alone, did not necessarily cause issues, but when combined with other workloads or new positions frequently caused stress in faculty members' lives. This was especially evident in faculty members, such as Penelope, who were new to the political landscape of their university and experienced frequent occurrences of confusion in her observations of the university culture. This is consistent with the research of Lewallen et al. (2003) who identified the faculty members' ability to cope with unfamiliarity as a stressor.

Based on responses from participants it is the recommendation of the researcher that university administrators take a more active role in understanding the more specialized load that faculty in high technology areas face. Often, unilateral decisions cited by participants in the study resulted in program resource reduction, or additional workload for faculty that disproportionately applied additional perceived pressure to faculty within those programs. Many participants understand the conflict administrators have and the political and structural challenges administrators face, but do not feel their own workload is being justifiably understood, or accounted for, either via extrinsic rewards such as salary or benefits, or intrinsic rewards such as appreciation from their 
superiors. In order to maintain the current and upcoming pool of faculty, who are willing and qualified to teach, these small changes and the faculty who may benefit from them, should be considered.

\section{Conclusions}

In conclusion, in order to further support faculty in high technology and indemand applied baccalaureate programs their experiences with non-teaching workload should be accounted for. Non-teaching workload for faculty is especially burdensome and often does not carry as much intrinsic benefit to the faculty member as evidenced by the responses from participants. It is the hope that this work and experiences recorded within it will contribute to the discussion of workloads for faculty teaching in hightechnology and in-demand areas. 


\section{Appendix B - Interview Protocol (Individual Interview)}

Attendee's will either interview in person, or participate in one-on-one web conferencing via Skype, Google Hangouts or other similar mediums. An electronic copy or hard copy consent form will be required to be filled out, signed and returned to the researcher before the session starts.

\section{Demographic Questions}

- Openers:

- How long have you taught at the baccalaureate level?

- Have you remained in one core job description or have you changed positions during this time?

○ Is your school R1, T1 etc?

- What field(s) or programs do you teach in?

○ Have you taught in one program or multiple programs?

- Have you taught in areas that would not be considered high-technology or applied baccalaureate areas?

- What brought/motivated you to teaching?

- How familiar are you with intrinsic vs. extrinsic reward theories and their relationship to job satisfaction and your career/career-path?

Define Perception: Your own way of understanding something, whether that understanding is through thought, ideas, visual and auditory input or other forms of sensory feedback.

Define Classroom Efficacy: A measure, whether qualitative or quantitative, of an instructor's success and aptitude at conveying and getting students to retain information.

RQ1: How do faculty perceive their balance in their program concerning non-teaching vs. teaching responsibilities?

- What is your working environment like within your program?

$\circ$ What is your perception of the balance of teaching and non-teaching workloads within your program?

- A last minute or important deadline project is introduced and your program needs to put together a comprehensive report on Student learning outcomes. Who might be delegated in your program to achieve this short term but important goal?

- Why that person?

- How would a different situation alter who might take that responsibility?

- Grant writing or Research project

- Accreditation needs

- Student Organization matter 
- Etc?

- If this person is you, could you elaborate on how that added responsibility makes you feel?

- Do you feel Appreciated/under-appreciated?

- Did you expect this responsibility as part of the job?

- Tell me about a time you felt that this responsibility detracts from time with students, personal or family time and/or vacation time.

RQ2

- How do faculty perceive their efficacy in the classroom when considering nonteaching responsibilities?

- Tell me about how about the impact (negative of positive) you feel nonteaching responsibilities have on your teaching in the classroom

- With what importance do you believe your institution places instructional ability/student outcomes/classroom efficacy etc?

- Can you tell me about a time you felt you sacrificed student experience for work-related responsibilities not directly linked to student outcomes?

- Can you tell me about a time when you felt student outcomes or experiences were improved by a non-teaching responsibility?

RQ3

- How do faculty in high technology areas perceive their workload?

- In general, do you feel your personal workload is appropriate, overestimated (Underworked) or underestimated (Overworked)?

○ Do you feel like non-teaching workloads are disproportionately assigned to faculty members?

- Can you tell me about your workload balance? (Online rank form)

- Prioritize your responsibilities in order from most time spent to least time spent (Over a typical week)

$\circ$ Teaching

- Grant Writing

$\circ$ Research

- Training

- University Service

- Accreditation/Certification

- Student Advisement

- Student Organizations

- Miscellaneous

○ Tell me about a time you genuinely felt overwhelmed by responsibilities at work. 
- Tell me about a time you genuinely felt underwhelmed by responsibilities at work.

- How often do you feel this way?

- How does this impact your job satisfaction or what does this feeling contribute to your overall health and well-being?

- How do these emotions affect your student's classroom experience? 


\section{Appendix C - Interview Protocol (focus group)}

Attendee's will receive a small name tag on which they can write their name of choosing (Alias allowed for anonymity) and an electronic or paper copy of a consent form in .pdf format they must sign and return to the researcher before the session starts.

Several projector slides will be prepared, one has short definitions of the terms below, and one slide has responsibilities to put in order of most time spent to least time spent. These responses will be collected on a google form pushed out by one of the moderators of the discussion during the initial stages of the focus group. The link is provided on a third slide via QR code or URL link.

Demographic Questions

- Round table introduction (using alias if necessary) and thank you to participants

a. Name to be addressed by?

--Short summary of definitions or terms used in questions and answers.--

1. High technology program

2. Applied baccalaureate

3. Non-teaching workload/responsibility

4. Classroom/Self Efficacy

5. Perception

- Highlighted demographic questions asked in Google form

- How long have you taught at the baccalaureate level?

- Have you remained in one core position or have you changed positions during this time?

- What field(s) do you teach in?

- Have you taught in one program or multiple programs?

- Have you taught in areas that would not be considered high-technology or applied baccalaureate areas?

- What brought/motivated you to teaching?

○ Are you familiar with intrinsic vs. extrinsic reward theories?

RQ1

- How do faculty perceive their balance in their program concerning non-teaching vs. teaching responsibilities?

○ What is your working environment like within your program?

- What is your perception of the balance of teaching and non-teaching workloads within your program?

- A last minute or important deadline project is introduced and your program needs to put together a comprehensive report on Student learning 
outcomes. Who might be delegated in your program to achieve this short term but important goal?

- Why that person?

- How would a different situation alter who might take that responsibility?

- Grant writing or Research project

- Accreditation needs

- Student Organization matter

- Etc?

- If this person is you, could you elaborate on how that added responsibility makes you feel?

- Do you feel Appreciated/under-appreciated?

- Did you expect this responsibility as part of the job?

- Tell me about a time you felt that this responsibility detracts from time with students, personal or family time and/or vacation time.

RQ2

- How do faculty perceive their efficacy in the classroom when considering nonteaching responsibilities?

- Tell me about how about the impact (negative of positive) you feel nonteaching responsibilities have on your teaching in the classroom

- With what importance do you believe your institution places instructional ability/student outcomes/classroom efficacy etc?

- Can you tell me about a time you felt you sacrificed student experience for work-related responsibilities not directly linked to student outcomes?

- Can you tell me about a time when you felt student outcomes or experiences were improved by a non-teaching responsibility or a responsibility not linked to student outcomes?

RQ3

- How do faculty in high technology areas perceive their workload?

- In general, do you feel your personal workload is appropriate, overestimated (Underworked) or underestimated (Overworked)?

○ Do you feel like non-teaching workloads are disproportionately assigned to faculty members?

- Can you tell me about your workload balance? (Online rank form)

- Prioritize your responsibilities in order from most time spent to least time spent (Over a typical week)

$\circ$ Teaching

- Grant Writing

○ Research 

○ Training
- University Service
- Accreditation/Certification
- Student Advisement
- Student Organizations
- Miscellaneous

- Tell me about a time you genuinely felt overwhelmed by responsibilities at work.

- Tell me about a time you genuinely felt underwhelmed by responsibilities at work.

- How often do you feel this way?

- How does this impact your job satisfaction or what does this feeling contribute to your overall health and well-being?

- How do these emotions affect your student's classroom experience? 
Appendix D - Focus Group Participant Information Slides

\section{Welcome and Thank you for participating!}

Alexander Richards - Doctoral Candidate in Educational Leadership and Policy Analysis (University of Missouri - Columbia)

\section{QR link to google form (demographics} questions)

https://tinyurl.com/yb2z2km8

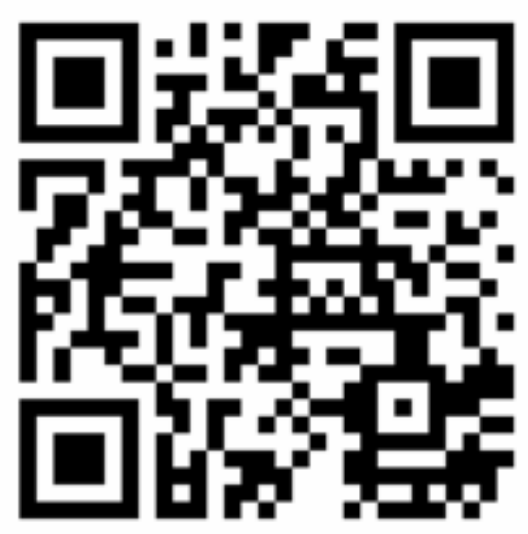




\section{Definitions}

Applied baccalaureate - Defined by Bragg, Townsend, and Rud (2009) as bachelor degree programs with a specific and targeted degree-related career outcomes. For example, Antomotive Technology degree students have a specific degree designed to prepare them for the unique skills associated with working in the automotive technology service industry.

Classroom Efficacy - Self-EDficacy as defined by Bandura (1977) as believing in ones self to understand, comprehend and accomplish a task required to avigate a situation. In the case of the stady, classroom efficacy inclades ones perceived ability to commanicate ideas and convey concepts and ideas in the classroom.

High technology programs - These programs are considered for the sake of the study to be programs with applied career skills in fast-paced, cutting edge career fields. Separate from many liberal arts degrees, these programs often possess higher costs-per student ratios and because of safety concerns, lower course offering sizes. In addition, these fields in comparison to typical liberal arts degrees can be categorized as having a higher relevant job-placement upon graduation.

Non-teaching workdoad/responsibility - While definitions vary, for the purpose of this research, this is any workload not directly related to in-classroom activities. For example, developing course curriculum for a class would not be considered non-teaching workload; however, writing a grant to enable a program to purchase a necessary, but expensive, piece of equipment to be used in the classroom or laboratory would be considered non-teaching workload.

Perception - Your own way of understanding something, whether that understanding is throngh thonght, ideas, visual and auditory input or other forms of sensory feedback.

\section{Workload Priority Sorting}

Teaching

Grant Writing

Research

Training

University Service

Accreditation/Certification

Student Advisement

Student Organizations

Miscellaneous 


\section{Appendix E - Google Form for Focus Group Participant Demographic Information}

\section{Alexander Richards - Dissertation Focus Group Demographics}

Demographic Questions for Dissertation Data Collection

${ }^{*}$ Required

1. My name or participant alias is: *

2. How long have you taught at the baccalaureate level? (As part of a baccalaureate degree) *

3. Have you remained in one core job description or have you changed positions over time? * Mark only one oval.

One Position - primarily teaching - single rank

One Position - primarily teaching - multiple rank

One Position - primarily administrative - single rank

One Position - primarily administrative - multiple rank

Multiple Positions - Teaching and Administrative - multiple ranks

4. Is your school primarily a teaching institution or research institution? * Mark only one oval.

Teaching Institution

Research Institution

5. What field(s)/programs do you teach in? *

6. Have you taught in areas that would not be considered high technology or applied technology areas?*

Mark only one oval.

$\longrightarrow$ Yes

No 


\title{
Appendix F - Consent Form to Participate in a Research Study
}

\author{
Researcher's Name(s): Alexander Richards \\ Project Number:2011733
}

Project Title: PERCEPTIONS OF NON-TEACHING WORKLOAD FOR FACULTY IN HIGH TECHNOLOGY BACCALAUREATE DEGREE PROGRAMS

\section{INTRODUCTION}

This consent may contain words that you do not understand. Please ask the investigator or the study staff to explain any words or information that you do not clearly understand.

You are being asked to participate in a research study. This research is being conducted will attempt to characterize the experiences of four-year baccalaureate faculty in high-technology or applied baccalaureate degree programs; specifically, with regard to their non-teaching workload. When you are invited to participate in research, you have the right to be informed about the study procedures so that you can decide whether you want to consent to participation. This form may contain words that you do not know. Please ask the researcher to explain any words or information that you do not understand.

You have the right to know what you will be asked to do so that you can decide whether or not to be in the study. Your participation is voluntary. You do not have to be in the study if you do not want to. You may refuse to be in the study and nothing will happen. If you do not want to continue to be in the study, you may stop at any time without penalty or loss of benefits to which you are otherwise entitled.

Should you elect to leave the study, or for any reason feel the need to have your specific responses, data, or audio/video recordings removed from the study the researcher will remove and destroy all copies and originals of such data and your participation will cease to continue. No further contact from the researcher to you will occur for the purposes of this study.

This research is not funded by any third or outside parties and all incidental expenses are paid for by the researcher.

\section{WHY IS THIS STUDY BEING DONE?}

The purpose of this research is to understand the experiences and perceptions of faculty members non-teaching workload in four-year applied baccalaureate and high technology programs.

\section{HOW MANY PEOPLE WILL BE IN THE STUDY?}

About 50-100 people will take part in this study regionally across the midwest.

\section{WHAT AM I BEING ASKED TO DO?}

You will be asked to participate in an approximately one (1) hour long focus group at your school, university, or via web conference

\section{AND/OR}

Participate in an approximately 30 minute long personal interview with the researcher at your location or via web conference 
Please note that participation in any one part does not warrant participation in any other component of the data collection process. The participant can choose to participate in as many or as few aspects or activities as they desire and or have the resources or time to participate in.

\section{HOW LONG WILL I BE IN THE STUDY?}

This study will take approximately $30-90$ minutes to complete per participant depending on the level of involvement and number of data collection activities the participant chooses to involve themselves in. You can stop participating at any time without penalty or request to withhold certain results from any of the three data collection methods at any time during the study.

\section{WHAT ARE THE BENEFITS OF BEING IN THE STUDY?}

Your participation will benefit the participants by potentially networking them with faculty members whom have a shared specific experience. It also could foster a degree of shared experience camaraderie among similar people with similar experiences and potentially new faculty who may otherwise feel as though they are alone in dealing with these issues.

\section{WHAT ARE THE RISKS OF BEING IN THE STUDY?}

While every step is made by the researcher to maintain privacy of personal data in relation to the study, any participant in the focus groups is subject to the risk of other focus group participants disclosing or discussing comments made during the focus group. It is generally considered that all comments and discussion in the focus group is exclusive to that group only, however enforcement of that policy once the collection period has ended is beyond the practical reach of the study.

\section{WHAT ARE THE COSTS OF BEING IN THE STUDY?}

There is no cost to you as participant.

\section{WHAT OTHER OPTIONS ARE THERE?}

You do not have any options offered as an alternative to participating in the study. You do have the option of not participating in this study, and will not be penalized for your decision.

\section{CONFIDENTIALITY}

Information produced by this study will be stored in the investigator's file and will not have any specific identifiable information contained in it. Information contained in your records may not be given to anyone unaffiliated with the study in a form that could identify you without your written consent, except as required by law.

In addition, if photographs, audiotapes or videotapes were taken during the study that could identify you, your consent and signing of this form gives the researcher express written consent and permission for their use in this research study using a pseudonym.

\section{WILL I BE COMPENSATED FOR PARTICIPATING IN THE STUDY?}

You will receive no payment for taking part in this study.

\section{WHAT IF I AM INJURED?}

There is no reasonable expectation of or anticipation of circumstances that would result and or potentially result in any risk of injury, either psychologically or physically to any study participants.

\section{WHAT ARE MY RIGHTS AS A PARTICIPANT?}


Participation in this study is voluntary. You do not have to participate in this study. You will also be informed of any new information discovered during the course of this study that might influence your health, welfare, or willingness to be in this study.

\section{WHO DO I CONTACT IF I HAVE QUESTIONS, CONCERNS, OR COMPLAINTS?}

Please contact Alexander Richards if you have questions about the research. Additionally, you may ask questions, voice concerns or complaints to the research team.

\section{WHOM DO I CALL IF I HAVE QUESTIONS OR PROBLEMS?}

If you have any questions regarding your rights as a participant in this research and/or concerns about the study, or if you feel under any pressure to enroll or to continue to participate in this study, you may contact the University of Missouri Campus Institutional Review Board (which is a group of people who review the research studies to protect participants' rights) at (573) 882-9585 or umcresearchcirb@missouri.edu.

You may ask more questions about the study at any time. For questions about the study or a research related injury, contact the principal investigator: Alexander Richards or his advisor, Sandra Hutchinson at:

Alexander Richards

University of Central Missouri

TR Gaines 112

Sandy Hutchinson
University of Central Missouri
LOV 4108
816-405-9306
hutchinson@ucmo.edu

arichards@ucmo.edu 


\section{Appendix G - ATMAE Recruitment Letter}

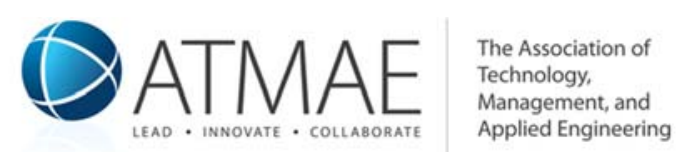

Hello ATMAE member,

My name is Alexander Richards and I am a Doctoral student in the Educational Leadership and Policy Analysis program at University of Missouri - Columbia. I would like to ask for your assistance in the completion of my dissertation research this summer.

I am seeking individuals who would be willing to participate in either a personal interview or focus group via web conferencing near the end of June/beginning of July. The interviews should last about 30 minutes, and the focus group should last approximately 1 hour. I am seeking individuals who teach or instruct in 4-year baccalaureate degree programs in applied baccalaureate or technical degree fields. Some of these fields include programs such as Construction Management, Automotive Technology, Engineering Tech/Applied Engineering, Etc. Please do not hesitate to ask if you feel your program may (or may not) fit the requirements! Also, I do not expect everyone to be willing an able to assemble a focus group on your campus with your colleagues... Even if by web. So if you can do either, both, or only a partial interview/participation it would still help me!

If you feel you would be able to contribute a few minutes of your time to my research it would be greatly appreciated! I hope to provide meaningful feedback to all participants regarding instructor workloads, specifically your own perceptions of your non-teaching workload.

Any questions, please do not hesitate to ask me. You may reach me atajrb8c@mail.missouri.edu, please do not hesitate to reach out and let me know if you are willing to participate in my study.

Most importantly, Thank You!

Alexander Richards

Assistant Professor - Automotive Technology Management

University of Central Missouri 


\section{VITA}

Alexander James Richards was born on October $8^{\text {th }}$, 1988 to James and Jane Richards in the town of Joliet, Illinois. He started this educational journey at a local junior college where he found his passion for the automobile industry. Less than a month after starting classes, Alex learned of the baccalaureate program at Southern Illinois University-Carbondale and soon after transferred into their high-technology baccalaureate program to obtain a B.A.S. degree in Automotive Technology. Once graduated, Alex pursued his second passion, teaching. He completed an M.S.Ed. in Workforce Education from Southern in 2013 and began working at the University of Central Missouri as an Assistant Professor of Automotive Technology Management. Alex currently resides in Missouri with his wife Ashley, three cats, Dust Bunny (DB), Jynx, and Rafa, and the family dog, Arya. 